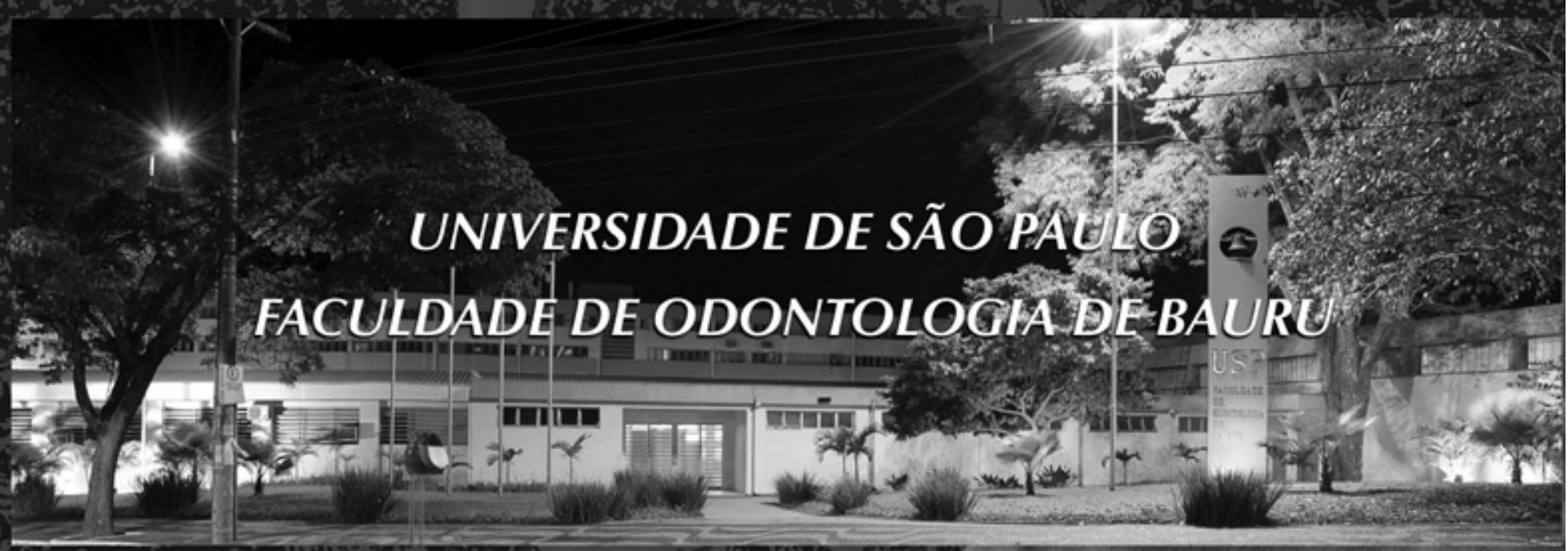

KÁTIA RODRIGUES REIS

\title{
Efeito da espessura da camada de cimento na integridade e resistência adesiva de pinos de resina reforçados por fibra de vidro
}





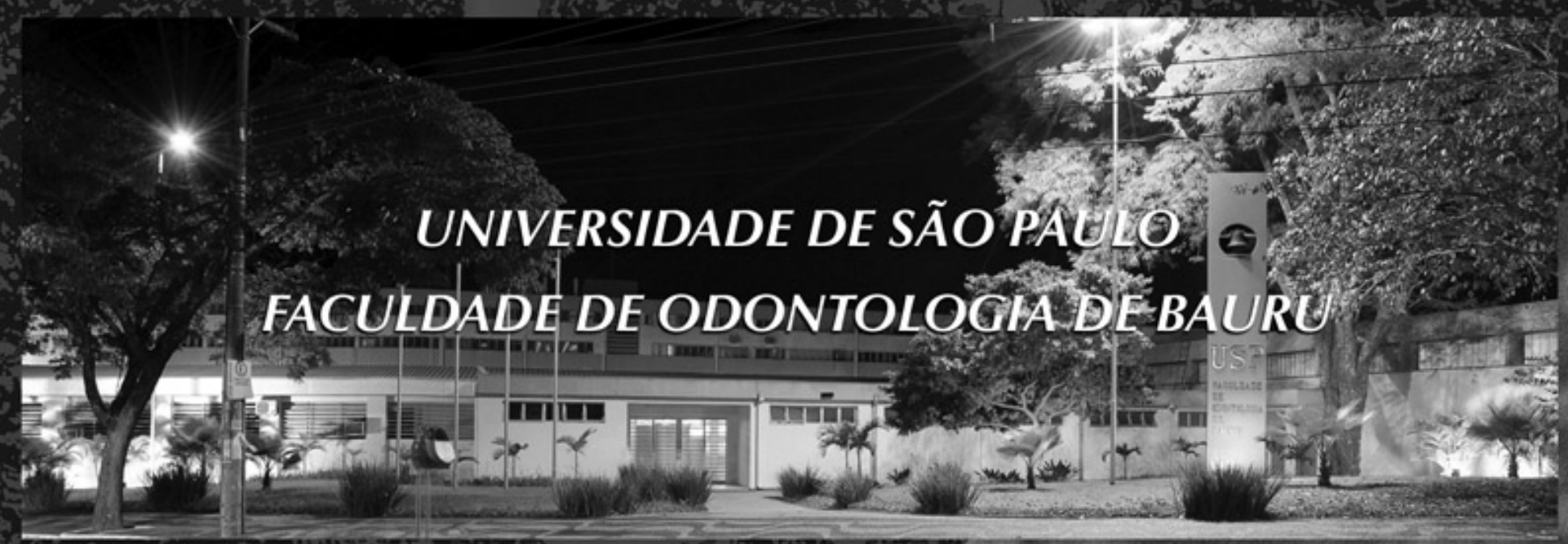

KÁTIA RODRIGUES REIS

\section{Efeito da espessura da camada de cimento na integridade e resistência adesiva de pinos de resina reforçados por fibra de vidro}

Tese apresentada à Faculdade de Odontologia de Bauru da Universidade de São Paulo para obtenção do título de doutor em Odontologia.

Área de concentração: Reabilitação Oral Orientador: Prof. Dr. Gerson Bonfante 
Reis, Kátia Rodrigues

R277e Efeito da espessura da camada de cimento na integridade e resistência adesiva de pinos de resina reforçados por fibra de vidro / Kátia Rodrigues Reis. Bauru, 2009.

198 p. : il.; $30 \mathrm{~cm}$.

Tese. (Doutorado) - Faculdade de Odontologia de Bauru. Universidade de São Paulo.

Orientador: Prof. Dr. Gerson Bonfante

Autorizo, exclusivamente para fins acadêmicos e científicos, a reprodução total ou parcial desta dissertação, por processos fotocopiadores e outros meios eletrônicos.

Assinatura do autor:

Data:

Comitê de Ética da FOB-USP

Processo $n^{0}: 84 / 2006$

Data: $29 / 11 / 2006$ 




\section{DADOS CURRICULARES}

\section{KÁTIA RODRIGUES REIS}

31 de Dezembro de 1977

$1996-1999$

$2000-2001$

$2003-2005$

$2005-2009$
Nascimento na cidade do Rio de Janeiro.

Curso de Odontologia na Faculdade de Odontologia da Universidade Federal do Rio de Janeiro.

Especialização em Prótese Dentária na Faculdade de Odontologia da Universidade do Grande Rio.

Mestrado em Odontologia (área de concentração: Reabilitação Oral) na Faculdade de Odontologia de Bauru da Universidade de São Paulo.

Doutorado em Odontologia (área de concentração: Reabilitação Oral) na Faculdade de Odontologia de Bauru da Universidade de São Paulo. 



\section{DEDICATÓRIA}

Aos meus pais, Herminia e Aldaizo, fontes incondicionais de amor, dedicação e compreensão. De vocês recebi todo o apoio necessário para a realização deste sonho. Vocês são exemplos de vida e vitória. Á vocês a minha eterna gratidão, respeito e amor.

Para sempre.

Ao meu primo André (in memorian), por todo o amor, carinho e companheirismo que sempre tivemos um pelo outro. Pelas saudades eternas deixadas em meu coração, e pelo eterno brilho que jamais se apagará. Ainda não obtivemos a sabedoria necessária para compreender a sua perda. Meu eterno primo preferido. 



\section{AGRADECIMENTOS ESPECIAIS}

Aos meus pais, Aldaizo e Herminia; pelo suporte emocional e financeiro. Obrigada por terem sido os meus melhores amigos. Os únicos que estiveram presentes em todos os momentos. Muito obrigada pelo apoio incondicional.

A vocês todo o meu amor, respeito e gratidão!

À minha irmã, Patrícia; por ter me dado o melhor presente que eu já recebi. Pelo exemplo de família, garra e coragem. E, acima de tudo, pela vida da Fernanda! Você é o meu maior elo entre o passado e o futuro. 



\section{AGRADECIMENTOS}

A Deus, cuja presença me serviu de fonte de conforto e esperança nos momentos em que precisei. O princípio, a voz, a luz interior que guiou as minhas atitudes para fazer o que me convencia ser o melhor em cada momento.

Ao meu orientador, Professor Gerson Bonfante; pela oportunidade de estar aqui, pelos ensinamentos compartilhados, pela confiança no meu trabalho, pela compreensão com os momentos de dificuldade e, principalmente, por toda a sabedoria e perspicácia, sempre tão peculiares. Não há palavras para agradecer por tudo isso!

Ao Professor Luiz Fernando Pegoraro; pela ajuda prestada no desenvolvimento deste trabalho, do início ao fim. Pelo conhecimento inesgotável sobre a Reabilitação Oral, tornando essa especialidade uma experiência fascinante e desafiadora. Pessoa e profissional admirável!

À Fundação de Amparo à Pesquisa do Estado de São Paulo (FAPESP), pelo fomento financeiro proporcionado a este estudo (Processo no. 2006/03759-4). Sem essa parceria, a realização deste trabalho se tornaria inviável.

Muito obrigada!

À Coordenação de Apoio ao Pessoal de Ensino Superior (CAPES), pela bolsa concedida durante o Doutorado, tornando a minha estada em Bauru mais viável.

À Dentsply, especialmente ao Rodrigo Reis, pela gentileza de ceder alguns materiais odontológicos utilizados nas pesquisas realizadas durante o curso de doutorado.

Muito obrigada! 

Ao Centro Integrado de Pesquisa (CIP), da Faculdade de Odontologia de Bauru, especialmente ao funcionário Marcelo, pela infra-estrutura física necessária para a confecção dos espécimes desta pesquisa e pelo uso da máquina EMIC.

Ao Departamento de Bioquímica, da Faculdade de Odontologia de Bauru, pela etapa de polimento das amostras deste trabalho.

Ao Núcleo de Apoio à Pesquisa em Microscopia Eletrônica de Varredura aplicada à Pesquisa Agropecuária (NAP/MEPA), da Escola Superior de Agronomia "Luiz de Queiroz" (ESALQ); em especial ao Professor Elliot Kitajima e ao funcionário Renato, pelo apoio na realização das análises em microscopia eletrônica de varredura.

Ao amigo Estevam; pelo aprendizado da metodologia deste trabalho, ainda que à distância. Pelo exemplo de sucesso e sabedoria.

Ao amigo de Pós-Graduação, Ronan, pela amizade e afinidade, bem como pela excelente parceria de trabalho.

À Ailla; por ter aberto as portas da sua casa para mim. Você tornou a minha estadia em Piracicaba uma experiência simples, segura e agradável.

Muito obrigada!

Ao amigo Lucas, por ter continuado agindo na minha história e, acima de tudo, por sempre inscrever em meu coração uma lei de vida cheia de alegria. 

Aos meus padrinhos, Sonja e Carlos, e às minhas primas Simone e Ana, por todo o carinho, respeito e dedicação que sempre tiveram com a minha família.

À minha amiga Lívia; pelo companheirismo e amizade infinitos. Só pela nossa amizade, esta viagem já teria valido à pena. Precisamos vir tão longe para estarmos tão perto. Embora diferentes, somos iguais. Amigas para sempre!

Às minhas amigas de Pós-Graduação, Luciana e Patrícia; pela amizade, compreensão e cumplicidade. Vocês tornaram a vida em Bauru muito mais amiga! Amigas para todos os momentos!

Às minhas amigas de toda a vida, Anna Carolina, Carla, Patrícia, Taís, Bárbara e Renata; por sempre estenderem os seus braços a cada retorno meu e sempre desejarem a minha volta. Tudo é uma coisa só. Amigas há muito e por muito tempo!

Ao Daniel, meu eterno mestre. Você simboliza o início, o meio e o fim. Agradeço simplesmente por você existir. Pessoa fundamental e transcendental.

Para sempre.

Ao Ernani, a melhor surpresa. Por toda a afinidade e afeto que existe entre nós. Por ter estado sempre presente, desde sempre. E por me compreender tão bem, como ninguém.

Aos meus amigos de Pós-Graduação, Cláudio, Fabiana, Ericsson e Wagner; pela amizade, sempre altruísta. Obrigada pelos momentos de alegria intra e extra-muro da FOB/USP que compartilhamos ao longo deste tempo! 

Aos amigos do curso de Doutorado em Reabilitação Oral (2005) da Faculdade de Odontologia de Bauru: Estevam, Rodrigo, Valdey, Thiago, Márcio e Andréia; pela convivência amistosa.

Ao Professor Pedro César Garcia de Oliveira; pela amizade, carinho e alegria. Por ser um exemplo de humanidade e simplicidade. Obrigada pelos conselhos e conversas, que sempre me ajudaram muito.

Ao Professor Paulo César Rodrigues Conti; pela simpatia e carinho. Pela ajuda prestada na aquisição de alguns materiais usados nas pesquisas do doutorado. Por ser um exemplo de docência e competência.

Ao Professor José Roberto Pereira Lauris; pelo auxílio na execução da análise estatística deste trabalho, sempre de forma prestativa e atenciosa.

Aos funcionários do Departamento de Prótese Dentária; pela assistência e atenção prestada durante o nosso período de convivência, em especial à Deborah, Cláudia, Valquíria, Marcelo e Reivanildo.

À Faculdade de Odontologia de Bauru da Universidade de São Paulo, pela formação de uma comunidade cujo objetivo comum é a excelência. Sinto muito orgulho em ter participado da história desta renomada instituição de ensino. 

"A mente que se abre a uma nova idéia jamais volta aos limites do seu tamanho original... ela cresce."

Albert Einstein 




\section{RESUMO}

A perda de adesão é uma falha comum reportada para os pinos reforçados por fibra e usualmente ocorre ao longo da interface adesiva entre a dentina radicular e o cimento resinoso. A espessura de cimento resinoso ideal para preservar a continuidade da interface adesiva cimento-dentina e aumentar a retenção do pino é desconhecida. O objetivo deste estudo foi avaliar a influência da espessura do cimento na integridade e na resistência adesiva de dois cimentos resinosos empregados para a cimentação de pinos reforçados por fibra. Trinta incisivos laterais superiores humanos com comprimentos radiculares semelhantes foram selecionados, secionados na junção cimento-esmalte e tratados endodonticamente. As raízes foram aleatoriamente divididas em seis grupos $(n=5)$, e os condutos radiculares foram preparados a uma profundidade de $8 \mathrm{~mm}$ usando uma das três brocas com diâmetro diferente: Broca Largo $\mathrm{n} \square 3$ para o grupo controle (L3 - $1 \mathrm{~mm}$ ); Broca Largo $\mathrm{n} \square 4$ (L4 - 1,25 mm) e Broca Largo $\mathrm{n} \square 5$ (L5 - 1,5 mm) para os grupos experimentais. Pinos de resina reforçados por fibra de vidro (Fibrekor post, Jeneric Pentron), $1 \mathrm{~mm}$ de diâmetro, foram cimentados aos condutos radiculares utilizando o cimento resinoso dual (Duolink, Bisco) ou o cimento resinoso autopolimerizável (C\&B Cement, Bisco). A porção de cada espécime contendo os pinos reforçados por fibra foi secionada transversalmente em três seções (cervical, média e apical) de $2 \mathrm{~mm}$ de espessura utilizando um disco diamantado em máquina de corte seriado sob refrigeração com água. As seções foram polidas, limpas ultrassonicamente e duplicadas com polivinil siloxano. Réplicas em resina epóxica das seções foram obtidas para a mensuração da espessura do cimento e da integridade adesiva na interface cimento-dentina por meio de MEV. As seções foram armazenadas em solução fisiológica a $37^{\circ} \mathrm{C}$ por uma semana e, então, submetidas ao teste push-out em uma máquina de ensaio universal à velocidade de $0,5 \mathrm{~mm} / \mathrm{min}^{-1}$, e a força máxima requerida para deslocar cada pino foi registrada $(\mathrm{N})$. Os dados foram analisados usando ANOVA a um critério, teste de Tukey e teste $t$ de Student $(\alpha=0,05)$. A correlação entre a integridade adesiva, a resistência adesiva e a espessura do cimento também foi determinada pelo coeficiente de Pearson $(\alpha=0,05)$. A comparação múltipla entre as condições experimentais para cada cimento revelou que os valores médios de integridade adesiva (\%) e de resistência adesiva (MPa) 

dos pinos reforçados por fibra cimentados com o cimento resinoso Duolink foram significantemente maiores no grupo controle (L3: 61,79 \pm 18,06 e 11,32 \pm 4,66) do que no grupo experimental com camada de cimento muito espessa (L5: 38,91 \pm 5,75 e $4,68 \pm 2,16)(p=0,018$ e $p=0,035)$, respectivamente. Embora não tenha sido observada diferença significante na integridade adesiva entre as diferentes espessuras de cimento avaliadas para o cimento resinoso C\&B Cement $(p>0,05)$, 0 grupo com camada de cimento muito espessa (L5: 10,67 \pm 4,59) foi significantemente mais retentivo do que o grupo controle (L3: 4,01 \pm 0,76) $(p=0,014)$. A comparação entre cimentos para cada condição experimental mostrou que o cimento resinoso Duolink foi mais retentivo do que o cimento resinoso C\&B Cement no grupo controle $(11,32 \pm 4,66$ e 4,01 $\pm 0,76, p=0,008)$, ao passo que o cimento resinoso C\&B Cement foi mais retentivo do que o cimento resinoso Duolink em L5 $(4,68 \pm 2,19$ e 10,67 $\pm 4,59, p=0,030)$, respectivamente. Somente a comparação entre o grupo experimental L4 e os outros grupos não foi significante para ambos os cimentos resinosos e testes realizados. O aumento da espessura do cimento diminuiu significantemente a integridade adesiva $(r=-0,5901 ; p=0,021)$ e a resistência adesiva $(r=-0,5387 ; p=0,038)$ para o cimento resinoso Duolink. A integridade adesiva correlacionou-se positivamente com a resistência adesiva para esse tipo de cimento resinoso $(r=0,6855 ; p=0,005)$. Diferentemente, não foi encontrada correlação significante entre a espessura do cimento e a integridade adesiva $(r=0,153 ; p=0,586)$ e nem entre a integridade adesiva e a resistência adesiva $(r=0,2969 ; p=0,283)$ registradas para C\&B Cement. Contudo, o aumento da espessura deste tipo de cimento resinoso aumentou significantemente a retenção do pino $(r=0,6576$; $p=0,008)$. Os dados sugeriram que a espessura da camada dos cimentos resinosos influenciou a integridade adesiva e a resistência adesiva dos pinos de resina reforçados por fibra. Para o cimento resinoso Duolink selecionado, os maiores valores de integridade adesiva e de resistência adesiva foram obtidos quando a camada mais fina de cimento foi testada (L3). Contudo, o cimento resinoso C\&B Cement apresentou maior retenção quando a espessura da camada de cimento aumentou muito (L5), embora a espessura do cimento não tenha desempenhado um papel importante na integridade adesiva da interface cimento-dentina para esse cimento resinoso.

Palavras-chave: Pinos de retenção dentária. Cimentos de resina. Microscopia eletrônica. 

ABSTRACT 



\section{ABSTRACT}

\section{Effect of the thickness of the resin cement on the bond integrity and strength of glass fiber-reinforced composite post}

Debonding is the most common cause of failure reported for glass fiberreinforced composite posts and occurs frequently along the adhesive interface between the resin cement and the root dentin. The ideal thickness of the resin cement to preserve the continuity along the cement-dentin interface and to increase the retention of the post is unknown. The purpose of this study was to evaluate the influence of the thickness of the resin cement on the bond integrity and strength of two resin cements used for glass fiber-reinforced composite posts cementation. 30 human maxillary incisors with similar root dimensions were selected, sectioned at the amelocemental junction and endodontically treated. The roots were randomly divided into six groups $(n=5)$, and the post spaces were prepared $8 \mathrm{~mm}$ deep using one of the three burs with different diameters: Largo bur $\mathrm{n} \square 3$ for the control group (L3 - 1mm); Largo bur $\mathrm{n} \square 4$ (L4 - 1,25-mm) e Largo bur $\mathrm{n} \square 5$ (L5 - 1,5-mm) for the experimental groups. Fiber-reinforced composite posts (Fibrekor post, Jeneric Pentron), 1-mm diameter, were cemented to post spaces by using the dual-cure (Duolink, Bisco) or self-cure system (C\&B Cement, Bisco). The portion of each specimen that contained the bonded fiber post was sectioned into three 2-mm thick serial slices (cervical, middle, apical) with the Isomet saw under water cooling. The slices were polished and ultrasonicated in deionized water. Polyvinyl siloxane impressions of the observable surfaces were taken and the surfaces replicated with epoxy resin for measuring of the thickness of the resin cement and the bond integrity by using MEV. The slices were stored in physiologic solution at $37^{\circ} \mathrm{C}$ for one week, and then submitted to the push-out test at a crosshead speed of $0.5 \mathrm{~mm} / \mathrm{min}^{-1}$. The maximum force required to dislocate each post was registered $(\mathrm{N})$. Data were analyzed by one-way ANOVA, Tukey test and $t$ test $(\alpha=0,05)$. The correlation between bond integrity, bond strength and thickness of the resin cement was also determined by correlation test $(\alpha=0,05)$. The multiple comparison test between the experimental conditions for each resin cement showed that the mean values of bond 

integrity (\%) and strength (MPa) of the fiber posts cemented with Duolink were significantly higher at the control group (L3: $61.79 \pm 18.06$ and $11.32 \pm 4.66)$ than those obtained for the experimental groups with the thicker layer cement (L5: $38.91 \pm$ 5.75 and $4.68 \pm 2.16)(p=0.018$ and $p=0.035)$, respectively. Although there was no significant difference on the bond integrity between the different thicknesses evaluated for C\&B Cement ( $p>0.05)$, the group with thicker layer (L5: $10.67 \pm 4.59)$ was significantly more retentive than the control group (L3: $4.01 \pm 0.76)(p=0.014)$. The comparison between cements for each experimental condition has showed that Duolink was more retentive than C\&B Cement at the control group (11.32 \pm 4,66 and $4.01 \pm 0,76, p=0.008)$, whereas C\&B Cement was more retentive than Duolink at L5 group (4.68 \pm 2.19 and $10.67 \pm 4.59, p=0.030)$, respectively. Only the comparison between the L4 experimental group and the others groups was not significant for both resin cements and tests conducted. The increase of the thickness of the cement significantly reduced the bond integrity $(r=-0.5901 ; p=0.021)$ and strength $(r=-0,5387$; $p=0.038$ ) for Duolink. Bond integrity positively correlated with bond strength for this type of resin cement $(r=0.6855 ; p=0.005)$. On the other hand, there was no significant correlation between the thickness of the cement and the bond integrity $(r=0.153$; $p=0.586)$ and neither between the bond integrity and strength $(r=0.2969 ; p=0.283)$ registered for $C \& B$ Cement. However, the increase of the thickness of this type of resin cement has significantly increased the retention of the post $(r=0.6576$; $p=0.008$ ). Data suggested that the thickness of resin cements affected both the bond integrity and strength of fiber posts. For the Duolink resin cement selected, the higher values of bond integrity and strength were obtained when the thinner layer was tested (L3). However, C\&B Cement has showed higher retention when the thickness of the cement increased excessively (L5), though the thickness of the cement has not played a role on the bond integrity of the cement-dentin interface for this resin cement.

Palavras-chave: Post and Core Techinique. Resin cements. Microscopy electron. 



\section{LISTA DE ILUSTRAÇÕES}

FIGURAS

Figura 1 Incisivo lateral superior apresentando raiz com comprimento $\geq 15 \mathrm{~mm}$, livre de cárie, fratura e tratamento endodôntico, e com ápice desenvolvido. O canal radicular apresentou diâmetro circular $\leq 1 \mathrm{~mm}$.

Figura 2 Seção da coroa do incisivo lateral superior perpendicular ao longo eixo do dente e acima da junção cementoesmalte, utilizando um disco de corte diamantado sob refrigeração abundante com água deionizada.

Figura 3 Brocas Largo $\mathrm{n}^{\circ} 3$, 4 e 5, apresentando 1,00 mm; 1,25 $\mathrm{mm}$ e $1,50 \mathrm{~mm}$ de diâmetro.

Figura 4 Pino de resina reforçado por fibra de vidro cilíndrico $n^{0} 1$ de $1,00 \mathrm{~mm}$ de diâmetro. 129

Figura 5 Desenho esquemático mostrando as três condições experimentais testadas no estudo. A) Grupo de espessura fina (grupo L3 - Controle); B) Grupo de espessura média (grupo L4); C) Grupo de espessura grossa (grupo L5).

Figura 6 Desenho esquemático mostrando o pino de fibra preso ao dispositivo-guia adaptado no paralelômetro e inserido no conduto radicular durante a cimentação. 133

Figura 7 Corte horizontal do espécime em três seções radiculares de dois $\mathrm{mm}$ de espessura utilizando um disco diamantado sob refrigeração abundante com água. 

Figura 8 Seção fixada ao disco de resina acrílica utilizando cera pegajosa, estando a superfície apical voltada para o disco 135

Figura 9 Seções radiculares. A) Cervical; B) Média; C) Apical. 135

Figura 10 Moldes das seções. A) Cervical; B) Médio; C) Apical. 135

Figura 11 Réplicas em resina epóxica. A) Cervical; B) Média; C) Apical. 137

Figura 12 Réplicas em resina epóxica cobertas com uma camada de ouro, após a metalização. A) Cervical; B) Média; C) Apical. 137

Figura 13 Microscópio eletrônico de varredura ZEISS DSM 940 A. 138

Figura 14 Mensuração da amostra utilizando o paquímetro eletrônico digital. 139

Figura 15 Carga aplicada pela haste cilíndrica sobre o pino em uma direção apico-coronal. 139

Figura 16 Fotomicrografia em MEV de espécime do cimento Duolink (L3 - grupo controle). Presença de descontinuidade na interface cimento/dentina (fenda) da região apical da raiz, apontada pela seta branca. P: pino; C: cimento; D: dentina. 148

Figura 17 Fotomicrografia em MEV de espécime do cimento Duolink (L3 - grupo controle). Presença de continuidade na interface cimento/dentina da região cervical da raiz, apontada pela seta branca. P: pino; C: cimento; D: dentina. 

Figura 18 Fotomicrografia em MEV de espécime do cimento Duolink (Grupo L4). Presença de descontinuidade na interface cimento/dentina (fenda) da região média da raiz, apontada pela seta branca. P: pino; C: cimento; D: dentina. 148

Figura 19 Fotomicrografia em MEV de espécime do cimento Duolink (Grupo L4). Presença de continuidade na interface cimento/dentina da região cervical da raiz, apontada pela seta branca. Notar a presença de fenda na interface entre o cimento e o pino. P: pino; C: cimento; D: dentina. 148

Figura 20 Fotomicrografia em MEV de espécime do cimento Duolink (Grupo L5). Presença de descontinuidade na interface cimento/dentina (fenda) da região média da raiz, apontada pela seta branca. P: pino; C: cimento; D: dentina. 149

Figura 21 Fotomicrografia em MEV de espécime do cimento Duolink (Grupo L5). Presença de continuidade na interface cimento/dentina da região cervical da raiz, apontada pela seta branca. P: pino; C: cimento; D: dentina. 149

Figura 22 Fotomicrografia em MEV de espécime do cimento C\&B Cement (L3 - grupo controle). Presença de descontinuidade na interface cimento/dentina (fenda) da região apical da raiz, apontada pela seta branca. P: pino; C: cimento; D: dentina. 149

Figura 23 Fotomicrografia em MEV de espécime do cimento C\&B Cement (L3 - grupo controle). Presença de continuidade na interface cimento/dentina da região cervical da raiz, apontada pela seta branca. P: pino; C: cimento; D: dentina. 

Figura 24 Fotomicrografia em MEV de espécime do cimento C\&B Cement (Grupo L4). Presença de descontinuidade na interface cimento/dentina (fenda) da região média da raiz, apontada pela seta branca. P: pino; C: cimento; D: dentina.

Figura 25 Fotomicrografia em MEV de espécime do cimento C\&B Cement (Grupo L4). Presença de continuidade na interface cimento/dentina da região cervical da raiz, apontada pela seta branca. P: pino; C: cimento; D: dentina. 150

Figura 26 Fotomicrografia em MEV de espécime do cimento C\&B Cement (Grupo L5). Presença de descontinuidade na interface cimento/dentina (fenda) da região média da raiz, apontada pela seta branca. P: pino; C: cimento; D: dentina. 150

Figura 27 Fotomicrografia em MEV de espécime do cimento C\&B Cement (Grupo L5). Presença de continuidade na interface cimento/dentina da região cervical da raiz, apontada pela seta branca. P: pino; C: cimento; D: dentina. 



\section{GRÁFICOS}

Gráfico 1 Box plot da integridade adesiva das regiões radiculares cervical, média e apical por condição experimental para o cimento Duolink (\%). Letras minúsculas se referem às diferentes condições experimentais quando todas as regiões radiculares foram agrupadas. Letras superescritas diferentes indicam diferenças significantes.

Gráfico 2 Box plot da integridade adesiva das regiões radiculares cervical, média e apical por condição experimental para o cimento C\&B Cement (\%). Letras minúsculas se referem às diferentes condições experimentais quando todas as regiões radiculares foram agrupadas. Letras superescritas diferentes indicam diferenças significantes.

Gráfico 3 Box plot da integridade adesiva das regiões radiculares cervical, média e apical por cimentos para o grupo controle (\%). Letras minúsculas se referem aos diferentes cimentos quando todas as regiões radiculares foram agrupadas. Letras superescritas diferentes indicam diferenças significantes.

Gráfico 4 Box plot da integridade adesiva das regiões radiculares cervical, média e apical por cimentos para o grupo L4 (\%). Letras minúsculas se referem aos diferentes cimentos quando todas as regiões radiculares foram agrupadas. Letras superescritas diferentes indicam diferenças significantes. 

Gráfico 5 Box plot da integridade adesiva das regiões radiculares cervical, média e apical por cimentos para o grupo L5 (\%). Letras minúsculas se referem aos diferentes cimentos quando todas as regiões radiculares foram agrupadas. Letras superescritas diferentes indicam diferenças significantes.

Gráfico 6 Box plot da resistência adesiva das regiões radiculares cervical, média e apical por condição experimental para o cimento Duolink (\%). Letras minúsculas se referem às diferentes condições experimentais quando todas as regiões radiculares foram agrupadas. Letras superescritas diferentes indicam diferenças significantes. 152

Gráfico 7 Box plot da resistência adesiva das regiões radiculares cervical, média e apical por condição experimental para o cimento C\&B Cement (\%). Letras minúsculas se referem às diferentes condições experimentais quando todas as regiões radiculares foram agrupadas. Letras superescritas diferentes indicam diferenças significantes. 152

Gráfico 8 Box plot da resistência adesiva das regiões radiculares cervical, média e apical por cimentos para o grupo controle $(\mathrm{MPa})$. Letras minúsculas se referem aos diferentes cimentos quando todas as regiões radiculares foram agrupadas. Letras superescritas diferentes indicam diferenças significantes. 154

Gráfico 9 Box plot da resistência adesiva das regiões radiculares cervical, média e apical por cimentos para o grupo L4 $(\mathrm{MPa})$. Letras minúsculas se referem aos diferentes cimentos quando todas as regiões radiculares foram agrupadas. Letras superescritas diferentes indicam diferenças significantes. 

Gráfico 10 Box plot da resistência adesiva das regiões radiculares cervical, média e apical por cimentos para o grupo L5 (MPa). Letras minúsculas se referem aos diferentes cimentos quando todas as regiões radiculares foram agrupadas. Letras superescritas diferentes indicam diferenças significantes.

Gráfico 11 Análise de regressão linear entre os valores de espessura do cimento e de integridade adesiva obtidos para Duolink. 155

Gráfico 12 Análise de regressão linear entre os valores de espessura do cimento e de integridade adesiva obtidos para $C \& B$ Cement. 155

Gráfico 13 Análise de regressão linear entre os valores de espessura do cimento e de resistência adesiva obtidos para Duolink. 156

Gráfico 14 Análise de regressão linear entre os valores de espessura do cimento e de resistência adesiva obtidos para C\&B Cement. 156

Gráfico 15 Análise de regressão linear entre os valores de resistência adesiva e de integridade adesiva obtidos para Duolink. 157

Gráfico 16 Análise de regressão linear entre os valores de resistência adesiva e de integridade adesiva obtidos para C\&B Cement. 



\section{LISTA DE TABELAS}

Tabela 1 Características dos cimentos resinosos. 131

Tabela 2 Protocolo de polimento das seções radiculares para análise em MEV

Tabela 3 Comparação da integridade adesiva encontrada nas diferentes condições experimentais para Duolink (\%). 145

Tabela 4 Comparação da integridade adesiva encontrada nas diferentes condições experimentais para C\&B Cement (\%). 145

Tabela 5 Comparação da integridade adesiva entre os cimentos no grupo controle (L3) (\%). 146

Tabela 6 Comparação da integridade adesiva entre os cimentos no grupo L4 (\%). 146

Tabela 7 Comparação da integridade adesiva entre os cimentos no grupo L5 (\%) 146

Tabela 8 Comparação da resistência adesiva encontrada para Duolink nas diferentes condições experimentais (MPa).

Tabela 9 Comparação da resistência adesiva encontrada para C\&B Cement nas diferentes condições experimentais (MPa). 152

Tabela 10 Comparação da resistência adesiva entre os cimentos no grupo controle (MPa).

Tabela 11 Comparação da resistência adesiva entre os cimentos no grupo L4 (MPa).

Tabela 12 Comparação da resistência adesiva entre os cimentos no grupo L5 (MPa) 



\section{LISTA DE ABREVIATURAS E SIGLAS}

\begin{tabular}{|c|c|}
\hline ANOVA & Análise de variância \\
\hline BIS-GMA & Bisfenol A glicidilmetacrilato \\
\hline DP & Desvio padrão \\
\hline EDTA & Ácido etileno-diamino tetracético \\
\hline E2BADMA & Bisfenol A Diglicidilmetacrilato etoxilado \\
\hline Kg & Quilograma \\
\hline $\mathrm{MPa}$ & Mega Pascal \\
\hline MEV & Microscopia eletrônica de varredura \\
\hline MET & Microscopia eletrônica de transmissão \\
\hline MIN & Minuto \\
\hline ML & Mililitro \\
\hline MM & Milímetro \\
\hline $\mathbf{N}$ & Newton \\
\hline$N$ & Número de espécimes da amostra \\
\hline $\mathrm{nM}$ & Nanometro \\
\hline $\mathrm{NaOCI}$ & Hipoclorito de sódio \\
\hline H & Hora \\
\hline PVC & Policloreto de vinila \\
\hline TEG-DMA & Trietilenoglicoldimetacrilato \\
\hline UDMA & Uretano dimetacrilato \\
\hline CM & Centímetro \\
\hline MV & Mili-Volt \\
\hline $\boldsymbol{P}$ & Nível de significância, probabilidade \\
\hline $\mathbf{S}$ & Segundo \\
\hline
\end{tabular}





\section{LISTA DE SÍMBOLOS}

$\begin{array}{ll}\mu \mathrm{m} & \text { micrometro } \\ { }^{\circ} & \text { graus } \\ { }^{\circ} \mathrm{C} & \text { graus centígrados } \\ \mathbf{n}^{\mathbf{0}} & \text { número } \\ \mathbf{\%} & \text { por cento }\end{array}$





\section{SUMÁRIO}

1 INTRODUÇÃO

2 REVISÃO DE LITERATURA

2.1 Desenvolvendo uma maior compreensão das tensões produzidas nos materiais compósitos durante a polimerização

2.2 Quais são os fatores que influenciam a retenção dos pinos de resina reforçados por fibra? 76

2.3 A espessura da camada de cimento influencia a retenção do pino?

2.4 Os dentes endodonticamente tratados restaurados com pinos reforçados por fibra apresentam sobrevida clínica longa?

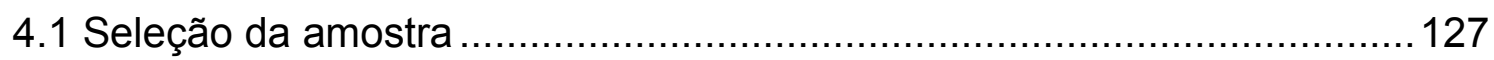

4.2 Formação dos grupos ............................................................ 128

4.3 Procedimentos de cimentação ..................................................... 131

4.4 Preparo dos espécimes para as mensurações em MEV .........................133

4.5 Mensuração da espessura do cimento e da integridade adesiva da interface cimento-dentina por meio de MEV

4.6 Preparo das seções radiculares para o teste push-out. 138

4.7 Forma de análise dos resultados 140 

5.1 Integridade adesiva da interface cimento/dentina............................... 144

5.2 Resistência adesiva ao deslocamento do pino ................................... 151

5.3 Associação entre a espessura do cimento e a integridade adesiva

5.4 Associação entre a espessura do cimento e a resistência adesiva

5.5 Associação entre a integridade adesiva e a resistência adesiva .

6 DISCUSSÃO 




\section{INTRODUÇÃO}

Os pinos de resina reforçados por fibra têm sido rotineiramente empregados para a restauração de dentes tratados endodonticamente com excessiva perda de estrutura dentária coronária, desde o seu advento no início da década de 90 . O sucesso clínico dessa nova modalidade terapêutica tem sido apregoado a algumas vantagens apresentadas pelos pinos reforçados por fibra de vidro em comparação aos pinos metálicos pré-fabricados ou fundidos, como o módulo de elasticidade (18$22 \mathrm{GPa}$ ) semelhante ao da dentina (18 GPa), reduzindo o risco de fratura radicular (PILO et al., 2002), a rapidez de uso clínico (GIACHETTI et al., 2004) e a presença de fibras com translucidez e coloração semelhantes às do dente, as quais otimizam as propriedades ópticas das restaurações estéticas e permitem a polimerização dos cimentos resinosos dual, devido à transmissão de luz através do pino ( $\mathrm{VICHI}$ et al., 2002; GRANDINI et al., 2004).

A cimentação dos pinos reforçados por fibra aos condutos radiculares tem sido realizada por meio de cimentos resinosos e adesivos dentinários à base de metacrilato, uma vez que esses materiais apresentam módulo de elasticidade semelhante ao pino e à dentina (PIRANI et al., 2005). A unidade biomecânica homogênea formada propicia uma distribuição mais uniforme do estresse, a qual preserva a estrutura dentária enfraquecida (DURET, REYNAUD e DURET, 1990; PEGORETTI et al., 2002) e reduz a microinfiltração na interface cimento-dentina, cáries secundárias e re-infecção da área peri-apical (BACHICHA et al., 1998; REID, KAZEMI e MEIERS, 2003). Esses fatores contribuem para o aumento da resistência à fratura radicular e da retenção dos pinos cimentados com cimentos resinosos em comparação aos agentes cimentantes convencionais (COHEN et al., 1998; ROSENSTIEL, LAND e CRISPIN, 1998).

Portanto, a hibridização dos tecidos dentinários radiculares pode contribuir para aumentar a resistência de união dos pinos reforçados por fibra. Na técnica adesiva, o condicionamento ácido remove a lama dentinária e desmineraliza a dentina radicular, de modo que o aumento da superfície de dentina disponível para adesão é obtido e uma rede fina de fibrilas colágenas é exposta. A infiltração dessa rede orgânica com monômeros resinosos leva à formação da camada híbrida e cria prolongamentos resinosos e ramificações laterais de adesivo, criando uma retenção 
micromecânica da resina no interior do substrato dentinário desmineralizado (PASHLEY et al., 1993). Para que a união adesiva aumente a retenção dos pinos reforçados por fibra, porém, é fundamental que a adesão entre o cimento e o pino e/ou a dentina esteja preservada, ou seja, sem a presença de uma fenda, espaço ou bolha.

Entretanto, a tensão de contração gerada durante a polimerização dos cimentos resinosos em camadas finas e em espaços confinados, como ocorre na cimentação dos pinos reforçados por fibra, pode exceder $20 \mathrm{MPa}$ (ALSTER et al., 1997a). Considerando que os valores de resistência de união gerados pela cimentação dos pinos reforçados por fibra no interior dos condutos radiculares são extremamente baixos (BOUILLAGUET et al., 2003; GORACCl et al., 2004), foi especulado que a contração de polimerização dos cimentos resinosos pode gerar tensões capazes de romper a união entre o cimento e a dentina radicular (FERRACANE, 2005). O alto fator-C (proporção entre a área de superfície aderida e a área de superfície não aderida) das cavidades longas e estreitas dos condutos radiculares (aproximadamente 200) leva ao aumento da tensão de polimerização, formando fendas na interface adesiva e reduzindo a resistência de união (BOUILLAGUET et al., 2003).

Estudos clínicos prospectivos (MONTICELLI et al., 2003; GRANDINI et al., 2005b; NAUMANN, BLANKENSTEIN e DIETRICH, 2005) e retrospectivos (FREDRIKSSON et al., 1998; FERRARI, VICHI e GARCIA-GODOY, 2000; FERRARI et al., 2000b; HEDLUND, JOHANSSON e SJOGREN, 2003) têm reportado taxas de sucesso de 95 a 99\% para os dentes restaurados com pinos reforçados por fibra, sem a ocorrência de nenhuma fratura radicular durante os períodos dos estudos, como ocorria com os pinos metálicos ou fundidos. A causa de insucesso mais comum reportada pelos estudos clínicos refere-se ao descolamento do complexo pino-cimento-restauração devido à perda de união entre as interfaces pino de fibracimento e/ou dentina radicular-cimento como resultado de inadequada resistência de união (FREDRIKSSON et al., 1998; MALFERRARI, MONACO e SCOTTI, 2003; MONTICELLI et al., 2003; AKSORNMUANG et al., 2004). Outro importante mecanismo de falha dos pinos reforçados por fibra refere-se à contaminação retrógrada da raiz via infiltração dos fluidos orais e micro-organismos devido à ausência de selamento e adaptação marginal adequados (BACHICHA et al., 1998), embora seja mais fácil remover um pino reforçado por fibra do que qualquer tipo de 
pino metálico (DE RIJK, 2000), oferecendo ao cirurgião-dentista a opção de retratamento endodôntico (GRANDINI et al., 2005a). A fratura do pino também foi observada em dentes apresentando até duas superfícies de estrutura coronária remanescente (fator- $\mathrm{C}$ de 0,2 a 0,5 ), devido ao alto estresse exercido sobre o pino e o núcleo sem nenhum suporte dos tecidos dentários duros contra as forças de cisalhamento (NAUMANN, BLANKENSTEIN e DIETRICH, 2005).

Vários estudos têm reportado o efeito adverso de inúmeros aspectos na retenção adesiva dos pinos reforçados por fibra (FERRARI et al., 2001; BOUILLAGUET et al., 2003; TAY et al., 2005; VALANDRO et al., 2005; AKGUNGOR e AKKAYAN, 2006). Apesar disso, a influência da espessura do cimento na retenção dos pinos reforçados por fibra foi pouco investigada (PEREZ et al., 2006; D'ARCANGELO et al., 2007). Existe evidência na literatura do efeito da espessura do cimento na tensão de contração de polimerização de camadas de compósitos (ALSTER et al., 1995). Conceitualmente, a maior contração de polimerização ocorrida na camada de cimento espessa pode resultar em maior tensão nas interfaces com a dentina e o pino, contribuindo para a formação de descontinuidades estruturais, tais como bolhas, espaços ou fendas, e reduzindo a retenção dos pinos reforçados por fibra (GRANDINI et al., 2005a). Poderia se esperar, portanto, que as pesquisas verificassem consistentemente uma pior performance para os pinos reforçados por fibra na presença de camadas espessas de cimento resinoso. No entanto, pouca informação foi encontrada considerando a relação entre a descontinuidade na interface adesiva e a retenção dos pinos reforçados por fibra (GORACCl et al., 2005c; ZICARI et al., 2008). Ainda, embora alguns estudos tenham avaliado o efeito da espessura do cimento na retenção dos pinos reforçados por fibra (PEREZ et al., 2006; D'ARCANGELO et al., 2007), existe pouca evidência da influência da espessura do cimento na continuidade da interface cimento-dentina (GRANDINI et al., 2005a).

Os resultados dos estudos considerando a retenção dos pinos intraradiculares em camadas de cimento resinoso apresentando diferentes espessuras parecem, contudo, bastante inconsistentes. Estudos laboratoriais reportaram que a espessura da camada de cimento pode ser aumentada consideravelmente para os cimentos resinosos em comparação aos cimentos convencionais (ASSIF e FERBER, 1982; CHAN, HARCOURT e BROCKHURST, 1993). Entretanto, pesquisas clínicas prospectivas demonstraram que o descolamento dos pinos reforçados por fibra 
ocorreu na presença de uma espessura de cimento aumentada (FREDRIKSSON et al., 1998; FERRARI, VICHI e GARCIA-GODOY, 2000; MALFERRARI, MONACO e SCOTTI, 2003). Outro estudo in vitro recente revelou que os maiores valores de resistência adesiva não foram obtidos quando a camada mais fina do cimento resinoso foi testada, mas quando os condutos radiculares medianamente alargados foram usados (D'ARCANGELO et al., 2007). Um ensaio laboratorial sugeriu que o aumento na espessura do cimento resinoso presente ao redor do pino reforçado por fibra não prejudicou a resistência adesiva (PEREZ et al., 2006). Os achados conflitantes parecem resultantes da grande variedade de modelos experimentais e materiais odontológicos utilizados nos ensaios de medição da retenção dos pinos intra-radiculares. Apesar disso, a presença de uma camada fina e uniforme de cimento resinoso tem sido considerada ideal para prover retenção aos pinos reforçados por fibra (GRANDINI, SAPIO e SIMONETTI, 2003).

Portanto, a espessura do cimento resinoso pode desempenhar um fator determinante na performance clínica dos pinos de resina reforçados por fibra (PEREZ et al., 2006), sendo ainda mais importante nas situações em que o canal radicular apresente uma forma oval ou amplamente alargada, especialmente quando o tratamento endodôntico foi repetido. Em tais situações, a adaptação da seção circular de um pino à forma do conduto radicular acarreta invariavelmente na presença de uma camada espessa de cimento (quando um pino de diâmetro inferior ao do canal radicular for utilizado), ou leva ao enfraquecimento do elemento dental devido ao sacrifício de tecido dentinário sadio (quando um pino de diâmetro superior ao do canal radicular for selecionado visando à formação de uma camada de cimento de espessura fina) (GRANDINI et al., 2005a). Para solucionar a problemática sobre qual seria a melhor opção para essas situações clínicas, os princípios conservadores que regem o preparo dos condutos radiculares estimularam uma mudança na forma dos pinos reforçados por fibra cilíndricos em direção aos desenhos cônicos ou duplo-cônicos, objetivando minimizar a quantidade de estrutura radicular sacrificada para adaptar o pino à anatomia do canal. Adicionalmente, foi sugerida uma técnica de individualização da forma do pino reforçado por fibra às paredes internas do conduto radicular por meio do reembasamento com uma camada de resina composta fotopolimerizável, caracterizando o "sistema de pino anatômico". Assim, uma íntima adaptação do pino ao conduto seria obtida, levando à formação de uma camada de cimento de 
espessura ainda menor, a qual aumentaria hipoteticamente as propriedades retentivas dos pinos anatômicos (GRANDINI, SAPIO e SIMONETTI, 2003).

Sabendo que os condutos radiculares configuram o pior cenário para uso dos materiais resinosos, e dada à controvérsia existente em relação ao comportamento dos cimentos resinosos quando utilizados com camadas de diferentes espessuras, observou-se a necessidade de investigar o efeito da espessura do cimento na integridade adesiva e na resistência adesiva de pinos reforçados por fibra cimentados aos condutos radiculares utilizando cimentos resinosos com diferentes modos de polimerização. 

2 REVISÃO DE LITERATURA 



\section{REVISÃO DE LITERATURA}

\subsection{Desenvolvendo uma maior compreensão das tensões produzidas nos materiais compósitos durante a polimerização}

A origem das tensões de polimerização dos materiais compósitos está relacionada com a reação química envolvendo a quebra das ligações duplas de carbono das moléculas monoméricas individuais, e com a formação de ligações carbono-carbono simples para formar as cadeias poliméricas. Essa reação, que envolve a liberação de uma quantidade significante de calor, provoca uma redução de volume à medida que as ligações covalentes são criadas e as distâncias moleculares e o volume livre são reduzidos (FERRACANE, 2005).

Vários fatores contribuem para a produção de tensões nos compósitos durante a polimerização. A contração gerada durante a polimerização ocorre simultaneamente com o material adquirindo rigidez à medida que as cadeias poliméricas crescem, tornam-se enoveladas e cruzam-se entre si ou com cadeias vizinhas. É importante enfatizar dois aspectos do desenvolvimento dessas tensões. Primeiramente, esse é um processo dinâmico no qual a contração e o módulo de elasticidade aumentam com o tempo. Segundo, a resina composta em processo de polimerização não é completamente sólida, e a deformação plástica ou viscosa pode reduzir as tensões durante o seu desenvolvimento (FERRACANE, 2005).

A polimerização dos materiais compósitos é um processo complexo e tempodependente, através do qual as propriedades do material sofrem uma mudança drástica em um período relativamente curto. O processo de polimerização dos materiais compósitos apresenta três fases distintas: a fase líquida, onde os materiais contraem embora nenhuma tensão seja desenvolvida; a fase visco-elástica, onde a contração induz parcialmente à formação de tensão, a qual, por sua vez, é parcialmente aliviada pelo fluxo viscoso; e uma fase elástica, onde toda a contração é transformada em tensão. A fase visco-elástica e a fase elástica se iniciam, respectivamente, aproximadamente 60 e 900 s após o início da mistura do material. A deformação plástica e a tensão elástica são maiores durante os primeiros $900 \mathrm{~s}$ da polimerização, quando o material se encontra entre as fases líquida e visco-elástica. 
O processo termina aproximadamente 4000 s após a mistura do material. Por fim, na fase elástica, o material se torna mais rígido, induzindo à ocorrência de tensões de superior magnitude a partir da mesma contração de polimerização (DE JAGER, PALLAV e FEILZER, 2005).

A técnica incremental tem sido sugerida como uma estratégia para aliviar as tensões de contração de polimerização nas resinas compostas por meio da deformação elástica e do fluxo do material resinoso em direção às superfícies livres ou não-aderidas. Para isso, o dentista deve modificar a localização do fluxo predominante do material a partir da adequada seleção da geometria da cavidade (fator-C) (FEILZER, DE GEE e DAVIDSON, 1987). Isso é possível porque nos estágios iniciais de polimerização (fase visco-elástica), a rede polimérica ainda é relativamente fluida e plástica, e conseqüentemente, o fluxo viscoso pode ocorrer sem induzir danos à estrutura interna do material resinoso ou à união adesiva (DAUVILLIER et al., 2000). Entretanto, essa técnica não pode ser aplicada para a cimentação adesiva dos pinos reforçados por fibra, uma vez que o procedimento de cimentação é realizado em um passo único. Além disso, considerando que as paredes do conduto radicular e do pino de fibra são rígidas, a superfície livre formada, equivalente ao anel de cimento resinoso localizado na embocadura do conduto radicular, é pequena e provavelmente insignificante para promover o alívio das elevadas tensões formadas no interior da película de cimento resinoso.

Portanto, o conhecimento da contração de polimerização e da distribuição das tensões decorrentes dessa contração na camada de cimento resinoso, é de fundamental importância para a avaliação da durabilidade da cimentação adesiva dos pinos reforçados por fibra. Embora a compreensão completa desse processo seja difícil, e a geometria encontrada clinicamente seja complexa para permitir a simulação laboratorial, as características dessas tensões têm sido alvo de numerosas investigações nos últimos 35-40 anos, e uma revisão desses tópicos será apresentada para a compreensão dos fatores que influenciam os fenômenos de tensão advinda da contração de polimerização.

Davidson; De Gee; Feilzer (1984) avaliaram a influência da tensão de polimerização, desenvolvida durante a polimerização dos compósitos, na adesão à dentina de resinas compostas autopolimerizáveis e fotopolimerizáveis, em ambos os modelos linear e tridimensional. O modelo linear consistiu de uma montagem no tensilômetro, a qual permitiu que as resinas compostas fossem aplicadas 
diretamente à dentina planificada. O aumento na resistência adesiva foi mensurado em intervalos de tempo diferentes a partir do início da mistura e comparado com o desenvolvimento da tensão de contração. Ao longo do processo de polimerização, a adesão sobreviveu à tensão de contração, devido ao fluxo de relaxamento, que ocorreu de modo significativo nessa configuração. No modelo tridimensional, as resinas são unidas a mais de duas paredes de dentina. Nessa situação o fluxo é severamente limitado, e os valores de tensão de contração podem exceder a resistência adesiva, levando à separação. Os autores concluíram que a forma da cavidade foi de grande importância na conservação da união resina-dentina.

Feilzer; De Gee; Davidson (1987) estudaram a tensão de polimerização em resinas compostas em função da forma da restauração. Os autores definiram a forma como fator de configuração, ou fator- $C$, equivalente ao índice da superfície aderida em relação à superfície não aderida (livre). Nesse modelo experimental, a configuração da restauração foi simulada por formas cilíndricas de várias dimensões. A tensão de polimerização foi mensurada continuamente. Esse trabalho mostrou que na maioria das configurações de cavidade relevantes clinicamente, o alívio das tensões pelo fluxo da resina não é suficiente para preservar a adesão à dentina provida pelos agentes de união.

Feilzer; De Gee; Davidson (1989) avaliaram a contração de polimerização em direção às paredes cavitárias de resinas compostas autopolimerizáveis e fotopolimerizáveis com carga e sem carga em relação à espessura do material. Nesse experimento, as resinas foram unidas a dois discos opostos, e o deslocamento axial, resultado da contração de polimerização, foi mensurado continuamente. Foi demonstrado que a contração aumentou com a diminuição da distância axial entre os discos oponentes, atingindo valores de quase três vezes a contração de polimerização linear.

Davidson; Van Zeghbroeck; Feilzer (1991) monitoraram o desenvolvimento da tensão de polimerização em cimentos resinosos e ionoméricos em camadas de cimento variando de 30 a $200 \mu \mathrm{m}$. Os autores afirmaram que a natureza e a magnitude do desenvolvimento da tensão dependeu imensamente da formulação e da espessura do cimento. Quanto maior for a espessura, mais rápido é o desenvolvimento da tensão de polimerização no cimento de ionômero de vidro, e mais lento no cimento resinoso. Os autores concluíram que a tensão de 
polimerização apresentou um efeito prejudicial à resistência coesiva do cimento ionomérico e à resistência adesiva do cimento resinoso.

Alster et al. (1995) realizaram um estudo para verificar os efeitos da espessura da camada e da tensão de contração na resistência à tensão de resinas compostas. As superfícies metálicas do tensilômetro foram polidas, jateadas, enxagüadas com acetona, e silanizadas. Um suporte com duas sondas mensuradoras do descolamento foi conectado ao cilindro inferior, e outro contendo os planos de contato para as sondas foi interligado ao cilindro superior do extensômetro. Cada sonda foi conectada a uma das duas saídas do extensômetro contendo o marcador digital. A altura do espaço entre as duas superfícies paralelas de adesão foi ajustada ao valor desejado com o auxílio de um espaçador de aço inoxidável, e o valor monitorado foi registrado. A haste foi levantada para facilitar a inserção da resina composta. Uma resina quimicamente ativada, Clearfil F2 (Kuraray, Osaka, Japan), foi usada para assegurar uma polimerização uniforme da fina camada de resina entre os dois discos metálicos. A resina composta disponível comercialmente em duas pastas foi misturada e colocada sobre a superfície de adesão inferior; após esse procedimento, a haste foi abaixada novamente até que 0 extensômetro mostrasse $\circ$ valor pré-ajustado. A contração da amostra foi monitorada pelo extensômetro e o descolamento registrado foi contra-balançado pelo movimento da haste do tensilômetro em uma direção oposta. A tensão de polimerização foi derivada do encurtamento da amostra de resina composta. Vinte min após o início do teste, a amostra foi automaticamente submetida à carga de tensão por uma haste à velocidade de $0,1 \mathrm{~mm} / \mathrm{min}$. $O$ valor da força no momento da falha foi registrado. A resistência à tensão foi calculada a partir do valor da força máxima e da área da superfície fraturada. A resistência à tensão foi determinada para as espessuras da camada de 50, 100, 200, 300, 400, 500, 600, $700 \mu \mathrm{m}, 1,4$ $\mathrm{mm}$, e $2,7 \mathrm{~mm}$. O tipo de falha foi avaliado visualmente em microscopia óptica. Como resultado, foi encontrado que a resistência à tensão variou inversamente com a espessura da camada de cimento. A resistência à tensão diminuiu gradualmente de $62 \pm 2 \mathrm{MPa}$ para a camada de $50 \mu \mathrm{m}$ para $31 \pm 4 \mathrm{MPa}$ para a camada de $2,7 \mathrm{~mm}$. Nenhuma das amostras fraturou prematuramente devido à tensão de polimerização. As falhas na resina foram exclusivamente coesivas para as camadas de espessura entre 50 e $400 \mu \mathrm{m}$. Entre 500 e $700 \mu \mathrm{m}$, as falhas foram coesivas ou mistas, enquanto nas camadas de 1,4 e 2,7 mm o modo de falha foi sempre misto. Foi 
concluído que se a adesão à estrutura dentária fosse melhorada, uniões adesivas mais finas poderiam melhorar o sucesso clinico das restaurações cimentadas.

Carvalho et al. (1996) afirmaram que a inserção da resina composta no interior das cavidades leva à competição entre as forças de contração de polimerização e a resistência adesiva à estrutura dentária. Os autores afirmaram que o grau de desenvolvimento do estresse pode ser controlado, em alguma extensão, pelo desenho da cavidade (fator-C), o uso de materiais de base, o tamanho, a forma e a posição dos incrementos de resinas compostas inseridos nas cavidades, e pelo modo de polimerização da resina composta (autopolimerizável ou fotopolimerizável). $\mathrm{O}$ alívio do estresse pode ser realizado pela manutenção do fator-C tão baixo quanto for possível, usando as resinas autopolimerizáveis, materiais de forramento com baixo módulo de elasticidade e, ao longo do tempo, pela sorção de água. Os autores concluíram que uma compreensão completa desses princípios permite aos clínicos exercerem maior controle sobre essas variáveis, melhorando a qualidade das restaurações adesivas.

Alster et al. (1997a) investigaram o efeito da espessura da camada na tensão de polimerização em finas camadas de resina composta. Esse estudo foi realizado seguindo a mesma metodologia descrita no trabalho realizado previamente no ano de 1995. Dois min após o início da mistura, o procedimento controlado por computador foi iniciado. A tensão de polimerização foi determinada para as espessuras da camada de 50,100, 200, 300,400,500, 600, $700 \mu \mathrm{m}, 1,4 \mathrm{~mm}$ e 2,7 $\mathrm{mm}$. Todos os experimentos foram realizados à temperatura ambiente $\left(23 \pm 1^{\circ} \mathrm{C}\right)$. Após $20 \mathrm{~min}$, as amostras foram submetidas à carga à velocidade de $0,1 \mathrm{~mm} / \mathrm{min}$ com o objetivo de determinar a confiabilidade da máquina de ensaio, a qual foi calculada com o auxílio da análise de regressão não-linear, utilizando como modelo uma equação derivada da Lei de Hooke. Os resultados revelaram que a tensão de polimerização e o índice de desenvolvimento da tensão de polimerização diminuíram à medida que a espessura da camada das amostras cilíndricas de resina composta aumentou. Esses achados podem ser explicados pela teoria de que a maior área de superfície não aderida presente nas amostras mais espessas em relação à área de superfície aderida permitiu maior capacidade de fluxo. Além disso, nenhuma das amostras fraturou devido à tensão de contração previamente à carga. A tensão de contração após 20 min diminuiu de 23,3 + 5,3 MPa para a camada de $50 \mu \mathrm{m}$ até 5,5 \pm 0,6 MPa para a camada de 2,7 mm. A confiabilidade da máquina foi de 0,029 
$\mathrm{mm} / \mathrm{MPa}$. Os autores concluíram que o método de medição mostrou-se adequado para a determinação da tensão de contração de polimerização em finas camadas de resinas compostas quimicamente ativadas, sendo capaz de estimar os níveis de tensão que ocorrem em filmes de resina composta na situação clínica.

No mesmo ano, Alster et al. (1997b) avaliaram a influência da complacência do material do substrato na tensão de contração de polimerização em diferentes espessuras de resina composta. Foi relatado que tanto na situação experimental como na prática clínica, quando as resinas compostas são usadas para várias aplicações técnicas, a extensão dos materiais do substrato pode reduzir substancialmente a tensão de polimerização. O modelo experimental usado foi similar ao descrito previamente (1997a). A complacência da máquina foi alterada pela variação da altura do espaço entre a superfície superior do cilindro e o suporte do plano de contato. As medições de tensão de polimerização foram divididas nos grupos A1 (o suporte com os planos de contato para as sondas foi ligado ao cilindro superior), A2 e A3 (o suporte com os planos foi ligado diretamente à cabeça do cilindro superior com uma porca única), B (o suporte com os planos foi ligado ao cilindro superior com o auxílio de duas porcas, deixando $5 \mathrm{~mm}$ de espaço entre a base da porca inferior e a superfície do cilindro) e $C$ (similar ao grupo $B$, porém com um espaço de $12 \mathrm{~mm}$ ), dependendo da medição da complacência do aparelho. Em cada grupo, a tensão de polimerização foi determinada para as camadas de resina composta de espessuras de 100, 200, 300, 400, 500 e $700 \mu \mathrm{m}$. Os mesmos experimentos foram realizados no grupo A3 para as camadas de espessuras de 100, $200,300,400 \mu \mathrm{m}$. Uma segunda resina composta foi testada para as camadas de espessura de 200, 400 e $700 \mu \mathrm{m}$. Os autores revelaram que quando um pequeno grau de complacência foi permitido, a tensão de polimerização diminuiu com o aumento da espessura da camada (A1 e A3). No grupo A2, a complacência foi suficiente para reduzir a tensão na camada de $100 \mu \mathrm{m}$ mais do que na camada de $200 \mu \mu \mathrm{m}$. Quando a complacência do tensilômetro foi aumentada de $0,029 \mu \mathrm{m} \mathrm{MPa}^{-}$ ${ }^{1}$ para $0,150 \mu \mathrm{m} \mathrm{MPa}^{-1}$, a tensão de contração nas camadas com espessura de 100 $\mu \mathrm{m}$ diminuiu de 22 para $7 \mathrm{MPa}$. Para as amostras de $700 \mu \mathrm{m}$ de espessura, a tensão diminuiu de 12 para $11 \mathrm{MPa}$. Desse modo, foi possível concluir que se a complacência dos materiais do substrato ocorre, uma camada mais fina de resina composta pode resultar em uma união mais confiável. 
Dauvillier et al. (2000) realizaram um estudo para determinar os parâmetros visco-elásticos ocorridos durante a polimerização, objetivando auxiliar a compreensão do processo de desenvolvimento da tensão de contração. Um método mecânico dinâmico foi usado no qual os materiais foram submetidos a ciclos de tensão periódicos em uma máquina de ensaio universal durante os primeiros 60 min de polimerização. Os parâmetros visco-elásticos (viscosidade e módulo de Young) foram calculados através da análise dos dados tensão-tração por meio de um modelo mecânico simples. Dois materiais restauradores de diferentes classes foram investigados: uma resina composta quimicamente ativada e um cimento de ionômero de vidro convencional. A comparação dos resultados mostrou diferenças significantes no desenvolvimento da viscosidade e rigidez na fase inicial de polimerização entre os materiais. Os resultados revelaram que o módulo de Young e a viscosidade da resina composta se desenvolveram rapidamente, enquanto os parâmetros do ionômero de vidro permaneceram aproximadamente constantes. $\mathrm{O}$ período de relaxamento do ionômero de vidro também permaneceu baixo durante os primeiros $15 \mathrm{~min}$, ao passo que o da resina composta aumentou consideravelmente. Esse achado apresenta significância clínica, uma vez que durante o estágio inicial de polimerização, os cimentos de ionômero de vidro apresentam maior capacidade de reduzir as tensões de contração através do fluxo viscoso do que as resinas compostas. A tensão de contração de polimerização será, portanto menor, e isso poderá contribuir para a preservação da integridade da união adesiva, ao passo que a rigidez final do ionômero de vidro é comparável à da resina composta.

Condon; Ferracane (2000) mensuraram a magnitude da tensão de polimerização de várias resinas compostas e o efeito do novo monômero MSAA (metacrilato derivado do álcool ali-estireno) na redução da tensão de polimerização. Onze resinas compostas disponíveis comercialmente e uma resina composta experimental foram avaliadas em uma máquina de ensaio mecânico para mensurar a tensão máxima gerada durante a polimerização sob condições confinadas. Os resultados revelaram uma relação significante entre o maior volume de carga inorgânica e o aumento da tensão de polimerização nas resinas comercialmente disponíveis. A introdução do monômero MSAA gerou uma redução de $30 \%$ na tensão de polimerização no material compósito experimental. Os autores concluíram que as resinas compostas que contêm menor teor de carga inorgânica geram níveis de tensão de polimerização mais baixos. A modificação da composição química 
tradicional pode resultar em materiais que produzem níveis de estresse de polimerização menores.

De Jager; Pallav; Feilzer (2005) realizaram um estudo de análise pelo método dos elementos finitos para prever a magnitude das tensões geradas pela contração de polimerização de cimentos resinosos, baseada na divisão do processo de polimerização em três fases distintas (líquida, visco-elástica e elástica). Para avaliar a relação tensão-contração do material durante o estágio inicial de polimerização, discos de cimento resinoso de polimerização dual (RelyX ARC, 3M ESPE, St Paul, MN USA) apresentando espessuras de 0,140 $\mathrm{mm}$ e 0,250 $\mathrm{mm}$ foram polimerizados em um tensilômetro. As superfícies dos dois cilindros, uma ligada à haste móvel contendo a célula de carga e a outra interligada à base fixa do tensilômetro, foram cobertas com uma fina camada de sílica e, subseqüentemente, silanizadas para assegurar uma ótima união entre o cilindro de aço inoxidável e as amostras inseridas entre os dois cilindros. O deslocamento axial das superfícies aderidas foi determinado com o auxílio de um extensômetro. Duas condições foram testadas: na primeira, a contração de polimerização das amostras era prejudicada (tensão=0), e na segunda, as amostras permaneceram livres para contrair na direção axial (condição não-prejudicada; carga=0). Na condição prejudicada, a haste móvel compensava automaticamente qualquer deslocamento axial da superfície adesiva para manter a altura original da amostra, enquanto na condição não-prejudicada a haste móvel compensava qualquer registro registrado pela célula de carga para manter uma carga zero sobre a amostra; deste modo, a amostra estava livre para contrair. Na condição não-prejudicada, os dados de contração linear foram obtidos, enquanto na condição prejudicada, os dados de tensão de polimerização foram agrupados, ambos em função do tempo de polimerização. A combinação de ambos os dados permitiu a visualização da relação tensão-contração. Para obter a tensão elástica em função do período de polimerização, ciclos tensão/carga foram realizados periodicamente durante a execução do teste na condição prejudicada. A cada $200 \mathrm{~s}$ a carga obtida foi reduzida a zero em $15 \mathrm{~s}$, mantida em zero por $30 \mathrm{~s}$, e em 15 s a condição de zero tensão foi reinstalada. Todos os experimentos foram repetidos cinco vezes e realizados à temperatura ambiente. Os parâmetros obtidos nos experimentos foram usados no modelo tridimensional da análise de elementos finitos. As tensões de contração do experimento foram comparadas com os resultados da análise pelo método dos elementos finitos. Os resultados revelaram 
que foi possível prever as tensões de contração para as camadas de cimento com espessura uniforme. Além disso, os menores valores de tensão de contração e deformação plástica foram encontrados na camada fina. O modelo estudado foi confiável em predizer as tensões experimentais.

Ferracane (2005) realizou uma revisão visando elucidar as origens das tensões produzidas nas resinas compostas durante a polimerização, descrever brevemente os métodos para mensurá-las, discutir a relação entre tensão de contração e suas conseqüências, identificar os materiais e os fatores que afetam a tensão de contração, e descrever as diversas estratégias propostas para reduzir essas tensões. Segundo o autor, a polimerização é acompanhada de uma contração significante e geração de tensão interna. Essa tensão tem sido considerada como a causa das discrepâncias marginais encontradas ao redor das restaurações de resinas compostas, as quais podem levar à sobrevida reduzida. O fenômeno de desenvolvimento da tensão de contração é altamente complexo, e embora existam muitas investigações, esse problema ainda permanece como um problema clínico significante. 


\subsection{Quais são os fatores que influenciam a retenção dos pinos reforçados por fibra?}

Os núcleos metálicos fundidos foram largamente usados para a restauração dos dentes tratados endodonticamente nas últimas décadas devido às suas propriedades físicas relacionadas à rigidez e à resistência (ASMUSSEN, PEUTZFELDT e HEITMANN, 1999). Porém, os pinos metálicos rígidos resistem às forças laterais sem distorcerem e são retidos por fricção entre o pino e o conduto radicular, resultando na transferência de forças de elevada magnitude diretamente para a dentina radicular menos rígida. A concentração do estresse em determinadas regiões da raiz onde as paredes de dentina sejam mais finas e, conseqüentemente, menos resistentes, predispunham à fratura radicular (FERRARI, VICHI e GARCIAGODOY, 2000). Assim, alguns autores enfatizaram a necessidade do uso de pinos intra-radiculares que apresentassem propriedades biomecânicas similares às da dentina (GRANDINI et al., 2005b).

A introdução dos pinos de resina epóxica reforçados por fibra de carbono, em 1990, criou uma alternativa aos pinos metálicos para a restauração dos dentes tratados endodonticamente, uma vez que o módulo de elasticidade dos pinos reforçados por fibra é mais próximo ao da dentina (DURET, REYNAUD e DURET, 1990). Os pinos reforçados por fibra flexionam sob carga e, conseqüentemente, distribuem os estresses entre o pino e a dentina, resultando na transmissão de forças de menor magnitude para a dentina (BATEMAN, RICKETTS e SAUNDERS, 2003). Portanto, a principal diferença entre os pinos metálicos rígidos e os pinos à base de resina flexíveis relaciona-se com o mecanismo de transmissão das forças da restauração para o dente. Os pinos flexíveis concentram a força no topo da raiz (região entre a coroa e a raiz) e transferem menos carga à estrutura radicular, enquanto os pinos metálicos transferem a força integralmente para o conduto radicular (GRANDINI et al., 2005b). O comportamento mecânico diferenciado pode explicar as diferenças encontradas no mecanismo de falha entre os pinos de fibra e os pinos metálicos. Enquanto os pinos metálicos tendem a produzir uma fratura radicular irreversível, se a fratura radicular ocorre na presença do pino de fibra, ela é usualmente localizada mais coronalmente e é mais facilmente retratável (MONTICELLI et al., 2003). 
Porém, os pinos reforçados por fibra de carbono não preencheram os requisitos estéticos, tal como os pinos metálicos, sendo contra-indicados para uso em restaurações de resina composta e coroas de porcelana pura, uma vez que a coloração escura e a opacidade desses pinos intra-radiculares poderiam prejudicar o resultado estético (VICHI, FERRARI e DAVIDSON, 2000). A evolução dos pinos reforçados por fibra ocorreu com a substituição dos pinos de fibra de carbono pelos pinos de fibra de quartzo e de vidro, cujas fibras apresentaram cor e translucidez semelhantes às do dente, e radiopacidade ao exame radiográfico (GRANDINI et al., 2005a). Assim, os pinos reforçados por fibra são biocompatíveis, apresentam uma técnica clínica simples, rápida e econômica, e são cimentados de forma passiva no interior dos condutos radiculares (MALFERRARI, MONACO e SCOTTI, 2003). A forma dos pinos reforçados por fibra também sofreu modificações, partindo dos pinos duplo-cilíndricos desenvolvidos para aumentar a retenção, em direção aos pinos com perfis cilíndricos, cônicos e duplo-cônicos, baseados na suposta retenção provida pelos procedimentos adesivos.

Atualmente, é notável o impacto benéfico que os procedimentos estéticos restauradores, baseados na confecção de restaurações estéticas de resina composta ou de cerâmica pura, utilizando pinos reforçados por fibra de vidro e/ou quartzo como sistema de retenção intra-radicular, trouxe para a vida de muitas pessoas. A recuperação da estética para esses pacientes contribui para a melhoria da qualidade de vida e da auto-estima dos mesmos, uma vez que eles podem novamente voltar a mastigar com eficiência, bem como voltar a sorrir.

Embora a reconstrução coronária com pinos reforçados por fibra de vidro esteja sendo considerada nos últimos anos como um grande avanço para a Odontologia, esse procedimento não está livre de complicações e eventuais limitações, principalmente devido à cimentação adesiva que tem sido alegada como vantajosa para esses sistemas restauradores. Nesse contexto, a literatura apresenta inúmeros estudos científicos que investigaram as diversas causas que podem levar ao insucesso da cimentação adesiva dos pinos reforçados por fibra, e uma revisão de literatura será apresentada a seguir para esclarecer quais são essas causas e as possíveis estratégias para solucioná-las.

Bachicha et al. (1998) avaliaram a microinfiltração de dentes tratados endodonticamente restaurados com diferentes pinos intra-radiculares. O sistema de filtração de fluido foi usado para quantificar a quantidade de microinfiltração de pinos 
de aço inoxidável e pinos reforçados por fibra de carbono cimentados aos condutos radiculares com diferentes cimentos. A análise estatística mostrou que houve uma diferença significante na microinfiltração entre os cimentos $(p<0,001)$. $O$ cimento de fosfato de zinco apresentou a maior microinfiltração, ao passo que o cimento resinoso C\&B Metabond apresentou a menor. Não houve diferença significante na microinfiltração entre os pinos reforçados por fibra de carbono e os pinos de aço inoxidável. Os resultados deste estudo indicaram que ambos os pinos cimentados com cimentos resinosos apresentaram menos infiltração do que aqueles cimentados com cimentos não-adesivos (cimento de ionômero de vidro e fosfato de zinco).

Visando avaliar a interface adesiva de pinos intra-radiculares por meio de microscopia confocal e microscopia eletrônica de varredura, Mannocci et al. (1999) realizaram um estudo no qual 42 pré-molares uni-radiculares, extraídos por razões periodontais foram tratados endodonticamente e divididos em sete grupos de seis dentes cada. Em cinco grupos, três tipos diferentes de pinos reforçados por fibra de carbono, pinos reforçados por fibra de quartzo e pinos de titânio foram usados em combinação com o sistema adesivo All Bond 2. Em dois grupos, dois tipos de pinos reforçados por fibra de carbono foram cimentados com o sistema adesivo Panavia 21. Após três semanas de armazenamento em soro fisiológico, os dentes foram seccionados longitudinalmente; uma metade foi observada por microscopia confocal e a outra por microscopia eletrônica de varredura. Os espécimes foram avaliados em relação à presença da zona de interdifusão resina dentina para detecção da presença de bolhas nas interfaces pino-resina-dentina e para a determinação da estrutura dos pinos reforçados por fibra. Os resultados do exame de microscopia confocal revelaram que as interfaces dos dentes restauradas com All Bond 2 apresentaram a maior percentagem de zona de interdifusão resina dentina em relação aquelas tratadas com Panavia $(p<0,05)$. Os autores concluíram que a estrutura e o tamanho do pino foram semelhantes em todos os pinos reforçados por fibra observados. Algumas bolhas estiveram presentes no interior da estrutura do pino reforçado por fibra.

De Rijk (2000) apresentou uma técnica para remoção dos pinos reforçados por fibra. Os autores afirmaram que a remoção dos pinos intra-radiculares dos dentes tratados endodonticamente pode se tornar um obstáculo no retratamento dos dentes com patologia periapical recorrente, freqüentemente levando à extração do dente que poderia ter sido salvo por meio do retratamento endodôntico. Os autores 
afirmaram também que os pinos reforçados por fibra apresentam como vantagens o modulo elástico adequado e a boa adesão entre o pino e o cimento, além de serem facilmente removidos, quando há a necessidade evidenciada pelos achados clínicos. Neste trabalho, um sistema especial para a remoção dos pinos reforçados por fibra foi desenvolvido, e o seu uso ilustrado e descrito. Concluiu-se que o procedimento de remoção do pino reforçado por fibra pode ser realizado em um período de tempo muito curto, geralmente inferior a $5 \mathrm{~min}$. Os dentes podem, então, ser restaurados com o mesmo tipo e tamanho do pino intra-radicular que estava em posição previamente à sua remoção.

Ferrari; Mannocci (2000) apresentaram um caso clínico para avaliar o uso de um sistema adesivo convencional de dois passos de "frasco único" (One Step, Bisco) na cimentação adesiva do pino reforçado por fibra. Uma paciente (58 anos, sexo feminino) apresentou-se com uma fratura radicular vertical em um incisivo central superior tratado endodonticamente há sete anos. Os exames clínicos e radiográficos demonstraram a necessidade de extração do dente. O pino foi cimentado no interior do conduto radicular da raiz fraturada e, então, a raiz foi extraída uma semana depois. A raiz foi seccionada longitudinalmente em uma direção mesio-distal para a obtenção de duas metades. Uma metade da raiz foi gentilmente descalcificada com ácido fosfórico $32 \%$ por $60 \mathrm{~s}$, lavada e seca com ar. A amostra foi então imersa em uma solução de hipoclorito de sódio $2 \%$ por 120 s para remover as proteínas e permitir a avaliação da formação da camada híbrida. A outra metade da raiz foi armazenada em ácido clorídrico por $24 \mathrm{~h}$ com o objetivo de dissolver completamente o substrato dentário e detectar os prolongamentos resinosos e a formação das ramificações laterais de adesivo. Após a lavagem abundante com água, os dois espécimes foram gentilmente secos com ar, metalizados com ouro e observados em MEV. Os resultados revelaram que o sistema adesivo One-Step formou uma camada híbrida entre a resina e a dentina radicular com espessura entre 3 e $5 \mu \mathrm{m}$. Os prolongamentos resinosos apresentaram 10-20 $\mu \mathrm{m}$ de comprimento e as ramificações laterais de adesivo foram evidentes. As imagens em MEV em pequeno aumento das amostras descalcificadas mostraram alta densidade e distribuição uniforme dos prolongamentos resinosos. A forma de cone-invertido característica dos prolongamentos resinosos também foi observada na amostra em maior aumento. No terço cervical do conduto radicular preparado, a densidade dos prolongamentos resinosos foi maior do que nos terços médio e apical. Os autores 
concluíram que o sistema adesivo de "frasco único" criou um embricamento mecânico com a dentina radicular condicionada sob as condições clínicas testadas.

No mesmo ano, Ferrari et al. (2000a) avaliaram laboratorialmente, empregando MEV, a morfologia da dentina radicular relativa à orientação, densidade e aumento da área superficial dos túbulos dentinários após o condicionamento ácido. Trinta dentes uni-radiculares foram divididos aleatoriamente em três grupos: Grupo 1 (usado para estudar a morfologia tubular); Grupos 2 e 3 (usados para a análise das alterações na densidade e extensão da área superficial após 0 condicionamento com ácido fosfórico 32\%). Os dentes do Grupo 2 foram examinados em MEV sem nenhum tratamento adicional. As amostras do Grupo 3 foram tratadas com o sistema adesivo e pinos reforçados por fibra foram cimentados no interior dos condutos radiculares. Posteriormente, esses dentes foram processados para avaliação da formação da camada híbrida e prolongamentos resinosos nos túbulos dentinários. As observações foram realizadas de acordo com a localização na dentina radicular, a densidade tubular foi estimada, e o aumento na área disponível para adesão após o condicionamento ácido foi calculado. Os resultados mostraram variabilidade na densidade e orientação dos túbulos nas diferentes áreas das amostras. A densidade dos túbulos no terço cervical foi significantemente maior do que aquela observada nos terços médio e apical $(p<0,01)$. O diâmetro dos túbulos diminuiu gradualmente em direção apical. A camada híbrida foi significantemente mais fina nas regiões de menor densidade dos túbulos (terço apical) em comparação às regiões com maior densidade tubular. A área superficial de dentina disponível para adesão aumentou $202 \%$ após o condicionamento ácido no terço cervical, $156 \%$ no terço médio e $113 \%$ no terço apical da dentina radicular. Concluiu-se que o aumento na área de superfície de dentina pode ser responsável pela maior resistência adesiva após o condicionamento ácido.

Ferrari; Vichi; Grandini (2001) realizaram um estudo para avaliar a influência de quatro procedimentos adesivos na formação de prolongamentos resinosos, ramificações laterais de adesivo e zona de interdifusão resina-dentina na cimentação adesiva intra-canal de pinos reforçados por fibra. Quarenta dentes anteriores tratados endodonticamente e extraídos por razões periodontais foram selecionados para esse estudo. As amostras foram randomizadamente divididas em quatro grupos de 10 amostras cada. Grupo 1: One-Step + cimento resinoso Duolink; Grupo 2: One- 
Step + cimento resinoso Dual Link; Grupo 3: One Step + cimento resinoso Dual Link; Grupo 4: Al Bond 2 + C\&B Cement (controle). No grupo 1, o sistema adesivo foi aplicado usando um micro-pincel fino, enquanto nos outros grupos utilizou-se um pincel pequeno. Nos grupos 1 e 2 a solução de primer-adesivo foi foto-polimerizada antes da inserção do cimento resinoso e do pino, enquanto no grupo 3 a combinação de cimento resinoso/adesivo foi foto-polimerizada através do pino translúcido (RTD, France). Uma semana depois, as raízes foram processadas para análise em MEV. O exame microscópico das interfaces restauradas do grupo 1 apresentou zona de inter-difusão resina-dentina significantemente maior do que nas amostras dos grupos 2, 3 e 4. Nas amostras dos grupos 2, 3 e 4, a morfologia da zona de inter-difusão resina-dentina apresentou-se uniforme nos terços cervical e médio dos condutos radiculares. Não foram encontradas diferenças significantes entre os grupos no terço cervical, ao passo que os terços médio e apical do grupo 1 apresentaram significantemente mais prolongamentos resinosos do que nos outros três grupos. No terço apical dos Grupos 2, 3 e 4, os prolongamentos resinosos apresentaram uma morfologia menos uniforme e menor comprimento do que os outros terços. Concluiu-se que o mecanismo de adesão criado entre a dentina radicular e o sistema adesivo pelo uso do pincel fino foi mais uniforme e mais previsível.

A resposta mecânica à aplicação de cargas externas de um novo pino reforçado por fibra de vidro foi simulada por meio da análise de um modelo bidimensional pelo método dos elementos finitos. Nesse trabalho, Pegoretti et al. (2002) utilizaram um pino novo apresentando forma cilíndrica com ponta cônica para permitir uma adaptação precisa ao conduto radicular e evitar bolhas que poderiam atuar como áreas concentradoras de estresses indesejados. Os dados mecânicos obtidos pelos testes de três pontos em alguns protótipos fabricados no laboratório estiveram presentes e foram usados no modelo de elementos finitos. Sob várias condições de carga, os campos de estresse resultantes foram comparados com aqueles obtidos para os dois pinos intra-radiculares disponíveis comercialmente (por exemplo, núcleo metálico fundido e pino reforçado por fibra de carbono) e com a resposta do dente natural. Os resultados indicaram que o núcleo metálico fundido produziu a maior concentração de estresses na interface pino-dentina. Por outro lado, os pinos reforçados por fibra apresentaram altos valores de estresses na região cervical devido à sua flexibilidade e também à presença de um material 
menos rígido para a confecção do núcleo. O pino reforçado por fibra mostrou o menor pico de estresse no interior da raiz devido à rigidez semelhante à da dentina. Foi concluído que o pino reforçado por fibra induziu um campo de estresse bastante similar ao do dente natural, à exceção da concentração de forças na região cervical da raiz.

Boschian Pest et al. (2002) compararam a resistência adesiva de vários cimentos e resinas compostas nas interfaces cimento-dentina e cimento-pino através de dois testes push-out realizados separadamente, e examinaram a integração entre o pino, o cimento e a dentina através da análise em MEV. A resistência adesiva entre o material cimentante e a dentina radicular foi avaliada pelo teste push-out em 50 dentes uni-radiculares. Para isso, os materiais cimentantes foram inseridos com uma ponta metálica descartável no interior dos condutos radiculares (sem nenhum pino), e as raízes foram seccionadas transversalmente em quatro seções de $2 \mathrm{~mm}$ de espessura. Para a avaliação da resistência adesiva entre o material cimentante e o pino, 60 placas de plástico de $3 \mathrm{~mm}$ de espessura foram preparadas colocando-se um pino cimentado no centro da placa. Os testes push-out foram realizados à velocidade de $0,5 \mathrm{~mm} / \mathrm{min}$ usando uma máquina de ensaio universal. Por fim, 30 dentes uni-radiculares foram tratados endodonticamente e pinos reforçados por fibra foram cimentados com diferentes cimentos adesivos. As amostras foram seccionadas longitudinalmente com um disco diamantado em baixa velocidade e preparadas para análise em MEV. A análise estatística foi realizada aplicando-se ANOVA a um critério, seguida pelo teste de Scheffe ao nível de significância de $0,05 \%$. O sistema adesivo de quarta geração All Bond 2 apresentou prolongamentos resinosos longos e numerosos ao longo da superfície radicular na análise em MEV. Contudo, a resistência adesiva equivalente apresentou somente uma ligeira superioridade na retenção para esse material. Os testes push-out realizados para Panavia F e Clearfil LB2V combinados com Tech 2000 ou Tech 21 X-op apresentaram os mais altos valores de resistência adesiva na interface pino-cimento. Ticore e Clearfil LB2V apresentaram os mais altos valores de resistência adesiva na interface cimento-dentina. Os autores concluíram que a cimentação adesiva dos pinos empregando resinas compostas é uma técnica alternativa comparável e em alguns casos superior à técnica tradicional que usa os cimentos resinosos. Além disso, os autores encontraram maior retenção para todos os cimentos unidos ao pino em comparação à dentina. 
Vichi; Grandini; Ferrari (2002) avaliaram a formação de prolongamentos resinosos, ramificações laterais de adesivos e a zona de interdifusão resina-dentina proporcionada por dois tipos de pincéis utilizados como carreadores da solução primer-adesivo na cimentação de pinos reforçados por fibra translúcidos. Vinte dentes tratados endodonticamente foram randomizadamente distribuídos em dois grupos de 10 espécimes cada (Grupo 1: micro pincel + Scotchbond 1 + Rely X ARC; Grupo 2: pequeno pincel plástico fornecido pelo fabricante + Scotchbond $1+$ Rely $X$ ARC). O exame microscópico das interfaces restauradas do Grupo 1 mostrou uma percentagem significantemente maior $(p<0,05)$ de zona de interdifusão dentinaresina do que aquela encontrada nos espécimes do Grupo 2. Não houve diferença estatisticamente significante entre os dois grupos nos terços cervical e médio, mas o terço apical do Grupo 1 mostrou uma formação de prolongamentos resinosos significantemente maior do que o Grupo 2. A morfologia de cone invertido característica dos prolongamentos resinosos foi observada no terço cervical e médio dos canais radiculares de ambos os grupos e no terço apical do grupo 1. No terço apical do Grupo 2, os prolongamentos resinosos apresentaram uma morfologia menos uniforme e de menor comprimento do que aqueles encontrados nos outros terços observados. Dessa forma, os autores concluíram que o uso de um micro pincel fino tem a capacidade de penetrar mais profundamente no interior do conduto radicular, sendo mais previsível e útil do que os pincéis usualmente fornecidos pelo fabricante.

Vichi et al (2002) avaliaram a eficácia de três sistemas adesivos de "frasco único" e dois sistemas adesivos de três passos na formação de prolongamentos resinosos, ramificações laterais de adesivo e zona de interdifusão resina-dentina na cimentação adesiva de pinos reforçados por fibra sob condições clínicas. Cinqüenta raízes tratadas endodonticamente, agendadas para extração por razões endodônticas ou periodontais, foram selecionadas para o estudo. As amostras foram randomizadamente divididas em cinco grupos de 10 unidades cada. Grupo 1: All Bond 2 + C\&B Cement (Bisco); Grupo 2: Scotchbond Multipurpose Plus + Opal Luting Composite (3M); Grupo 3: Scotchbond 1 + Rely X ARC (3M); Grupo 4: OneStep + C\&B Cement (Bisco); Grupo 5: All Bond experimental + Post Cement HI-X (Bisco). Pinos reforçados por fibra de quartzo (Aestheti-Plus, RTD) foram cimentados aos condutos radiculares, e, uma semana depois, as raízes foram extraídas e processadas para análise em MEV. Os resultados revelaram que todos os sistemas 
adesivos demonstraram a formação de prolongamentos resinosos, ramificações laterais de adesivo e zona de interdifusão resina-dentina. Os Grupos 1 e 2 apresentaram maior percentagem de formação de zona de interdifusão resinadentina do que os Grupos 3, 4 e 5. A morfologia da zona de interdifusão resinadentina e dos prolongamentos resinosos apresentou aspecto mais uniforme nos terços cervical e médio dos condutos radiculares em comparação à região apical. Não foram encontradas diferenças estatisticamente significantes entre os grupos na região cervical, enquanto que nos terços médio e apical, os dois sistemas de frasco único (Grupos 3 e 4) apresentaram significantemente menor formação de prolongamentos resinosos do que os grupos controle 1 e 2, e o grupo 5 experimental. Concluiu-se que os sistemas adesivos de três passos podem criar um embricamento micro-mecânico maior entre os materiais adesivos e a dentina condicionada em comparação aos sistemas de passo único.

A comparação por microscopia confocal e microscopia eletrônica de varredura das interfaces pino-resina-dentina foi realizada por Mannocci et al. (2003) em dentes tratados endodonticamente restaurados com sistemas adesivos e resinas, e que apresentavam a necessidade de extração após seis meses e até seis anos de serviço clínico. Dezesseis dentes uni-radiculares foram incluídos na investigação e divididos em dois grupos: Grupo 1 (os dentes foram tratados endodonticamente e restaurados com pinos reforçados por fibra de carbono e resina composta); Grupo 2 (os dentes foram tratados da mesma maneira e restaurados com coroas metalocerâmicas). Os resultados revelaram que dois terços das interfaces observadas apresentaram a penetração de resina nos terços médio e cervical do conduto radicular, enquanto somente um terço das interfaces observadas apresentou infiltração de resina no terço apical do conduto radicular. A perda de adesão entre o adesivo e a área de dentina infiltrada por resina, e a perda de adesão entre o cimento resinoso e o adesivo foram os modos de falha mais freqüentemente observados em um terço das interfaces analisadas. Não houve diferença entre as interfaces pino-resina-dentina dos dentes restaurados e os dentes não restaurados com as coroas metalo-cerâmicas. Os dentes extraídos após longos períodos de serviço clínico apresentaram áreas mais abundantes de perda de adesão do adesivo na zona de inter-difusão resina dentina.

Para determinar se a interação química adversa e a permeabilidade adesiva são responsáveis pela incompatibilidade entre os adesivos auto-condicionantes de 
passo único e as resinas compostas de polimerização química e dual, Tay et al. (2003a) desenvolveram um estudo analisando o uso do Xeno CF Bond (DentsplySankin) em dentina humana hidratada $(\mathrm{H})$ ou desidratada $(\mathrm{DH})$. $\mathrm{Na}$ avaliação da resistência adesiva à micro-tração, a resina composta híbrida dual (Bis-Core) foi ativada usando: (1) o modo foto-polimerizável (somente a pasta base) (F), (2) fotoativação com retardo (a pasta base foi posicionada no topo do adesivo polimerizado no escuro por 20 min antes da foto-ativação) (FR), e (3) o modo auto-polimerizável (pastas base e catalisadora no escuro) (A). O co-iniciador químico (B; BondLink) também foi aplicado ao adesivo polimerizado antes da união com a resina composta no modo auto-polimerizável. Isso resultou em sete grupos experimentais: (1) F-H (controle); (2) FR-H; (3) FR-DH; (4) A-H; (5) A-DH; (6) A-B-H; and (7) A-B-DH. Para a microscopia eletrônica de transmissão, a resina composta dual foi substituída nos sete grupos por uma resina composta microparticulada foto-polimerizável (Metalfix CX) e uma resina composta microparticulada experimental auto-polimerizável apresentando a mesma composição. Os espécimes foram imersos em nitrato de prata amoníaco por $24 \mathrm{~h}$ e após a redução dos íons de prata diamino, seções desmineralizadas e não pigmentadas foram examinadas para a nano-infiltração no interior das interfaces resina-dentina dos sete grupos. Os resultados revelaram que, para o modo foto-polimerizável, a resistência adesiva caiu substancialmente no grupo dentina desidratada FR-H, mas não em FR-DH. Para o modo autopolimerizável, a menor resistência adesiva foi encontrada em A-H e somente aumentou ligeiramente em A-DH. O uso do co-iniciador químico com o sistema adesivo aumentou a resistência adesiva em A-B-H. Somente A-B-DH não foi significantemente diferente de F-H. Dois depósitos anormais de prata foram observados nas interfaces resina-dentina. Uma camada contínua de prata foi observada quando a resina composta auto-polimerizável foi aplicada ao adesivo na ausência do co-iniciador químico (A-H, A-DH). Bolhas de água impregnadas com prata foram identificadas quando a resina composta auto-polimerizável foi unida à dentina hidratada $(\mathrm{A}-\mathrm{H}$; $\mathrm{A}-\mathrm{B}-\mathrm{H})$. Bolhas de água semelhantes foram vistas em $\mathrm{FR}-\mathrm{H}$ no qual a interação química adversa não deveria ocorrer. Concluiu-se que a interação química adversa entre os componentes da resina composta autopolimerizável e o adesivo auto-condicionante de passo único testado foi a principal causa de redução na resistência adesiva, enquanto a permeabilidade adesiva foi a menor causa de redução na resistência adesiva. A combinação desses dois fatores 
contribuiu para a redução substancial na resistência adesiva quando compósitos de polimerização química ou dual foram associados com a dentina hidratada.

Sabendo que os adesivos contendo componentes resinosos hidrofílicos são vulneráveis ao movimento de água após a polimerização, Tay et al. (2003b) testaram a hipótese de que a associação do adesivo de frasco único (OptiBond Solo Plus) às resinas compostas de polimerização química ou dual é comprometida pela permeabilidade adesiva, até mesmo com o uso de co-iniciadores químicos. Para a realização desse estudo, duas versões dos co-iniciadores químicos (ativadores) foram investigadas: a resina contendo o ativador OptiBond Solo Plus (A), e uma solução livre de resina contendo $2 \%$ de sulfinato benzínico de sódio (B). Para o teste de micro-tração, a dentina humana hidratada $(\mathrm{H})$ ou desidratada $(\mathrm{DH})$ foi associada à resina composta dual (Bis-Core) sob o modo de ativação foto $(F)$ ou autopolimerizável $(A)$. O modo de foto-ativação com retardo $(F R)$ também foi empregado para simular o grau de polimerização mais lento das resinas compostas autopolimerizáveis sem a influência da interação química adversa. Nove grupos foram testados: 1) F-H (controle); 2) FR-H; 3) FR-DH; 4) A-H; 5) A-DH; 6) AA-H; 7) AA-DH; 8) AB-H; e 9) AB-DH. Para a microscopia eletrônica de transmissão, uma resina composta foto-polimerizável e uma resina composta auto-polimerizável experimental apresentando a mesma composição foram usadas para os nove grupos. Somente os resultados de resistência adesiva dos grupos experimentais FR-D (Grupo 3) e ABDH (Grupo 9) não foram significantemente diferentes do grupo controle $\mathrm{F}-\mathrm{H}$ $(p>0,05)$. A microscopia eletrônica de transmissão revelou a presença de discretas bolhas de água preenchidas com prata ao longo da interface resina-adesivo nos grupos 2, 6 e 8, e no interior da resina composta no grupo 4. A interação química adversa nos grupos 4 e 5 resultou na observação de uma linha de depósitos de prata ao longo da interface adesivo/resina. Concluiu-se que as resinas compostas após contato prolongado com a dentina hidratada aderida com OptiBond Solo Plus é afetada pela permeabilidade intrínseca do adesivo. O uso associado do ativador é apenas ligeiramente efetivo na melhoria da adesão desse adesivo com as resinas compostas de polimerização química ou dual. Embora o uso da solução salina de sulfinato benzínico de sódio elimine completamente a interação química adversa, a permeabilidade inerente ao adesivo polimerizado prejudica a união das resinas compostas de polimerização química ou dual à dentina hidratada. 
Le Bell et al. (2003) avaliaram a profundidade de polimerização iniciada pela luz alcançada pelos pinos de resina reforçados por fibra de vidro. O grupo experimental foi constituído por um polímero foto-polimerizável pré-impregnado com resina monomérica dimetacrilato reforçada com fibras de vidro. A mesma resina sem o reforço com fibras foi usada como controle. Seis comprimentos diferentes (variando de quatro a $24 \mathrm{~mm}$ ) de cilindros protegidos pela luz preenchidos com os materiais testados foram foto-polimerizados em uma das extremidades. O grau de conversão dos monômeros foi determinado na extremidade oposta utilizando-se espectroscopia. O espectro foi registrado em seis pontos diferentes. A microdureza dos materiais testados foi mensurada iniciando-se na superfície exposta pela luz em direção à outra extremidade do cilindro. Os resultados demonstraram que ambos os grupos apresentaram redução no grau de conversão com o aumento no comprimento do cilindro. O grupo experimental apresentou grau de conversão superior ao grupo controle. A mensuração de microdureza confirmou a redução constante do grau de conversão pelos valores de dureza Vickers reduzidos a partir do aumento do comprimento do cilindro experimental. Concluiu-se que os pinos reforçados por fibra geraram grau de conversão quase similar após a fotopolimerização em comparação à resina monomérica sem fibras. Contudo, nos cilindros mais longos, os pinos reforçados por fibra apresentaram grau de conversão ligeiramente superior à resina sem reforço com fibras. Os autores sugeriram que os resultados podem ter sido decorrentes da habilidade das fibras em conduzir a luz.

Reid; Kazemi; Meiers (2003) investigaram o efeito do teste de fadiga na integridade do núcleo e na microinfiltração de dentes restaurados com diferentes sistemas de pinos intra-radiculares. Cinqüenta dentes uni-radiculares foram restaurados com um dos seguintes sistemas de pinos e núcleos de resina composta: pino de titânio (Parapost) cimentado com o cimento de fosfato de zinco; e CosmoPost, C-Post, Esthetic C-Post e Fibrekor Post cimentados com cimento resinoso. As amostras foram posicionadas em uma máquina de ensaio universal para serem impactadas a $45 \square$ em relação ao longo eixo do dente com uma força de $55 \mathrm{~N}$ à freqüência de $3 \mathrm{~Hz}$ totalizando 100.000 ciclos. Após 60.000 ciclos, as amostras foram submetidas a termo-ciclagem. A integridade do núcleo e a microinfiltração do pino foram avaliadas periodicamente a cada 100.000 ciclos. Os resultados revelaram que as amostras não apresentaram deslocamento dos núcleos, 
embora os pinos metálicos tenham apresentado aumento significante da microinfiltração em comparação aos pinos não-metálicos no final do estudo $(p<0,05)$.

Bouillaguet et al. (2003) realizaram um estudo para testar as hipóteses de que a resistência adesiva dos cimentos resinosos à dentina radicular (1) seria reduzida em função do fator de configuração, processo de polimerização e tipo de cimento e (2) seria menor próximo ao ápice do dente. Quarenta e oito dentes uni-radiculares receberam pinos endodônticos cimentados com Single/Rely $X$ ARC, ED Primer/Panavia F, C e B Metabond ou Fuji Plus. Os espécimes foram divididos em dois grupos: grupo de raízes intactas (os pinos foram cimentados usando os procedimentos clínicos padrão) e grupo de raízes planificadas (os pinos foram aplicados diretamente no interior dos canais radiculares). As raízes foram secionadas em porções de 0,6 mm de espessura, desgastadas mesio-distalmente e tracionadas até a ocorrência da falha à velocidade de $1 \mathrm{~mm} / \mathrm{min}$. A análise estatística foi realizada com ANOVA a um critério e teste de Tukey $(\alpha=0,05)$. Os resultados revelaram que as raízes intactas apresentaram resistência adesiva significantemente inferior em relação às raízes planificadas. A resistência adesiva dos pinos cimentados nas raízes intactas não apresentou diferença significante para os sistemas de cimentação adesiva Single/Rely X ARC e ED Primer/Panavia F; contudo, ambos foram significantemente inferiores $(p<0,05)$ em comparação aos cimentos C e B Metabond e Fuji Plus. Para Single/Rely X ARC e Fuji Plus, observouse um decréscimo significante na resistência adesiva na dentina localizada no terço apical. Os autores concluíram que as tensões de polimerização e os problemas associados com o acesso ao conduto radicular prejudicam a formação de uma união adesiva de alta resistência quando pinos endodônticos são cimentados com cimentos resinosos.

O estudo de Sahafi et al. (2004) avaliou o efeito do cimento, material do pino, tratamento de superfície e forma (1) na retenção dos pinos cimentados aos condutos radiculares de dentes humanos extraídos e (2) na morfologia de falha. Pinos de titânio (ParaPost XH), fibra de vidro (ParaPost Fiber White) e zircônia (Cerapost) receberam um dos vários tratamentos de superfície - jateamento, tratamento CoJet, aplicação de Metal primer II, ou jateamento seguido de aplicação de silano - e foram cimentados aos condutos radiculares $(n=10)$. Após o armazenamento em água a $37^{\circ} \mathrm{C}$ por sete dias, a retenção foi determinada pela remoção dos pinos. A morfologia de falha dos pinos extraídos foi analisada e quantificada estereomicroscopicamente. 
O tipo de cimento, o material e a forma do pino influenciaram a retenção e a morfologia de falha dos pinos. Em função da aderência limitada do cimento ao conduto radicular, os tratamentos de superfície não apresentaram um efeito positivo na retenção. Os autores concluíram que a seleção do cimento é crítica para os três tipos de pinos, sendo que os pinos paralelos apresentaram retenção superior aos pinos cônicos.

Monticelli; Goracci; Ferrari (2004) avaliaram microscopicamente as características estruturais da unidade pino-núcleo confeccionada com pino reforçado por fibra e diferentes tipos de resinas compostas usadas como materiais de núcleo. Quarenta incisivos superiores tratados endodonticamente receberam pinos reforçados por fibra (Aesthetic Post Plus, RTD) cimentados com One-Step/C\&B Cement (Bisco). As raízes foram divididas randomizadamente em oito grupos de acordo com o material utilizado para a confecção do núcleo coronário: Z100 (3M ESPE), Lumiglass (RTD), Gradia (GC), Build-it! (Jeneric Pentron). Nos demais grupos, os mesmos materiais foram usados para a confecção dos núcleos, adicionando-se o uso de uma matriz plástica (Composipost, Core Form, RTD). Os espécimes foram secionados perpendicularmente ao longo eixo do dente, e processados para observação em MEV. Os resultados indicaram que, na ausência da matriz, os núcleos construídos com Gradia apresentaram a mais alta integridade, e aqueles construídos com Z100 apresentaram melhor adaptação à superfície do pino. Na presença da matriz, Buld-it! apresentou os resultados mais satisfatórios, sendo o único material que apresentou resultados superiores na presença da matriz. Os autores concluíram que quando as resinas compostas são usadas para confeccionar o núcleo sobre o pino reforçado por fibra, uma homogeneidade do núcleo e uma integração pino-núcleo superior são atingidas se a reconstrução coronária é realizada sem o uso da matriz.

Aksornmuang et al. (2004) avaliaram a resistência adesiva à micro-tração do material compósito empregado para a confecção do núcleo coronário em diferentes regiões dos pinos reforçados por fibra usando diferentes tratamentos de superfície. Vinte e cinco pinos reforçados por fibra de vidro (Snowpost) e 25 pinos reforçados por fibra de quartzo (Aesthetic-Plus) foram divididos randomizadamente em cinco grupos de acordo com o tratamento de superfície: (1) sem tratamento (controle); (2) sistema adesivo dual, Clearfil Liner Bond 2V; (3) Clearfil Liner Bond 2V fotopolimerizado por $20 \mathrm{~s}$; e (4) agente de união silano, Clearfil Photobond associado a 
Porcelain Bond Activator; (5) Clearfil Photobond associado a Porcelain Bond Activator foto-polimerizado por $20 \mathrm{~s}$. Os pinos foram cimentados no interior de cavidades artificiais usando o material compósito para núcleo Clearfil DC Core fotopolimerizado por $60 \mathrm{~s}$ a partir do topo da cavidade. Após $24 \mathrm{~h}$ de armazenamento em água, cada espécime foi secionado serialmente em bastões para o teste de micro-tração. Os dados foram divididos em três regiões (superior/ média/ inferior) e analisados através de ANOVA a três critérios e teste de Dunnet $(\alpha=0,05)$. Os resultados revelaram que não houve diferença significante na resistência adesiva entre as três regiões $(p<0,05)$. A resistência adesiva foi melhorada pela aplicação do agente de união silano. Para Snowpost, a foto-polimerização do sistema adesivo dual aplicado à superfície do pino melhorou significantemente a resistência adesiva $(p<0,05)$, ao passo que não afetou a resistência adesiva para o pino Aesthetic-Plus (p.0,05). Foi concluído que a resistência adesiva entre o pino reforçado por fibra e o material compósito para núcleo depende do tipo de pino e do tratamento de superfície. Não houve diferença na resistência adesiva regional dos pinos reforçados por fibra.

Goracci et al. (2004) compararam a mensuração da sistência adesiva de pinos reforçados por fibra através das técnicas de micro-tração e push-out. Trinta dentes tratados endodonticamente receberam pinos reforçados por fibra cimentados com Excite DSC/Variolink II (Grupo A) ou Rely X Unicem (Grupo B). Dentro de cada grupo, a resistência adesiva dos pinos reforçados por fibra foi analisada com a técnica de microtração com e sem desgaste proximal, e com o teste push-out. Os resultados mostraram que o elevado número de falhas prematuras (16,9\% no Grupo A, $27,5 \%$ no Grupo B) e os valores altos do desvio padrão tornam questionável a confiabilidade da técnica de micro-tração com desgaste proximal. Na técnica de micro-tração sem desgaste, somente cinco bastões foram obtidos em seis raízes, ao passo que os espécimes remanescentes falharam prematuramente durante a fase de corte. No teste push-out, nenhuma falha prematura ocorreu, a variabilidade da distribuição dos dados foi aceitável, e foi possível analisar as diferenças regionais na resistência adesiva entre os níveis radiculares. No geral, baixos valores de resistência adesiva foram registrados para os pinos reforçados por fibra cimentados adesivamente aos condutos radiculares. Concluiu-se que o teste push-out parece ser mais confiável do que a técnica de micro-tração para a mensuração da resistência adesiva dos pinos reforçados por fibra. 
Giachetti et al. (2004) realizaram um estudo para avaliar a performance de sistemas de cimentação adesiva dual e foto-polimerizável usados em combinação com pinos de fibra translúcida, por meio do teste pull-out e análise em MEV. Quarenta dentes tratados endodonticamente foram divididos randomizadamente em dois grupos de 20 espécimes cada: Grupo 1 (sistema foto-polimerizável): Excite e Tetric Flow; e Grupo 2 (sistema dual): All Bond 2 + Rely X ARC. Pinos de fibra duplocônicos foram usados (2,1/1,4 mm de diâmetro). Os dentes foram armazenados em solução fisiológica $0,9 \%$ a $37 \square \mathrm{C}$. Uma semana depois, o teste pull-out foi realizado em todos os espécimes. Dez espécimes foram selecionados randomizadamente para cada grupo e os pinos processados para análise em MEV. A análise estatística foi realizada aplicando-se a análise de variância (ANOVA) seguida pelo teste $t$ ao nível de significância de $0,05 \%$. Os resultados revelaram que não houve diferença estatisticamente significante $(p>0,05)$ entre a retenção obtida para o grupo do sistema foto-polimerizável $(275,2 \pm 58,9 \mathrm{~N})$ e para o sistema dual $(301,4 \pm 40,1 \mathrm{~N})$. A análise em MEV mostrou que em todos os espécimes o descolamento do pino ocorreu na interface cimento-dentina, e os pinos extraídos apresentaram-se quase inteiramente cobertos por uma camada de cimento resinoso. Apesar disso, bolhas de grande extensão foram observadas na região apical em alguns pinos. Adicionalmente, ambos os grupos mostraram várias bolhas pequenas na camada de cimento dos terços médio e apical dos pinos. Alguns túbulos dentinários visíveis nas paredes de dentina apareceram obstruídos pelo material resinoso, enquanto outros se apresentaram abertos. Foi possível observar algumas fibras de vidro que provavelmente soltaram da superfície do pino e foram englobadas pelo cimento resinoso. Concluiu-se que o sistema dual pareceu ser o mais apropriado por permitir a polimerização em áreas que não seriam de outra forma atingidas pela luz. Por outro lado, na região apical, a polimerização incompleta do sistema fotopolimerizável melhorou a adaptação do pino e permitiu a obtenção de melhor selamento apical e uma distribuição mais uniforme do estresse ao longo das paredes do conduto radicular.

Perdigão; Geraldeli; Lee (2004) avaliaram o efeito dos sistemas de cimentação adesiva e da região radicular na resistência adesiva de pinos reforçados por fibra de vidro e pinos de zircônia. Trinta e dois dentes uni-radiculares foram tratados endodonticamente e randomizadamente divididos em oito grupos $(n=4)$. Dois sistemas de pinos (Cosmopost, um pino de zircônia; e FRC Postec, um pino 
reforçado por fibra de vidro) foram cimentados com diferentes sistemas de cimentação adesiva. Os pinos cimentados com One-Step e Post Cement Hi-X foram usados como o adesivo foto-polimerizável controle, ao passo que os pinos ParaPost Fiber White cimentados com ParaPost Adhesive e ParaPost Resin Cement foram usados como o adesivo auto-polimerizável controle. As raízes foram secionadas em regiões cervical, média e apical. O teste push-out foi realizado em cada seção para mensurar a resistência adesiva regional. As médias foram analisadas com ANOVA a dois critérios e teste de Duncan. Os pinos reforçados por fibra apresentaram a maior retenção independentemente do sistema de cimentação empregado. As médias para a região radicular média $(5,0 \pm 0,8 \mathrm{MPa})$ não foram significantemente diferentes daquelas obtidas para as regiões radiculares cervical e apical. As médias da região radicular cervical $(6,2 \pm 0,9 \mathrm{MPa})$ foram significantemente maiores do que aquelas encontradas para a região apical $(4,5 \pm 1,1 \mathrm{MPa})$.

Roberts et al. (2004) investigaram o efeito do pino transmissor de luz na profundidade de polimerização de resinas compostas. Moldes de resina acetálica foram preenchidos com resina composta e um pino transmissor de luz foi inserido no centro e foto-polimerizado de acordo com as recomendações do fabricante. O grupo controle foi constituído por moldes idênticos sem a presença dos pinos transmissores de luz, e a resina foi foto-polimerizada de modo similar. Os moldes foram seccionados usando disco diamantado sob irrigação abundante com água em distâncias determinadas, e a profundidade de polimerização foi determinada pelo índice superfície/base de dureza Knoop. Os resultados revelaram que a presença do pino aumentou $(p<0.001)$ os valores de dureza Knoop nas regiões apicais simuladas em comparação ao grupo controle. Contudo, não houve diferença na profundidade de polimerização entre os grupos e também quando avaliado usando o índice superfície/base. Os autores afirmaram que os pinos transmissores de luz podem apresentar utilidade limitada quando analisados de acordo com o critério de proporção de dureza Knoop.

Grandini et al. (2004) avaliaram através de MEV o procedimento de passo único para a cimentação de pinos reforçados por fibra de vidro. Quarenta raízes extraídas por razões periodontais foram selecionadas para o estudo. Os dentes foram randomizadamente divididos em quatro grupos $(n=10)$. Grupo 1: One Step, foto-polimerizado por $20 \mathrm{~s}+$ cimento resinoso dual foto-polimerizado por $20 \mathrm{~s}$; OneStep, não foto-polimerizado + cimento resinoso dual foto-polimerizado por $30 \mathrm{~s}$; 
Grupo 3: One Step, não foto-polimerizado + cimento resinoso dual foto-polimerizado por $60 \mathrm{~s}$; Grupo 4: One-Step, não foto-polimerizado + cimento resinoso dual fotopolimerizado por $90 \mathrm{~s}$. Os pinos reforçados por fibra translúcida (DT posts, RTD) foram cimentados nos condutos radiculares, e então, as raízes foram processadas para analisar a continuidade da zona de interdifusão resina-dentina, a presença ou ausência de fendas e a densidade e morfologia dos prolongamentos resinosos. Contudo, o exame microscópico das interfaces adesivas mostrou que a percentagem de zona de interdifusão resina-dentina foi significantemente maior no grupo 1 do que nos outros três grupos $(p<0,05)$. A formação dos prolongamentos resinosos foi evidente em todos os grupos. A forma de cone invertido característica dos prolongamentos resinosos foi observada nos terços cervical e médio de todos os grupos, e no terço apical do grupo 1. Nos grupos 2, 3 e 4, os prolongamentos resinosos no terço apical apresentaram-se mais curtos e menos uniformes. Os autores concluíram que quando o pino reforçado por fibra translúcida foi cimentado no interior do conduto radicular, o procedimento de cimentação envolvendo a fotopolimerização do sistema adesivo previamente à colocação do cimento foi mais satisfatório, sob o ponto de vista da análise em MEV, do que os procedimentos envolvendo a polimerização simultânea do adesivo e do cimento (procedimento em passo único).

Tay et al. (2005) apresentaram um modelo matemático teórico para comprovar as variáveis que influenciam a união adesiva de materiais de obturação endodôntica aos canais radiculares. Os autores mostraram que o fator- $\mathrm{C}$ apresenta uma correlação negativa com a espessura do cimento nos canais radiculares. Para o canal com diâmetro apical de tamanho 25 e comprimento de $20 \mathrm{~mm}$, o fator-C variou de 46 até 23,461 à medida que a espessura do cimento diminuiu (500-1 $\mu \mathrm{m})$, comparado com o fator- $\mathrm{C}$ de 32 quando o canal radicular foi preenchido somente com cimento. Foi demonstrado que à medida que a espessura do adesivo é reduzida, a contração volumétrica é reduzida, resultando na redução da tensão de contração (fator-S). O fator-C acima de 954 calculado em uma camada de cimento de espessura menor do que $25 \mu \mathrm{m}$ é compensado parcialmente pelo aumento na área de união e diminuição no volume de contração. Contudo, a interação desses dois fatores (fator-C e fator-S) relacionados geometricamente indicou que a adesão dos materiais adesivos aos canais radiculares é altamente desfavorável quando 
comparada com as restaurações intra-coronárias indiretas com espessura da camada de cimento resinoso semelhante.

Goracci et al. (2005b) mensuraram a adesão entre dois tipos de pinos translúcidos pré-fabricados (FRC Postec, Ivoclar-Vivadent, FRC; Light-Post, RTD, LP), e dois tipos de compósitos fluidos usados como materiais para núcleo (UnifilFlow, GC, UF; Tetric Flow, Ivoclar-Vivadent, TF), com e sem a aplicação do silano (Monobond-S, Ivoclar-Vivadent, S) na superfície do pino. A resistência adesiva na interface entre o pino e o núcleo foi mensurada com a técnica de micro-tração sem desgaste proximal. Trinta bastões foram obtidos por grupo a partir dos cilindros do material compósito, contruído ao redor do pino através do acréscimo de pequenos incrementos de resina composta. As diferenças na resistência adesiva entre os grupos foram testadas com ANOVA a dois critérios. Os resultados revelaram que a silanização do pino apresentou um efeito significante na adesão $(p<0,05)$. Os autores concluíram que a aplicação do silano à superfície do pino previamente à reconstrução coronária aumentou significantemente a resistência adesiva do pino ao núcleo de resina composta.

Goracci et al. (2005a) testaram a hipótese nula de que o uso dos adesivos dentinários não aumenta a retenção dos pinos reforçados por fibra cimentados adesivamente aos condutos radiculares. Trinta e seis dentes uni-radiculares receberam pinos reforçados por fibra cimentados aos condutos radiculares com o sistema adesivo auto-condicionante (ED Primer/Panavia 21) e o sistema adesivo convencional (Excite DSC/Variolink II), com ou sem o acompanhamento de adesivos dentinários. A resistência adesiva e a ultra-estrutura interfacial foram avaliadas usando o teste push-out e a análise em MEV. Os resultados revelaram que, para ambos os cimentos resinosos, a resistência adesiva obtida nos espécimes cimentados com cimento resinoso não diferiu significantemente daqueles em que a dentina intra-radicular foi tratada primeiramente com o adesivo dentinário. Concluiuse que, na presença das fendas interfaciais e da incompleta remoção da lama dentinária, a resistência ao deslocamento dos pinos reforçados por fibra foi assegurada pela resistência friccional.

Goracci et al. (2005c) avaliaram a resistência adesiva e a ultra-estrutura de cimentos resinosos auto-adesivos - Rely X Unicem (3M ESPE), auto-condicionantes - ED Primer/Panavia 21 (Kuraray Co), e convencionais - Excite DSC/Variolink II (Ivoclar-Vivadent) usados para cimentar pinos reforçados por fibra de vidro. Em cada 
grupo, sete raízes foram usadas para a realização dos testes push-out e duas foram processadas para observação em MET. A resistência adesiva alcançada pelo sistema de cimentação adesiva convencional Excite DSC/Variolink II $(10,18 \pm 2,89)$ foi significantemente maior do que no sistema auto-condicionante ED Primer/Panavia $21(5,04 \pm 2,81)$ e no cimento auto-adesivo Rely X Unicem (5,01 \pm 2,63), os quais foram semelhantes entre si. As micrografias da interface entre Variolink II e a dentina intra-radicular revelaram que a lama dentinária foi removida totalmente e uma camada híbrida espessa de 8-10 $\mu \mathrm{m}$ foi obtida. Nos outros grupos, a lama dentinária não foi dissolvida completamente e as obturações dos túbulos dentinários permaneceram. Fendas estiveram presentes entre o complexo hibridizado e a camada adesiva nos espécimes do Panavia 21, e entre a lama dentinária e a dentina radicular subjacente nos espécimes do Rely $X$ Unicem. A resistência adesiva e os achados microscópicos estiveram de acordo e indicaram que o potencial adesivo do cimento resinoso convencional foi maior. Os autores concluíram que os monômeros resinosos ácidos responsáveis pelo condicionamento do substrato dentinário nos cimentos resinosos Panavia 21 e Rely $X$ Unicem pareceram incapazes de remover efetivamente a camada espessa de lama dentinária criada na dentina durante o preparo do conduto radicular.

Pirani et al. (2005) testaram a hipótese de que a hibridização da dentina intraradicular elimina as fendas na interface adesiva, melhorando o selamento coronário e a retenção dos dentes restaurados com pinos reforçados por fibra. Os condutos radiculares receberam dois tipos de pinos reforçados por fibra cimentados com os sistemas de cimentação adesiva Single Bond/Rely X ARC e All Bond 2/Duolink com e sem foto-polimerização do sistema adesivo. A hibridização da dentina foi analisada em seções longitudinais das interfaces nos terços cervical e médio dos condutos radiculares. A formação de fendas na interface adesiva foi avaliada através de réplicas de resina dessas seções. Embora a hibridização da dentina intra-radicular não tenha sido comprometida, independentemente se os sistemas adesivos foram ou não foto-polimerizados antes da cimentação do pino, a presença freqüente das fendas interfaciais ao longo da camada híbrida ou na interface pino-cimento refletiu o desafio da cimentação adesiva intra-canal. Os autores concluíram que o sucesso clínico associado aos pinos reforçados por fibra é devido provavelmente à retenção friccional. 
Le Bell et al. (2005) avaliaram as propriedades de adesão de pinos préfabricados de resina reforçados por fibra de carbono com matriz polimérica cruzada e pinos confeccionados individualmente de resina reforçada por fibra de vidro com matriz polimérica semi-interpenetrada. Pinos de titânio serviram como controle. As coroas de terceiros molares extraídos foram removidas e o espaço do pino foi confeccionado e condicionado. Os pinos foram tratados com adesivo resinoso à base de dimetacrilato, fotopolimerizados e cimentados aos condutos radiculares com cimento resinoso dual. Após a termociclagem, as amostras foram seccionadas em discos com um, dois e quatro $\mathrm{mm}$ de espessura $(n=12)$. A análise do modo de falha foi realizada em um estereomicroscópio. Os resultados revelaram que a força de resistência ao deslocamento aumentou com o aumento da espessura do disco de dentina em todos os grupos (ANOVA, $p<0,01$ ). Nos discos de dentina com quatro $\mathrm{mm}$ de espessura, os pinos com matriz polimérica semi-interpenetrada apresentaram a maior força de resistência ao deslocamento e a diferença em relação ao pino de titânio foi significante. Contrário aos outros pinos, os pinos reforçados por fibra com matriz polimérica semi-interpenetrada não apresentaram nenhuma falha adesiva (pino-cimento), sugerindo melhor adesão interfacial do cimento a esses pinos.

Valandro et al. (2005) avaliaram a resistência adesiva à tração de pinos de resina reforçados por fibra de vidro cimentados com três sistemas adesivos diferentes e um cimento resinoso. A hipótese nula testada foi que a resistência adesiva produzida pelos sistemas adesivos seria semelhante. Trinta dentes bovinos foram divididos em três grupos, de acordo com o sistema adesivo: G1, Scotchbond Multi-Purpose; G2, Single Bond; G3, Tyrian SPE/One Step Plus. Os pinos reforçados por fibra de vidro foram condicionados com ácido fosfórico a $37 \%$ por um minuto, silanizados e cimentados com o cimento resinoso dual Enforce. Os espécimes foram armazenados por $24 \mathrm{~h}$, fixados em um aparelho e submetidos ao teste de tração em uma máquina de teste universal $(1 \mathrm{~mm} / \mathrm{min})$. Os dados foram submetidos à ANOVA e teste de Tukey $(\alpha=0,05)$. Os resultados revelaram que G1 $(30,2 \pm 5,8 \mathrm{Kgf})$ apresentou a maior resistência à tração $(p<0,001)$ quando comparado a G2 $(18,6 \pm$ $5,8 \mathrm{Kgf})$ e G3 $(14,3 \pm 5,9 \mathrm{Kgf})$, os quais mostraram-se estatisticamente similares. A análise dos espécimes revelou que todas as falhas ocorreram entre o sistema adesivo e a dentina radicular. Concluiu-se que o sistema adesivo convencional de três passos proveu a maior resistência à tração para os pinos reforçados por fibra 
quando comparados aos sistemas adesivos auto-condicionante de passo único e convencional de dois passos. A hipótese nula foi rejeitada $(p<0,001)$.

Pirani et al. (2005) testaram a hipótese de que a hibridização da dentina intraradicular elimina a fenda interfacial, e contribui para a melhoria do selamento coronário e da retenção de dentes restaurados com pinos reforçados por fibra. Os espécimes foram aleatoriamente divididos em quatro grupos $(n=10)$ baseados no tipo de cimento resinoso, adesivo e pino empregados, e se o adesivo dentinário correspondente foi ou não foto-polimerizado antes do posicionamento do pino de fibra. A hibridização da dentina foi analisada nos terços cervical, médio e apical de seções longitudinais das interfaces dos canais radiculares. A formação da fenda interfacial foi analisada em réplicas de resina dessas seções. Embora a hibridização da dentina intra-radicular não tenha sido comprometida, independente se os adesivos foram ou não fotopolimerizados antes da cimentação, a ocorrência universal de fendas interfaciais ao longo da camada híbrida ou da interface pinocimento refletiu o desafio da adesão aos condutos radiculares. Os autores sugeriram que o sucesso clínico associado ao uso de pinos reforçados por fibra deve-se predominantemente ao fenômeno da retenção friccional.

Mallmann et al. (2005) avaliaram a resistência adesiva de sistemas adesivos autopolimerizável e foto-polimerizável em diferentes áreas de dentina intra-radicular (terços cervical, médio e apical). Vinte dentes uni-radiculares foram instrumentados e preparados para receber um pino translúcido reforçado por fibra (Light-Post). Os condutos radiculares foram irrigados com hipoclorito de sódio $0,5 \%$ por um minuto, enxaguados com água e secos com pontas de papel absorvente. Os dentes foram divididos em dois grupos $(n=10)$ : Single Bond (foto-polimerizável) e Scotchbond Multi-Purpose Plus (autopolimerizável). O cimento resinoso Rely X ARC foi inserido no interior dos condutos radiculares usando brocas Lentullo. O pino foi então posicionado e a foto-polimerização do cimento resinoso foi realizada por $40 \mathrm{~s}$. Cada raiz foi secionada perpendicularmente em seções de $1 \mathrm{~mm}$ de espessura, resultando em aproximadamente quatro fatias por região radicular. As superfícies proximais de cada seção foram desgastadas usando broca diamantada até que o pino fosse tocado. A área aderida foi calculada, as seções foram posicionadas em um aparelho especial e submetidas ao teste de micro-tração à velocidade de $1 \mathrm{~mm} / \mathrm{min}$. Os dados foram analisados usando ANOVA e teste de Tukey. Os valores de resistência adesiva foram: Scotchbond Multi-Purpose Plus: cervical= 10,8, médio= 7,9, apical= 
7,1; Single Bond: cervical $=8,1$, médio $=6,0$, apical $=6,9$. Os autores concluíram que diferenças significantes foram encontradas entre os sistemas adesivos somente para o terço cervical. Adicionalmente, o terço cervical apresentou valores de resistência adesiva maiores do que os terços médio e apical $(p<0,0001)$.

Chersoni et al. (2005) realizaram um estudo in vivo para investigar a hipótese de que o movimento de fluidos através da camada dos adesivos simplificados ocorre nos condutos radiculares. Os condutos radiculares foram preparados em dentes uniradiculares tratados endodonticamente, e seis sistemas adesivos diferentes foram aplicados às paredes de dentina dos condutos radiculares. Moldagens foram obtidas com polivinilsiloxano, e réplicas foram fabricadas com o uso de material de moldagem à base de poliéter. Réplicas das hemi-seções foram examinadas em MEV. Os resultados revelaram que a transudação de fluidos foi evidente nas superfícies adesivas de todos os sistemas adesivos convencionais simplificados e auto-condicionantes. Diferentemente, a maioria dos espécimes cimentados com o sistema adesivo convencional de três passos não apresentou fluidos. Os autores concluíram que a permeabilidade dos adesivos simplificados resulta em movimento de água, até mesmo na dentina radicular dos dentes tratados endodonticamente. Isso pode afetar adversamente a união dos cimentos resinosos dual e autopolimerizável.

Monticelli et al. (2006a) investigaram a influência de diferentes adesivos dentinários e silanos na resistência adesiva da resina composta unida a pinos reforçados por fibra de quartzo condicionados com etóxido de sódio. O silano préhidrolizado foi aplicado sem o adesivo e comparado com sistemas de dois componentes nos quais a hidrólise do silano ocorreu após a mistura com o monômero ácido nos adesivos dentinários. A nanoinfiltração ao longo das interfaces pino/núcleo foi examinada após a penetração do nitrato de prata usando MEV. Os resultados revelaram maior resistência adesiva e adaptação mais uniforme entre a superfície condicionada do pino reforçado por fibra e o núcleo de resina composta após o tratamento do pino com os agentes de união adesivo/silano. A combinação do silano com os sistemas adesivos auto-condicionantes de dois passos melhorou a retenção química dos compósitos ao redor de pinos reforçados por fibra com nanoinfiltração mínima. Os autores concluíram que, embora a combinação do adesivo/silano tenha melhorado a adesão do pino, a nanoinfiltração excessiva leva à 
rápida sorção de água, a qual pode provocar degradação hidrolítica na interface pino/núcleo.

No mesmo ano, Monticelli et al. (2006b) avaliaram a influência de diferentes procedimentos de condicionamento da superfície do pino na resistência adesiva à micro-tração entre pinos reforçados por fibra e materiais para núcleo de resina composta. Sessenta pinos DT Light Post foram divididos em 10 subgrupos usando cinco tratamentos de superfície diferentes e dois materiais resinosos para a confecção do núcleo. Os tratamentos químicos da superfície do pino incluíram o condicionamento com permanganato de potássio, tratamento com peróxido de hidrogênio $10 \%$, tratamento com etóxido de sódio $21 \%$, condicionamento com permanganato de potássio e ácido clorídrico $10 \%$, e silanização (grupo controle). O núcleo foi confeccionado usando Core Past XP (Dent Mat) e Unifil Flow (GC). Duas amostras de cada grupo foram selecionadas randomizadamente para investigar 0 aspecto morfológico da interface pino/núcleo em MEV. Os espécimes remanescentes foram seccionados para a obtenção de bastões para a realização do teste de micro-tração à velocidade de $1 \mathrm{~mm} / \mathrm{min}$. A análise estatística foi realizada usando ANOVA a dois critérios e teste de Tukey $(\alpha=0,05)$. A análise em MEV mostrou uma rede de união interpenetrada entre a superfície do pino reforçado por fibra tratada e o material compósito em todos os grupos testados. Os resultados obtidos com o permanganato de potássio influenciaram significantemente os valores de resistência adesiva à micro-tração em ambos os materiais testados. $\mathrm{O}$ tratamento da superfície do pino melhorou a resistência adesiva particularmente da resina Core Paste XP. Os autores concluíram que os procedimentos de condicionamento apresentaram efeito semelhante na superfície do pino e melhoraram a adesão dos núcleos de resina composta como resultado da retenção química e micro-mecânica.

Akgungor; Akkayan (2006) investigaram o efeito de diferentes sistemas adesivos e modo de polimerização na resistência adesiva de pinos de fibra translúcidos em diferentes regiões do conduto radicular. Quarenta caninos superiores foram secionados na junção cemento-esmalte, e as raízes foram tratadas endodonticamente. Após o preparo do conduto radicular, as raízes foram divididas em quatro grupos de 10 espécimes cada, e os condutos radiculares foram tratados com um dos quatro sistemas adesivos diferentes: sistema adesivo foto-polimerizável de frasco único Excite; sistema adesivo dual de frasco único Excite DSC; ou primer auto-condicionante Clearfil Liner Bond 2V com sistema adesivo foto-polimerizável, 
Bond $\mathrm{A}$; ou primer auto-condicionante Clearfil Liner Bond 2V com sistema adesivo dual, Bond A + B. Pinos translúcidos reforçados por fibra (DT Light Post), 2,2 mm de diâmetro, foram cimentados com Panavia $\mathrm{F}$ após os procedimentos adesivos. As raízes foram segmentadas em seções de $3 \mathrm{~mm}$ de espessura, perpendicular ao longo eixo, nas regiões cervical, média e apical do conduto radicular. O teste pushout foi realizado em uma máquina de ensaio universal à velocidade de $0,5 \mathrm{~mm} / \mathrm{min}$. Os dados foram analisados utilizando ANOVA a um e dois critérios, e teste de Tukey $(\alpha=0,05 \%)$. Os mecanismos de adesão à dentina nas diferentes regiões dos condutos radiculares foram avaliados em MEV. Os resultados revelaram que os maiores valores de resistência adesiva foram obtidos para o primer autocondicionante Clearfil Liner Bond $2 \mathrm{~V}$ combinado com o sistema adesivo fotopolimerizado. O sistema adesivo de polimerização dual resultou em significantemente menor resistência adesiva em combinação com o primer autocondicionante Clearfil Liner Bond 2V. Os sistemas adesivos de frasco único fotopolimerizável e dual apresentaram resistência adesiva semelhantes. Os valores de resistência adesiva regional dos sistemas adesivos de frasco único foram reduzidos significantemente na região apical. Os primers auto-condicionantes não demonstraram diferenças regionais na dentina radicular. Os autores concluíram que o sistema auto-condicionante usado neste estudo não foi afetado pelas variações morfológicas na dentina radicular em comparação aos sistemas adesivos de frasco único. A polimerização dual não aumentou os valores de resistência adesiva dos sistemas adesivos testados.

Mallmann et al. (2007) avaliaram a resistência adesiva à dentina radicular de dois sistemas adesivos e dois pinos reforçados por fibra. Quarenta dentes uniradiculares foram instrumentados, e os condutos radiculares foram preparados para receber pinos de resina composta reforçados por fibra de quartzo opacos (Aesthetic Post) ou translúcidos (Light Post). Dois sistemas adesivos foram usados: Scotchbond Multi-Purpose Plus (autopolimerizável) e Single Bond (foto-ativado). Os dentes foram divididos em quatro grupos $(n=10)$ : Scotchbond Multi-Purpose Plus + Light Post, Scotchbond Multi-Purpose Plus + Aesthetic Post, Single Bond + Light Post e Single Bond + Aesthetic Post. Após a cimentação, as raízes foram perpendicularmente secionadas em fatias de $1 \mathrm{~mm}$ de espessura, e desgastadas nas superfícies proximais. Os espécimes foram então divididos em três regiões: cervical, média e apical. Para determinar a resistência adesiva, a área de adesão de 
cada espécime foi calculada, e os espécimes foram posicionados em um aparelho para testar a resistência à micro-tração à velocidade de $1 \mathrm{~mm} / \mathrm{min}$. Os dados foram analisados usando ANOVA a três critérios e teste de Tukey $(\alpha=0,05)$. Os espécimes fraturados foram examinados em estereomicroscópio para determinar o modo de fratura. Os resultados revelaram que houve diferença significante somente entre as regiões radiculares $(p<0,001)$. O terço cervical $(9,16 \pm 1,18 \mathrm{MPa})$ apresentou os maiores valores de resistência adesiva, especialmente para Scotchbond MultiPurpose Plus. As regiões média e apical apresentaram valores inferiores $(7,08 \pm$ 0,92 e 7,31 $\pm 0,60 \mathrm{MPa}$, respectivamente). Os fatores principais pino e adesivo não apresentaram significância e interação estatística. Não foram encontradas fraturas coesivas no interior do cimento, no pino ou na dentina radicular. Os autores concluíram que ambos os sistemas adesivos testados apresentaram adesão confiável quando usados com os pinos de resina reforçados por fibra opacos e translúcidos.

Boff et al. (2007) avaliaram o efeito do modo de ativação do cimento resinoso empregado na cimentação adesiva de pinos de resina reforçados por fibra na resistência adesiva ao deslocamento determinada pelo teste push-out. Quarenta pré-molares inferiores foram tratados endodonticamente e divididos aleatoriamente em quatro grupos. Nos grupos G1, G2 e G3, o sistema adesivo convencional de dois passos Single Bond (3M ESPE) foi aplicado e foto-polimerizado por 20 segundos; em G4, o sistema adesivo convencional de três passos Scotchbond Multi-Purpose Plus (3M ESPE) foi usado como um adesivo autopolimerizável. O cimento resinoso dual Rely X ARC (3M ESPE) foi foto-polimerizado em G2 e G3, mas não em G1 e G4. O pino translúcido Light-Post (Bisco) foi usado em G3, e o pino opaco AestheticPlus (Bisco) foi usado nos outros grupos. As raízes foram seccionadas em três partes (cervical, média e apical); cada seção foi submetida ao teste push-out à velocidade de $0,5 \mathrm{~mm} / \mathrm{min}$. Os dados foram analisados pela ANOVA e teste de Tukey $(\alpha=0,05)$. A foto-polimerização de ambos o adesivo e o cimento resinoso em G2 aumentou significantemente a resistência adesiva em relação a G1, onde apenas o adesivo foi foto-polimerizado. Não foi encontrada diferença entre G2 (pino opaco) e G3 (pino translúcido). O adesivo autopolimerizável apresentou a maior resistência adesiva em todas as regiões radiculares. As regiões média e apical apresentaram resistência adesiva semelhantes, embora significantemente menores do que a região cervical $(p<0,001)$. Os autores concluíram que a resistência adesiva à dentina 
radicular variou em função do modo de ativação do sistema de cimentação adesivo e regiões radiculares.

Faria e Silva et al. (2007) avaliaram o grau de conversão de um cimento resinoso dual usado na cimentação de pinos reforçados por fibra com diferentes translucências. Para mensurar o grau de conversão, moldes de polivinilsiloxano foram preparados para simular condutos radiculares. Os pinos, Aesthetic-Post ou Light-Post, foram cimentados nesses moldes e, após a foto-ativação, foram removidos para obter o espectro do cimento resinoso por meio de espectroscopia. $O$ espectro foi obtido em três profundidades: superficial, média e profunda. Para o pino Light-Post, o cimento resinoso localizado mais profundamente apresentou o menor grau de conversão, e não foi encontrada diferença significante no grau de conversão entre as outras profundidades. Para o pino Aesthetic-Post, a profundidade superficial apresentou grau de conversão maior do que as profundidades média e profunda, as quais não foram significantemente diferentes entre si. Light-Post apresentou grau de conversão maior do que Aesthetic-Post somente na profundidade média. Concluiuse que o grau de conversão foi dependente da profundidade para os pinos LightPost.

Radovic et al. (2007) avaliaram a influência de diferentes pré-tratamentos e tratamentos de superfície na resistência adesiva à micro-tração de resinas compostas unidas a pinos reforçados por fibra. Trinta e dois pinos reforçados por fibra foram divididos em dois grupos de acordo com o pré-tratamento de superfície realizado: jateamento (Rocatec-Pre, 3M ESPE) ou nenhum pré-tratamento. Em cada um dos dois grupos, os pinos receberam três tipos de tratamentos adicionais: (1) aplicação do silano (Monobond S, Ivoclar Vivadent); (2) aplicação do adesivo (Unifil Core self-etching Bond, GC); (3) nenhum tratamento. Uma resina composta dual (Unifil Core, GC) foi aplicada nos pinos para produzir os espécimes cilíndricos. Os espécimes foram secionados para a obtenção dos bastões usados no teste de micro-tração à velocidade de $0,5 \mathrm{~mm} / \mathrm{min}$. A morfologia da interface pino/resina e da superfície do pino foi avaliada em MEV. A análise estatística foi realizada com ANOVA a dois critérios e teste de Tukey $(p=0,05)$. Os resultados revelaram que $o$ pré-tratamento da superfície do pino não foi um fator significante na resistência adesiva da união pino-resina $(p=0,08)$, ao passo que as demais modalidades de tratamentos e a interação entre o pré-tratamento e o tratamento apresentaram influência significante na resistência adesiva $(p<0,001)$. Quando nenhum tratamento 
foi realizado, a resistência adesiva foi significantemente maior nos pinos jateados. A aplicação adicional do adesivo resultou em uma resistência adesiva significantemente menor nos pinos jateados. Quando nenhum pré-tratamento foi realizado, a aplicação do silano resultou em maior resistência adesiva do que a aplicação do adesivo. Concluiu-se que o jateamento pode gerar um aumento na resistência adesiva à micro-tração dos pinos reforçados por fibra, eliminando a necessidade de tratamentos adicionais.

Faria e Silva et al. (2007) avaliaram o grau de conversão do cimento resinoso dual empregado na cimentação adesiva de pinos reforçados por fibra apresentando translucências diferentes. Moldes de polivinil siloxano foram obtidos para simular os condutos radiculares e permitir a mensuração do grau de conversão. Os pinos, Aestheti-Post ou Ligh-Post, foram cimentados nesses moldes e, após a fotoativação, removidos para a mensuração do espectro do cimento resinoso por espectroscopia FT-Raman. O espectro foi mensurado em três profundidades: superficial, média e profunda. Para Light-Post, o cimento resinoso mostrou o menor grau de conversão em grandes profundidades, e não foi encontrada diferença significante no grau de conversão entre as outras profundidades. Para Aestheti-Post, a profundidade superficial apresentou os valores de grau de conversão superiores àqueles encontrados nas profundidades média e profunda, os quais não foram significantemente diferentes entre si. Light-Post apresentou grau de conversão superior a Aestheti-Post apenas na profundidade média. A conclusão do trabalho foi que a eficácia do Light-Post considerando o grau de conversão é dependente da profundidade.

Bonfante et al. (2008) realizaram um estudo para testar a hipótese nula de que a continuidade da interface cimento-dentina de pinos reforçados por fibra cimentados aos canais radiculares não é afetada pela localização ao longo do canal radicular ou armazenamento em água por três meses. Quarenta incisivos bovinos foram secionados perpendicularmente ao longo eixo do dente para padronizar o comprimento radicular em $15 \mathrm{~mm}$. Os canais radiculares foram endodonticamente tratados, e os condutos preparados a $10 \mathrm{~mm}$ usando uma broca de 1,5 $\mathrm{mm}$ de diâmetro. Os pinos de resina reforçados por fibra de vidro (Fibrekor, Jeneric Pentron Incorporated, Wallingford, CT, USA) foram cimentados aos condutos radiculares utilizando quatro sistemas de cimentação adesiva: Multilink, Variolink II (Ivoclar, Vivadent, Liechtenstein), Enforce Dual e Enforce PV (Dentsply, Rio de Janeiro, 
Brasil). Após a cimentação, as raízes foram secionadas longitudinalmente, para expor a interface entre o pino e o cimento e entre o cimento e a dentina, e as superfícies observáveis foram polidas e limpas ultrassonicamente com água deionizada. Moldes das superfícies foram obtidos utilizando polivinil siloxano, e as superfícies duplicadas utilizando resina epóxica, permitindo a análise das réplicas por meio de MEV (início). As metades originais foram então imersas em solvente, duplicadas e avaliadas (condição experimental 2). Após três meses de armazenamento em água e uma segunda imersão em solvente, novas réplicas foram confeccionadas e analisadas (condição experimental 3). A proporção (\%) entre o comprimento $(\mathrm{mm})$ da interface adesiva disponível e a extensão real de interface cimento-dentina aderida foi calculada. Os resultados mostraram valores percentuais significantemente baixos de interface aderida para Multilink $(8,25 \%)$ e Variolink II (10,08\%) quando comparados com Enforce Dual (25,11\%) e Enforce PV $(27,0 \%)$ na análise inicial. A mesma tendência foi observada após a imersão no solvente sem mudanças significantes. Entretanto, após três meses de armazenamento em água e uma segunda imersão em solvente, a integridade adesiva foi significantemente reduzida a valores abaixo de $5 \%$ (Multilink $=3,31 \%$, Variolink $=1,87 \%$, Enforce Dual $=1,20 \%$, e Enforce PV $=0,75 \%)$. A maioria das fendas localizou-se nos terços médio e apical, inicialmente e após a imersão em solvente. Após três meses, os gaps foram detectados inclusive no terço cervical. Devido à baixa integridade adesiva apresentada pela interface cimento-dentina, e ao elevado custo dos sistemas de cimentação adesiva, foi concluído que o uso desses materiais para a cimentação adesiva de pinos intra-radiculares é questionável.

A resistência adesiva e a capacidade de selamento de cinco cimentos resinosos empregados rotineiramente para a cimentação de pinos reforçados por fibra foram avaliadas por Zicari et al. Cinquenta dentes uni-radiculares extraídos foram randomizadamente divididos em cinco grupos e restaurados utilizando Parapost Fiber Lux e os seguintes cimentos: Panavia 21 (PAN), Clearfil Esthetic Cement (CLF), Variolink II (VAR), RelyX Unicem (UNI) e o cimento auto-adesivo experimental GC (EGC). Após uma semana de armazenamento em água a $37^{\circ} \mathrm{C}$, três seções (cervical, média e apical) de $2 \mathrm{~mm}$ de espessura foram preparadas para cada espécime. A capacidade de selamento foi quantificada pelo sistema de filtração de fluidos (Flodec) durante $10 \mathrm{~min}$, e em seguida a resistência adesiva push-out foi imediatamente mensurada. Foi revelado que a resistência adesiva e a capacidade 
de selamento não foram significantemente diferentes entre as seções cervical, média e apical para cada cimento. A maior resistência adesiva foi mensurada para CLF $(14,60+/-3,63 \mathrm{MPa})$, a qual não foi significantemente diferente de PAN (12,57+/-2,45 MPa), mas foi significantemente maior do que $\operatorname{VAR}(11,09+/-4,09 \mathrm{MPa})$, UNI $(11,29+/-4,31 \mathrm{MPa})$ e EGC (7,65+/-4,79 MPa). Considerando a capacidade de selamento, não foram encontradas diferenças significantes entre PAN, CLF e VAR, e entre UNI and EGC. A resistência adesiva correlacionou com a capacidade de selamento $(p<0.001)$. Os autores concluíram que os cimentos auto-condicionantes apresentaram a maior resistência adesiva. Apesar da eficácia promissora dos cimentos auto-adesivos, a sua interação com a dentina radicular pode ser mais fraca para minimizar a infiltração na interface pino-cimento-dentina. 


\subsection{A espessura da camada de cimento influencia a retenção do pino intra- radicular?}

Para avaliar o efeito da espessura do cimento resinoso na retenção de pinos intra-radiculares serrilhados, Assif; Bleicher (1986) dividiram 125 dentes anteriores em cinco grupos $(n=25)$. Os grupos foram divididos em função do diâmetro do pino e do conduto radicular: Grupo 1 (Pino com $1 \mathrm{~mm}$ de diâmetro e conduto radicular com 1,25 mm de diâmetro); Grupo 2 (Pino com $1 \mathrm{~mm}$ de diâmetro e conduto radicular com 1,5 mm de diâmetro); Grupo 3 (Pino com 1,25 mm de diâmetro e conduto radicular com 1,5 mm de diâmetro); Grupo 4 (Pino com 1,25 mm de diâmetro e conduto radicular com 1,75 mm de diâmetro); Grupo 5 (Pino com 1,5 mm de diâmetro e conduto radicular com 1,75 mm de diâmetro). Nos grupos 1, 3 e 5, o diâmetro do conduto radicular foi $0,25 \mathrm{~mm}$ maior do que o diâmetro do pino, enquanto nos grupos 2 e 4 , o diâmetro do conduto foi $0,5 \mathrm{~mm}$ maior do que o diâmetro do pino. Os condutos foram preparados a $7 \mathrm{~mm}$ de profundidade usando a broca do sistema de pinos Para-Post, enxagüados com água destilada, e secos com jatos de ar e pontas de papel absorvente. A resina composta foi misturada, diluída e injetada no interior do conduto radicular usando uma seringa adequada. Os pinos foram cobertos com a resina composta, introduzidos no interior do conduto radicular e mantidos sob pressão digital até a polimerização do cimento. As raízes foram fixadas em caixas de resina acrílica paralelas ao longo eixo para permitir o carregamento ao longo do longo eixo do dente. Os dentes foram armazenados em solução salina fisiológica até o momento do teste. Os espécimes foram submetidos ao teste de tração na máquina Instron Universal Testing à velocidade de $50 \mathrm{~mm} / \mathrm{min}$. Os autores não encontraram diferença significante entre os grupos. As seguintes conclusões foram obtidas: 1) Quando a resina composta Prosthodent foi usada para a cimentação dos pinos intra-radiculares Para-Post, a adaptação do pino ao conduto radicular não foi crucial. A variação na espessura da camada de resina composta em até $500 \mu \mathrm{m}$ não diminuiu a retenção do pino; 2) A variação no diâmetro dos pinos não afetou a retenção; 3) A retenção obtida para as combinações de pinos e cimentos foi alta e adequada para resistir ao deslocamento do pino; 4) Quanto mais fino for o pino dentro do conduto radicular, a cimentação com material compósito é recomendada. 
Um estudo laboratorial foi realizado em 1993 por Chan; Harcourt; Brockhurst (1993) para comparar a retenção de pinos pré-fabricados cimentados a condutos radiculares adaptados ou mal adaptados utilizando diferentes agentes cimentantes (cimento de fosfato de zinco, cimento de policarboxilato de zinco, cimento de ionômero de vidro e cimento resinoso). Oitenta e três incisivos centrais superiores, e primeiro e segundo pré-molares inferiores humanos foram tratados endodonticamente e preparados para a cimentação dos pinos intra-radiculares de aço inoxidável (Whaledent Para-Post Plus: 1,25 mm de diâmetro). As raízes foram incluídas com resina epóxica em cilindros utilizando silicone de moldagem (Silastic RTV). Os condutos radiculares foram preparados a nove $\mathrm{mm}$ de profundidade usando as brocas do sistema de pinos Whaledent Para-Post com dois diâmetros diferentes: Broca P-42-5 (1,25 mm de diâmetro) e Broca P-42-7 (1,75 mm de diâmetro). Os espécimes preparados foram randomizadamente distribuídos em um dos oito grupos experimentais de acordo com o preparo do conduto radicular e com o agente cimentante usado para cimentar o pino intra-radicular. A resistência adesiva à tração vertical $(\mathrm{N})$ foi registrada no momento do deslocamento do pino. Os resultados da ANOVA a um critério demonstraram uma diferença altamente significante na retenção entre os oito grupos $(p<0,001)$. A comparação individual entre os grupos mostrou que os valores de retenção obtidos para todos os cimentos nos condutos de tamanho similar foram estatisticamente diferentes. Os valores de retenção obtidos para cada cimento individual nos diferentes condutos também foram estatisticamente diferentes. Os pinos cimentados aos condutos radiculares mal adaptados apresentaram resistência ao deslocamento significantemente maior do que os pinos cimentados aos condutos radiculares bem adaptados, independentemente do tipo de cimento usado. Nos condutos radiculares bem adaptados, o cimento resinoso apresentou aproximadamente o dobro da retenção dos outros três cimentos. Não foi encontrada diferença na retenção obtida pelo cimento de fosfato de zinco, policarboxilato de zinco e ionômero de vidro. Nos condutos radiculares mal adaptados, o cimento resinoso novamente apresentou a maior retenção, sendo seguido pelo cimento de fosfato de zinco, ionômero de vidro e policarboxilato. Foi concluído que a cimentação do pino em condutos radiculares bem adaptados não aumentou a retenção à tração vertical do pino para todos os cimentos avaliados. 
Hagge; Wong; Lindemuth (2002) investigaram o efeito da espessura do cimento na retenção de pinos endodônticos pré-fabricados. Sessenta e quatro dentes unirradiculares foram instrumentados endodonticamente, obturados com guta percha e cimento endodôntico à base de eugenol e divididos em quatro grupos $(n=16)$. Os condutos radiculares foram preparados a $10 \mathrm{~mm}$ de profundidade usando as brocas do sistema de pinos Parapost com quatro diâmetros diferentes: Broca Parapost tamanho 5 (Grupo 1; Coltene/Whaledent, Mahway, NJ); Broca Parapost tamanho 5,5 (Grupo 2; Coltene/Whaledent); Broca Gates Glidden tamanho 6 (Grupo 3; Dentsply/Maillefer); Broca Parapost tamanho 6 (Grupo 4; Coltene/Whaledent). Pinos do sistema de pinos Parapost (tamanho 5) foram então cimentados com cimento resinoso (Panavia 21 OP, J Morita, Irvine, CA). Após $48 \mathrm{~h}$ de armazenamento, os espécimes foram montados em canos de PVC com resina acrílica, e os pinos foram removidos por tração usando uma máquina de ensaio universal a $1 \mathrm{~mm} / \mathrm{min}$. Os valores médios (AKGUNGOR e AKKAYAN) de retenção encontrados foram: Grupo $1=15,07 \pm 6,11$; Grupo $2=25,60 \pm 7,39$; Grupo $3=$ $43,15 \pm 7,81$; Grupo $4=37,75 \pm 6,35$ ). A análise de variância e os testes Bonferroni revelaram que os valores de retenção do Grupo 3 foram significantemente maiores do que o Grupo 1 e o Grupo $2(p<0,05)$, e que o Grupo 4 apresentou valores de retenção significantemente maiores do que o Grupo $1(p<0,05)$. Concluiu-se que os pinos Parapost cimentados com Panavia 21 OP foram significantemente mais retentivos nos condutos radiculares amplamente alargados comparados com os condutos radiculares preparados com a broca calibrada de tamanho similar ao do pino.

O estudo realizado por Chen et al. (2003) objetivou analisar a influência do diâmetro dos condutos radiculares e da presença de um sulco retentivo na retenção de pinos metálicos pré-fabricados. Vinte e quatro dentes uni-radiculares, foram descoronados, tratados endodonticamente e incluídos em blocos de resina. Os condutos radiculares foram preparados com uma broca Peeso $\mathrm{n}^{\circ} 2$ a $8 \mathrm{~mm}$ de profundidade, e metade dos espécimes foram sucessivamente tratados com a broca Peeso $\mathrm{n}^{\circ} 3$ a $8 \mathrm{~mm}$ de profundidade para os grupos de canais estreitos e de canais largos, respectivamente. O pino pré-fabricado Keeper (Aichi Steel Co.) foi cimentado ao conduto radicular com cimento resinoso. O conjunto foi termociclado 2000 vezes $\left(4-60{ }^{\circ} \mathrm{C}\right)$, e a retenção do pino foi mensurada. Posteriormente, o pino removido e apresentando estrutura intacta foi jateado, e um sulco foi confeccionado com uma 
broca cone invertido no interior do conduto radicular. Seis pinos tratados foram recimentados em ambos os grupos de canais estreitos e canais largos, e a resistência à retenção foi mensurada. Os pinos cimentados nos condutos estreitos $(84,26 \pm 31,85 \mathrm{~N})$ apresentaram retenção superior $(p<0,05)$ aos pinos cimentados nos condutos largos $(41,92 \pm 22.36 \mathrm{~N})$. A retenção dos pinos recimentados aumentou em ambos os grupos de condutos estreitos $(104,29 \pm 11,89 \mathrm{~N})$ e condutos largos $(96,65 \pm 6,91)$ que receberam o sulco retentivo. Foi concluído que os pinos pré-fabricados apresentaram menor retenção nas raízes apresentando condutos radiculares amplos. A confecção do sulco retentivo ao longo da circunferência do conduto radicular aumentou significantemente a retenção dos pinos cônicos curtos.

Grandini et al. (2005a) analisaram a espessura da camada de cimento e a uniformidade de pinos de fibra de vidro convencionais e pinos anatômicos. Vinte raízes de dentes ântero-superiores foram tratadas endodonticamente e preparadas para a inserção do pino de fibra. A dentina radicular foi condicionada com o sistema adesivo One-Step, o cimento resinoso de polimerização dual (Duolink) foi usado para cimentar os pinos de fibra convencionais em metade dos espécimes (grupo 1) e os pinos anatômicos na outra metade dos espécimes (grupo 2). Para esses pinos, uma camada de resina fotopolimerizável foi adicionada para permitir o reembasamento do pino previamente à cimentação, objetivando melhorar a adaptação no interior do conduto radicular. As raízes foram secionadas paralelas ao longo eixo do dente e preparadas para observação em MEV. A espessura do cimento foi mensurada a 1-mm, 4,5-mm, e 8-mm em cada raiz, e a presença de fendas ou bolhas no interior do cimento resinoso ou na interface adesiva foi avaliada. As diferenças na espessura da camada de cimento ao redor dos dois tipos de pinos em cada um dos três níveis dos condutos radiculares foram testadas através do teste $t(p=0,05)$. Adicionalmente, dentro de cada grupo, as diferenças entre as espessuras da camada de cimento mensuradas nas três regiões examinadas no conduto radicular foram avaliadas estatisticamente através de ANOVA a um critério $(p=0,05)$. Os resultados revelaram que, para os pinos anatômicos experimentais, a camada de cimento foi significantemente mais fina e mais uniforme nas regiões radiculares cervical e média. Em ambos os grupos, fendas e bolhas foram detectadas no interior do cimento resinoso e do material do núcleo coronário, e entre o pino de fibra e o cimento. Fendas também foram visíveis entre o pino e o material de reembasamento. Concluiu-se que a espessura do 
cimento resinoso foi significantemente menor no grupo do pino anatômico do que no grupo controle (pinos padronizados), à exceção da região apical do conduto radicular, onde não houve diferença estatisticamente significante. Uma boa adaptação do pino anatômico foi evidente em todos os espécimes.

Perez et al. (2006) realizaram um estudo com o objetivo de avaliar a influência da espessura do cimento na resistência adesiva de um pino de fibra em relação à dentina radicular. Dezoito dentes humanos uni-radiculares foram secionados a nível cervical sob irrigação a água para padronizar o comprimento radicular em $16 \mathrm{~mm}$. Os canais radiculares foram tratados endodonticamente, e preparados utilizando uma broca calibrada para receber o sistema de pinos compósitos reforçados por fibras de quartzo (Light Post, Bisco) de formato cilíndrico e paredes paralelas em dois estágios. Previamente à cimentação, a superfície do pino foi condicionada com ácido fosfórico $37 \%$ por um min, enxagüada, seca e silanizada com um agente de união silano (Espe-Sil, 3M Espe). Os espécimes foram aleatoriamente distribuídos em dois grupos ( $n=9$ ): grupo 1 (espessura do cimento pequena), no qual pinos reforçados por fibra de tamanho $\mathrm{n}^{\circ} 3$ foram cimentados utilizando o sistema adesivo convencional de três passos (All Bond 2, Bisco, Schaumburg, USA) e o cimento resinoso de polimerização dual (Duolink, Bisco); e grupo 2 (espessura do cimento grande), no qual pinos reforçados por fibra de tamanho $n^{\circ} 1$ foram cimentados como no grupo 1. Os espécimes foram seccionados, produzindo cinco amostras de 1,5 $\mathrm{mm}$ de espessura. Para a avaliação da espessura do cimento, fotografias das amostras foram obtidas utilizando um microscópio óptico (Leica Mo DNRXP, x100 a $\mathrm{x} 200$ ), e as imagens foram analisadas em um computador. A espessura do cimento foi analisada utilizando o programa Image Tool 3.0 (Dental Diagnostics Science). A espessura do cimento média $(\mu \mathrm{m})$ de cada amostra foi obtida a partir de quatro medições realizadas em quatro regiões opostas das amostras. Após a medição da espessura do cimento, cada amostra foi submetida ao teste push-out em uma máquina de ensaio universal (Emic DL - 1000), e posteriormente analisada no microscópio óptico (x80) para classificar os tipos de falha da seguinte maneira: tipo I: falha adesiva entre a dentina radicular e o cimento; tipo II: falha adesiva entre $\mathrm{O}$ cimento e o pino; e tipo III: falha coesiva no cimento. O resultados revelaram que os valores de resistência adesiva (MPa) obtidos para os grupos 1 e 2 não mostraram diferenças significantes $(p=0,0558)$; embora as espessuras do cimento para ambos os grupos tenham sido significantemente diferentes $(p<0,01)$. $O$ aumento da 
espessura do cimento não diminuiu a resistência adesiva significantemente $\left(r^{2}=0,1389, p=0,0936\right)$. Predominantemente, o modo de falha do tipo II foi observado em ambos os grupos. Os autores concluíram que o aumento da espessura do cimento ao redor do pino de fibra não prejudicou a resistência adesiva.

D`Arcangelo et al. (2007) avaliaram a relação entre a espessura do cimento resinoso e a resistência adesiva entre pinos reforçados por fibra e a dentina radicular. Oitenta incisivos superiores humanos com comprimentos radiculares semelhantes foram selecionados, seccionados ao nível da junção cemento-esmalte, e tratados endodonticamente. As raízes foram divididas em quatro grupos $(n=20)$, e os condutos foram preparados a uma profundidade de $8 \mathrm{~mm}$ utilizando uma das brocas de diâmetros diferentes: broca Torpan ISO 90 para o grupo controle (D90); e brocas Torpan ISSO 100 (D100), broca Torpan ISSO 120 (D120), ou broca Enapost ISSO 140 (D140) para os três grupos experimentais. Pinos reforçados por fibra de quartzo (Endo Lightpost) com 0,9 mm de diâmetro apical foram cimentados (Panavia 21) em cada espécime após os procedimentos de adesão.Os espécimes foram então submetidos ao teste pull-out utilizando uma máquina de teste universal à velocidade de $1,0 \mathrm{~mm} / \mathrm{min}$, e a força máxima requerida para deslocar o pino foi registrada $(\mathrm{N})$. Os valores médios de resistência adesiva para os grupos experimentais, D100 $(181,7(55,3))$ e D120 $(210,7(55,0))$ foram maiores $(p=0,036$ e $<0,001$, respectivamente) do que aqueles obtidos para o grupo controle D90 (138,5 $(49,2))$. O menor valor foi registrado para o grupo D140 $(91,1(36,0))$. Todos os grupos experimentais mostraram resultados significantemente diferentes, quando comparados com o grupo controle. Uma comparação múltipla entre os grupos experimentais mostrou diferenças significantes $(p<0,001)$. A comparação entre D100 e D120 não foi significante. Os dados sugeriram que a espessura da camada de cimento influenciou a resistência à tração (pull-out) dos pinos reforçados por fibra. Para o pino selecionado, os maiores valores de resistência adesiva não foram obtidos quando a camada de cimento mais fina foi testada (D90), e sim quando os condutos alargados foram usados (D100 e D120). Contudo, quando a espessura da camada do cimento foi muito grande (D140), a resistência ao deslocamento dos pinos reforçados por fibra foi significantemente diminuída.

Baseados na teoria de que o cimento deve apresentar uma espessura mínima durante um período de tempo suficiente para permitir a adaptação das restaurações indiretas, Kious et al. (2009) compararam a espessura da camada de seis cimentos 
resinosos, sendo dois cimentos de ionômero modificado por resina (FujiCEM e RelyX Luting Plus), dois cimentos resinosos (Panavia 21 e Rely X ARC) e dois cimentos resinosos auto-adesivos (Maxcem e RelyX Unicem) durante três minutos. Para isso, os autores determinaram a espessura $(\mu \mathrm{m})$ de cada cimento $(n=7)$ à temperatura ambiente durante um, dois e três minutos após o início da mistura, de acordo com o método de teste de polimerização descrito em ISO Standard 9917. Os resultados demonstraram que, à exceção de um cimento modificado por resina aos três minutos, todos os materiais produziram espessuras da camada de cimento abaixo de $30 \mu \mathrm{m}$ aos três minutos e abaixo de $26 \mu \mathrm{m}$ aos dois minutos. Concluiu-se que todos os materiais testados estiveram de acordo com o padrão ISO de espessura da camada de cimento de $25 \mu \mathrm{m}$ até os dois minutos após a mistura.

O estudo de Al-Tayyan et al. (2008) teve dois objetivos: (1) comparar a retenção entre um sistema de pinos formado por feixes de fibras flexíveis de inserção direta e um sistema de pinos de resina reforçados por fibras pré-fabricadas rígidas. Para isso, dentes uni-radidulares $(n=36)$ foram descoronados, limpos, tratados endodonticamente e preparados para a cimentação dos pinos rígidos $\mathrm{e}$ flexíveis à profundidade de $10 \mathrm{~mm}$ usando uma broca de tamanho 2 . As raízes foram divididas aleatoriamente em três grupos: la, Ib e II $(n=12)$. Pinos de fibras flexíveis foram inseridos nos grupos la e lb. Esses estavam disponíveis em três diâmetros de fibras: pequeno $(0,9 \mathrm{~mm})$, médio $(1,2 \mathrm{~mm})$ e grande $(1,5 \mathrm{~mm})$. Esses grupos de fibras foram cimentados no interior dos condutos radiculares com Variolink II. A diferença entre la e lb relacionou-se à proporção do volume dos feixes de fibras com o volume do cimento. As raízes no grupo II foram restauradas com pinos reforçados por fibras pré-fabricadas rígidas no. 2 e cimentados com o cimento resinoso fotopolimerizável provido pelo fabricante. Após $24 \mathrm{~h}$ de armazenamento, as forças axiais foram aplicadas aos pinos progressivamente até a falha à $0,5 \mathrm{~mm} / \mathrm{min}$. Os resultados mostraram que as forças de resistência axial média para os grupos la, lb, e II não foram significantemente diferentes a 166, 157 e $151 \mathrm{~N}$, respectivamente $(p>0,05)$. A conclusão foi que não houve diferença significante na retenção do sistema de pinos formado por feixes de fibras flexíveis e o sistema de pinos reforçados por fibra pré-fabricado rígido. A redução no volume do cimento ao redor dos pinos flexíveis não apresentou um efeito significante na retenção axial das restaurações. 


\subsection{Os dentes tratados endodonticamente restaurados com pinos reforçados por fibra apresentam sobrevida clínica longa?}

Fredriksson et al. (1998) realizaram uma avaliação retrospectiva clínica e radiográfica para avaliar o resultado do tratamento de dentes tratados endodonticamente com o sistema Composipost (C-Post) após dois ou três anos. Sete cirurgiões-dentistas, que apresentavam grande experiência com o sistema de pinos Composipost, foram selecionados a partir de cinco regiões diferentes da Suécia para contribuir com os dados para a pesquisa. $80 \%$ do número total de pacientes tratados com esse sistema pelos cirurgiões-dentistas foram selecionados randomizadamente através da randomização simples com tabelas de números. Duzentos e trinta e seis pacientes (91 homens e 145 mulheres; idade média de 57 anos, variando de 31 a 88 anos) foram selecionados para a avaliação. Desse total, 146 pacientes concordaram em participar do exame clínico para a realização da pesquisa. A amostra foi constituída por 236 dentes restaurados com pinos de resina epóxica reforçados por fibra de carbono, 130 superiores e 106 inferiores, com um período de restauração médio de 32 meses (variação de 27 a 41). As restaurações finais dos dentes tratados endodonticamente consistiam de coroas metalo-cerâmicas $(80 \%)$, coroas cerâmicas $(10 \%)$, e restaurações de resina composta. Os dados registrados nas fichas odontológicas estavam disponíveis no momento do exame, e correlacionaram com a avaliação clínica. Os exames clínicos foram realizados independentemente por dois observadores calibrados. As condições periodontais, os sinais radiográficos e os resultados protéticos foram registrados. Os resultados revelaram que cinco dentes $(2 \%)$ haviam sido extraídos por razões não relacionadas com o sistema Composipost. As condições periodontais tais como acúmulo de placa, saúde gengival, sangramento à sondagem e profundidade de bolsa ao redor dos dentes com pinos Composipost foram similares aos dentes controles. Nenhum deslocamento ou fratura do pino, ou da raiz foi observado clínica ou radiograficamente. $\mathrm{O}$ exame radiográfico da altura óssea mensurada do ápice até a margem óssea mesial ou distalmente mostrou diferenças no lado mesial, mas não na superfície distal $(p<0,05)$ entre os dentes tratados com Composipost e os dentes controles. Os autores concluíram que os resultados promissores obtidos após dois ou três anos de serviço clínico indicaram que o sistema de pinos reforçados por fibra 
de carbono pode ser uma alternativa viável para os sistemas de pinos e núcleos dentários convencionais.

Ferrari; Vichi; Garcia-Godoy (2000) realizaram um estudo retrospectivo para avaliar o resultado do tratamento de sistemas de núcleos metálicos fundidos e Composipost após quatro anos de serviço clínico. Duzentos pacientes foram incluídos no estudo e divididos em dois grupos de 100 dentes endodonticamente tratados restaurados com um pino. Grupo 1: os sistemas Composipost foram cimentados no interior dos condutos radiculares seguindo as instruções dos fabricantes. Grupo 2: os núcleos metálicos fundidos foram cimentados no interior dos condutos radiculares de acordo com a técnica tradicional. Os indivíduos foram rechamados após seis meses, um, dois e quatro anos e os exames clínicos e radiográficos foram realizados. Os resultados endodônticos e protéticos foram registrados. No grupo $1,95 \%$ dos dentes restaurados com Composiposts apresentaram sucesso clínico; $3 \%$ da amostra foram excluídos devido à falta de colaboração com o tratamento e $2 \%$ apresentaram falha endodôntica. No grupo 2, $84 \%$ dos dentes restaurados com núcleos metálicos fundidos apresentaram sucesso clínico. Dois por cento da amostra foi excluída devido a falta de colaboração com o tratamento, 9\% apresentaram fratura radicular, e 2\% mostraram deslocamento da coroa e $3 \%$ apresentaram falha endodôntica. A análise estatística revelou diferenças estatisticamente significantes entre os grupos 1 e $2(p<0,001)$. Os resultados desse estudo retrospectivo indicaram que o sistema Composipost foi superior ao núcleo metálico fundido convencional após quatro anos de uso clínico.

Ferrari et al. (2000b) avaliaram a performance clínica de C-Posts, Aestheti Posts e Aestheti Plus Posts após o período de uso clínico variando de um a seis anos. $80 \%$ do número total de pacientes tratados por três dentistas foram selecionados através de randomização simples com tabelas numeradas randomizadas. O total de 719 pacientes (idade média de 53 anos, variando de 20 a 80 anos) tratados com 850 C-Posts, 215 pacientes tratados com 249 Aestheti Posts e 234 pacientes tratados com 290 Aestheti Plus Posts foram selecionados para avaliação. Quatro combinações de sistemas adesivos foram usadas. As restaurações finais dos dentes foram coroas metalo-cerâmicas (52\%), coroas cerâmicas $(38 \%)$ e resinas compostas. Os dados obtidos a partir das fichas odontológicas estavam disponíveis no momento do exame, e os registros correlacionaram com os exames clínicos e radiográficos. Os parâmetros protéticos e 
os sinais radiográficos foram registrados. Os exames clínicos foram realizados independentemente por dois observadores calibrados. Os pacientes retornaram a cada seis meses e os exames clínicos e radiográficos foram realizados. A análise estatística da tabela de vida Acturial e a comparação da curva de sobrevida MantelHaenszel foram realizadas ao nível de confidência de 95\%. Os resultados revelaram um índice de falha de 3,2\% devido a duas razões: 25 pinos descolaram durante a remoção das restaurações provisórias e 16 dentes apresentaram lesões periapicais ao exame radiográfico. Todos os pinos descolados foram cimentados em dentes apresentando originalmente menos de $2 \mathrm{~mm}$ de dentina coronária remanescente. Não foram encontradas diferenças estatísticas significantes entre os quatro grupos. Não houve fratura radicular, deslocamento do pino ou da coroa. Os resultados desse estudo restrospectivo indicaram que os pinos de fibra em combinação com os materiais adesivos podem ser usados rotineiramente.

Malferrari; Monaco; Scotti (2003) realizaram um estudo clínico prospectivo para avaliar a performance de pinos de resina epóxica reforçados por fibras de quartzo usados na restauração de dentes tratados endodonticamente após o período de 30 meses. Os critérios de inclusão dos dentes no estudo foram: necessidade de confecção de coroa protética, tratamento endodôntico realizado há no mínimo três meses (sem a presença de sintomas objetivos e subjetivos) e ausência de lesão ao exame radiográfico. Em 132 pacientes (idade entre 18 a 65 anos), 180 dentes tratados endodonticamente foram restaurados com pinos de fibra de quartzo Aesthetic-Plus cimentados com o sistema adesivo All-Bond 2 e o cimento resinoso C\&B Cement de acordo com as recomendações do fabricante. O núcleo foi confeccionado com Core-Flo ou Bis-Core, e coroas de cerâmica pura ou metalocerâmicas foram utilizadas como restaurações finais. Os dados relativos ao número de canais radiculares, estrutura dentária remanescente (completa: 66 a 100\% do dente; parcial: 33 a $65 \%$ do dente; ou ausente: 0 a $32 \%$ do dente), forma do conduto radicular (circular, oval ou semicircular) e dentição antagonista foram registrados. Os parâmetros considerados como falha clínica foram o deslocamento, perda de adesão ou fratura dos pinos; fratura da raiz ou do núcleo coronário e deslocamento da coroa protética. Os pacientes foram reavaliados aos seis, 12, 24 e 30 meses após a cimentação do pino por três observadores não mascarados. Os resultados revelaram que uma falha coesiva envolvendo a margem do núcleo de resina foi observada após duas semanas, e duas fraturas adesivas foram evidenciadas após dois meses. 
Estas duas falhas adesivas envolveram o descolamento do cimento-pino-núcleo das paredes de dentina do conduto radicular em dois caninos (um superior e um inferior). Ambos os dentes apresentaram pouca estrutura dentária remanescente (ausente: 0 a $32 \%$ ) e um diâmetro do conduto radicular muito grande, provavelmente devido ao preparo excessivo durante o tratamento endodôntico. Embora tenham sido usados pinos $n^{\circ} 2$ (1,8 mm de diâmetro cervical), foi encontrada uma camada de cimento espessa nesses dentes. Todas as três falhas ocorreram durante a remoção da coroa provisória. O percentual de insucesso clínico foi de 1,7\% durante o período de 30 meses, entretanto foi possível substituir a restauração nos três casos. Concluiu-se que, após o período de 30 meses, a reabilitação de dentes tratados endodonticamente restaurados com pinos de fibra de quartzo apresentou bons resultados clínicos. Não foi observado nenhum descolamento da coroa ou da prótese, e nenhuma fratura da raiz, pino ou núcleo.

Monticelli et al. (2003) avaliaram prospectivamente a performance clínica de três tipos de pinos translúcidos ao longo do período entre dois e três anos. 225 pacientes (idade média de 51 anos; variando de 10 a 78 anos) apresentando um pré-molar necessitando de tratamento endodôntico e restauração com pinos de fibra e coroa de porcelana foram selecionados. A amostra foi randomizadamente dividida em três grupos de 75 pacientes cada. O mesmo tipo de pino foi usado em todos os pacientes dentro do grupo: grupo 1 = Aesthetic Plus; grupo $2=\mathrm{DT}$; e grupo $3=\mathrm{FRC}$ Postec. A cimentação adesiva dos pinos foi realizada com o sistema adesivo fotopolimerizável (One-Step) e o cimento resinoso de polimerização dual (Duolink) nos grupos 1 e 2, enquanto os materiais adesivos quimicamente ativados (Excite DSC como sistema adesivo e MultiLink como cimento resinoso) foram usados no grupo 3 . Os pacientes retornaram após seis, 12, e 24 meses, e o exame clínico e radiográfico foi realizado. Dois observadores realizaram os exames clínicos e radiográficos independentemente. Esses observadores foram diferentes do operador que havia realizado as restaurações e estavam mascarados em relação aos tipos de materiais usados. Para alguns pacientes, dados do acompanhamento após 30 meses também foram coletados. A análise estatística de tabela de vida Acturial e a curva de sobrevida Mantel-Haenszel foram realizadas ao nível de significância de $95 \%$. Os resultados revelaram que o descolamento do pino ocorreu em oito casos (3,5\%); em outros seis casos, a recorrência da lesão periapical foi reportada. Os autores concluíram que a análise estatística não revelou nenhuma diferença significante no 
índice de sobrevida dos pinos testados, sugerindo que todos foram igualmente e suficientemente confiáveis para o uso clínico.

Hedlund; Johansson; Sjogren (2003) realizaram um estudo retrospectivo para avaliar o desempenho clínico de pinos reforçados por fibra de carbono. 48 pacientes (24 homens e 24 mulheres; idade média de 62 e 61,3 anos, respectivamente) foram selecionados para compor a amostra do estudo. Sessenta e cinco pinos de fibra de carbono (Composipost e Endopost) foram avaliados através da análise de fichas odontológicas e radiografias. Os dados foram coletados a partir dos registros odontológicos considerando os tipos de pinos, os agentes cimentantes usados, os materiais usados para o núcleo, a duração de uso clínico dos pinos, o tipo de restaurações finais e ajuste, re-cimentação, fratura, deslocamento e/ou fratura dos pinos e/ou das raízes e/ou dos núcleos, ou sintomatologia pós-operatória. Adicionalmente, a forma do preparo do conduto radicular foi analisada através do exame radiográfico, sendo classificada como reta ou alargada. Dois avaliadores realizaram as análises. Todos os pinos reforçados por fibra de carbono foram cimentados com cimentos resinosos, sendo 93\% com Panavia. As resinas compostas usadas para o núcleo foram Z-100 em 51\% e Cawex Clearfil em 34\%. As marcas comerciais remanescentes não foram anotadas nas fichas odontológicas. As restaurações finais dos dentes tratados foram coroas metalo-cerâmicas (80\%), coroas cerâmicas $(14 \%)$, coroas veneer $(3 \%)$ e dois dentes apresentaram restaurações provisórias. Após o período de uso clínico médio de 2,3 \pm 0,8 anos (média de 2,1 anos, variação de 1-4,9 anos), o índice de falha reportado foi de $3 \%$. As falhas ocorreram em um canino superior restaurado com uma coroa unitária metalo-cerâmica, e em um primeiro pré-molar inferior pertencente a uma prótese parcial fixa do tipo cantilever. $49 \%$ dos condutos preparados foram classificados como retos e $11 \%$ como alargados; não foram encontrados dados disponíveis para analisar a forma dos condutos radiculares remanescentes. Os autores concluíram que, embora o índice de falha encontrado tenha sido menor do que aquele reportado comumente para os pinos metálicos, mais estudos clínicos são necessários para analisar a adequabilidade dos pinos reforçados por fibra de carbono para o uso rotineiro como uma alternativa aos núcleos metálicos fundidos.

Naumann; Blankenstein; Dietrich (2005) realizaram um estudo clínico prospectivo para avaliar a sobrevida de reconstruções protéticas em dentes apresentando vários graus de estrutura dentária remanescente restaurados com 
pinos cônicos ou cilíndricos. Os critérios de inclusão no estudo relativos ao dente ou ao paciente foram: (1) canal radicular livre de sintomas e apresentando selamento apical mínimo de $4 \mathrm{~mm}$; (2) ausência de periodontite avançada não-tratada; (3) mobilidade dentária igual ou inferior a grau 2; e (4) disponibilidade para retorno em intervalos regulares para avaliação. Oitenta e três indivíduos receberam 105 pinos reforçados por fibra de morfologia cônica (Luscent Anchors, Dentatus, Sweden) e cilíndrica com paredes serradas (Fibrekor, Jeneric Pentron, USA). Os pinos foram cimentados no interior dos condutos radiculares com o sistema adesivo EBS-Multi (3M ESPE) e o cimento resinoso de polimerização dual Compolute (3M, ESPE, Germany), e a reconstrução coronária foi confeccionada com a resina composta Clearfil Core (Kuraray, Japan). O período de observação mínimo foi de 24 meses (média: 27 meses). Os pacientes retornaram após seis, 12 e 24 meses para a revisão clínica. A avaliação clínica foi realizada por um examinador único. A falha foi definida como perda da retenção do pino, fratura radicular horizontal ou vertical, fratura do pino e fratura da reconstrução coronária. Um ano após a cimentação do pino, uma radiografia foi obtida para detectar as lesões endodônticas periapicais e excluir a possibilidade de sintomas radiográficos de falha como, por exemplo, lesão periodontal como sintoma de fratura radicular. A análise estatística foi realizada em uma sub-amostra constituída de uma restauração por indivíduo selecionada aleatoriamente. $O$ teste exato de Fisher foi usado para comparar as freqüências de falhas após 12 e 24 meses. A análise Kaplan-Meier foi usada para analisar a falha ao longo do tempo em ambos os grupos. Diferenças no tempo de sobrevida entre os tipos de pinos foram testadas com o teste log-rank. Os resultados revelaram que $3,8 \%$ das restaurações falharam após 12 meses e 12,8\% após 24 meses, respectivamente. Entretanto, todos os dentes que falharam puderam ser restaurados novamente. Não houve diferença na freqüência de falha entre os tipos de pinos após 12 ou 24 meses. O teste log-rank não revelou diferença na sobrevida entre os dois tipos de pino $(p=0,37)$. As conclusões foram que o índice de sobrevida apresentado pelos pinos de fibra de vidro cilíndricos e cônicos após dois anos foi similar. A fratura e a perda de retenção do pino foram os tipos de falhas mais freqüentes, embora a maioria das falhas tenham sido reparáveis.

Grandini et al. (2005b) avaliaram clinicamente o uso de pinos de fibra de quartzo e resinas compostas diretas empregadas para a restauração de dentes tratados endodonticamente. 81 indivíduos (45 homens e 36 mulheres; idade média 
de 35,17 anos, variando de 15 a 56 anos) que receberam tratamento endodôntico e restaurações diretas em 38 dentes anteriores e 62 dentes posteriores (33 prémolares e 29 molares), foram selecionados a partir de três consultórios particulares para compor a amostra desse estudo ( $n=100$ dentes). Os critérios de inclusão envolveram a confirmação clínica e radiográfica da necessidade para o tratamento de canal, presença de no mínimo $50 \%$ de estrutura coronária sadia nos dentes anteriores ou presença de dois a três paredes de estrutura coronária residual sadia nos dentes posteriores, e a satisfação dos pacientes em relação à estética e à função, sem que houvesse a necessidade de confecção de coroas protéticas. Os dentes selecionados para compor a amostra do estudo receberam o seguinte protocolo clínico: tratamento endodôntico, cimentação adesiva de pinos de fibra translúcidos (DT post) utilizando o sistema adesivo convencional de 1 passo (OneStep, Bisco) e o cimento resinoso de polimerização dual (Duolink, Bisco), e restauração direta de resina composta micro-híbrida (Gradia Direct, GC). Os indivíduos retornaram após seis, 12, 24 e 30 meses para avaliação clínica e radiográfica. Durante as consultas de retorno, uma análise da estabilidade e da longevidade das restaurações foi realizada de acordo com os seguintes critérios: (1) presença ou ausência de lesões periapicais; (2) infiltração marginal e integridade; (3) estabilidade de cor; (4) pigmentação superficial; (5) perda de retenção devido à fratura do pino ou fratura do material restaurador. As restaurações foram avaliadas por dois operadores que não confeccionaram as restaurações e que não foram revelados no momento do retorno (estudo cego). Após 2 anos, os resultados revelaram que quatro dentes apresentaram ligeira descoloração que não exigiu a substituição da restauração. Após 30 meses, quatro dentes apresentaram lesões periapicais (os canais radiculares foram retratados endodonticamente), cinco dentes apresentaram perda parcial da restauração (essas restaurações foram reparadas usando-se a mesma resina composta empregada para a confecção da restauração inicial) e seis dentes apresentaram ligeira pigmentação marginal (esses dentes também foram reparados usando o mesmo material empregado para a restauração inicial). Concluiu-se que após 30 meses de serviço clínico, os 100 dentes tratados endodonticamente restaurados com pinos de fibra e restaurações diretas de resina composta apresentaram resultados clínicos favoráveis. 

3 PROPOSIÇÃO 



\section{PROPOSIÇÃO}

O objetivo deste trabalho foi avaliar e correlacionar a espessura, a integridade adesiva e a resistência adesiva de dois cimentos resinosos empregados para a cimentação adesiva de pinos reforçados por fibra aos condutos radiculares utilizando três espessuras de cimento diferentes.

As hipóteses nulas testadas foram de que a espessura do cimento não influencia a integridade adesiva da interface cimento-dentina (1) e a resistência adesiva ao deslocamento do pino (2), dentro de cada cimento, e essas independem do modo de polimerização do cimento resinoso testado em cada espessura (hipóteses 3 e 4 , respectivamente). 

4 MATERIAL E MÉTODOS 



\section{MATERIAL E MÉTODOS}

\subsection{Seleção da amostra}

Trinta incisivos laterais superiores humanos recentemente extraídos por razões periodontais ou ortodônticas foram selecionados para este estudo. Os depósitos externos de tecidos moles e duros foram removidos utilizando-se um aparelho ultrassônico (Profi Class, Dabi Atlante, Ribeirão Preto, SP, Brasil). Os dentes apresentando raízes com comprimento inferior a $15 \mathrm{~mm}$ ou com cárie, fratura, tratamento endodôntico prévio, ápice incompleto, canal oval ou diâmetro do canal superior a $1 \mathrm{~mm}$ foram excluídos (Figura 1). As coroas anatômicas apresentaram dimensões similares, medindo 5,15 \pm 0,9 mm mesiodistalmente e 6,9 $\pm 1,3 \mathrm{~mm}$ vestibulolingualmente. Os dentes selecionados foram armazenados em solução salina fisiológica contendo timol $0,1 \%$ a $4^{\circ} \mathrm{C}$ até o início do experimento. Para separar as porções coronária e radicular, os dentes foram fixados a uma base na máquina de corte seriado (Isomet 1000 precision saw, Buehler, Lake Bluff, IL, EUA) utilizando cera pegajosa plastificada (Kota Ind. e Com. Ltda., São Paulo, SP, Brasil), e secionados perpendicularmente ao longo eixo do dente, $1 \mathrm{~mm}$ acima da junção cemento-esmalte, utilizando um disco diamantado em baixa velocidade (Extec dia. Wafer blade, Extec Corp., Enfield, CT, USA) sob refrigeração abundante com água (Figura 2).

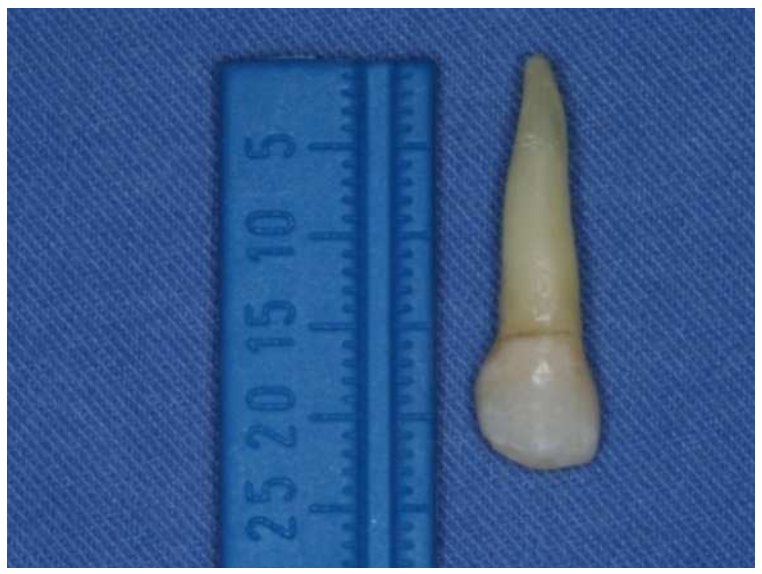

Figura 1 - Incisivo lateral superior apresentando raiz com comprimento $\geq 15 \mathrm{~mm}$, livre de cárie, fratura e tratamento endodôntico, e com ápice desenvolvido. O canal radicular apresentou diâmetro circular $\leq 1 \mathrm{~mm}$.

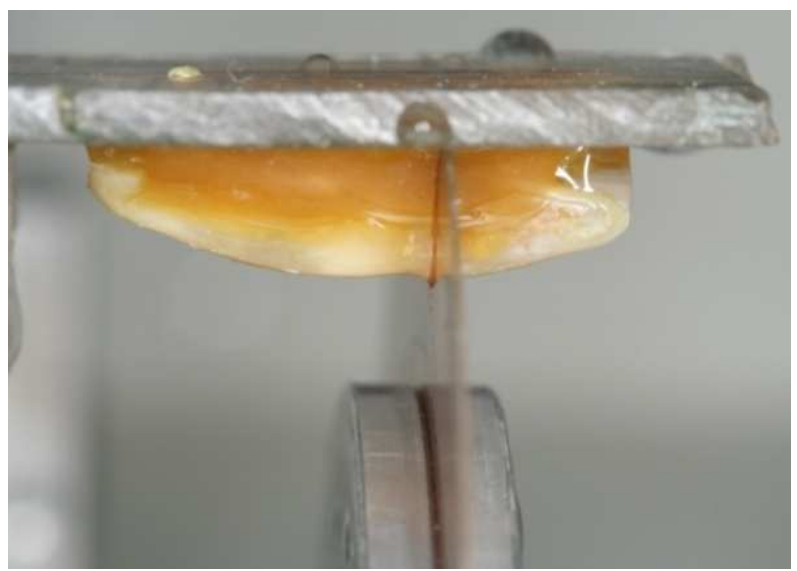

Figura 2 - Seção da coroa do incisivo lateral superior perpendicular ao longo eixo do dente e acima da junção cemento-esmalte, utilizando um disco de corte diamantado sob refrigeração abundante com água deionizada. 
A técnica step-back usando limas-K de aço inoxidável (Dentsply Maillefer, Ballaiguess, Switzerland) e irrigação alternada com a solução de EDTA 17\% (Biodinâmica, Ibiporã, PR, Brasil) e de NaOCl 5\% (Pharmácia Specifica, Bauru, SP, Brasil) foi empregada para o tratamento endodôntico. O preparo final dos canais radiculares apresentou $6^{\circ}$ de conicidade e $0,35 \mathrm{~mm}$ de diâmetro apical localizado 1 $\mathrm{mm}$ aquém do ápice. A patência do canal foi estabelecida com o uso da lima-K \#10 (Dentsply Maillefer, Ballaiguess, Switzerland). Os canais alargados foram enxagüados com água destilada de uma seringa endodôntica e secos com pontas de papel absorvente (Tanari pontas de papel absorvente, Tanariman Industrial Ltda, Manacapuru, AM, Brasil).

A obturação dos canais radiculares foi realizada com o cimento livre de eugenol (Material de selamento de canais radiculares, AH Plus, Dentsply International Inc., Petrópolis, RJ, Brasil) utilizando a técnica de condensação lateral de pontas de guta-percha (Guta-percha pontas, Dentsply International Inc., Petrópolis, RJ, Brasil). Após o tratamento endodôntico, os orifícios dos canais radiculares foram novamente examinados, e aqueles apresentando diâmetro igual ou inferior a $1 \mathrm{~mm}$ foram selecionados para o estudo. As raízes foram armazenadas em água destilada a $37^{\circ} \mathrm{C}$ por $48 \mathrm{~h}$ previamente ao preparo do conduto radicular.

\subsection{Formação dos grupos}

Para avaliar se o modo de polimerização do cimento resinoso e a espessura da camada de cimento influenciam a integridade adesiva e a resistência adesiva da interface cimento-dentina de pinos reforçados por fibra de vidro, dois cimentos resinosos - Duolink (Bisco, Schaumburg, IL, USA) e C\&B Cement (Bisco, Schaumburg, IL, USA) - e três espessuras de cimento diferentes (fina, média e grossa) foram investigados. Para cada cimento resinoso empregado para a cimentação do pino reforçado por fibra, as raízes foram aleatoriamente divididas em três grupos de cinco espécimes $(n=5)$, em função da espessura da camada de cimento formada entre o pino e o conduto (condição experimental). Em cada grupo, o preparo do conduto foi realizado utilizando uma das três brocas apresentando diâmetros diferentes: Broca Largo n³ (Dentsply International Inc., Petrópolis, RJ, 
Brasil) de 1,00 mm de diâmetro para o grupo controle (L3); e Broca Largo $\mathrm{n}^{\circ} 4$ (Dentsply International Inc., Petrópolis, RJ, Brasil) de 1,25 mm de diâmetro (L4); ou Broca Largo $\mathrm{n}^{\circ} 5$ (Dentsply International Inc., Petrópolis, RJ, Brasil) de 1,50 mm de diâmetro (L5) para os grupos experimentais (grupos de espessura média e grossa, respectivamente). No grupo controle (L3), os canais radiculares foram preparados utilizando a broca Largo $\mathrm{n}^{\circ} 3$ a $10 \mathrm{~mm}$ de profundidade, mensurada a partir da superfície radicular secionada. Nos grupos experimentais (L4 e L5), os canais radiculares foram preparados inicialmente utilizando a broca Largo $n^{\circ} 3$, a $10 \mathrm{~mm}$ de profundidade, e então alargados a $8 \mathrm{~mm}$ de profundidade utilizando as brocas Largo $\mathrm{n}^{\circ} 4$ e 5 , respectivamente. O pino reforçado por fibra de vidro cilíndrico $\mathrm{n}^{\circ} 1$ (Fibrekor post - Jeneric Pentron Incorporated, Wallinfgford, CT, USA) (comprimento: 20mm; tipo de fibra: $71 \%$ por peso de fibras de vidro unidirecionais em $29 \%$ por peso de resina epóxica) selecionado para o estudo apresentou diâmetro constante $(1,00 \mathrm{~mm})$. A porção apical do conduto preparado $(2 \mathrm{~mm})$ atuou como guia de inserção para o pino em relação ao longo eixo da raiz (Figuras 3 a 5).

A combinação entre o modo de polimerização do cimento e o diâmetro da broca utilizada para o preparo do conduto radicular resultou na formação de seis sub-grupos: Duolink/L3, Duolink /L4, Duolink /L5, C\&B Cement/L3, C\&B Cement /L4, C\&B Cement /L5.

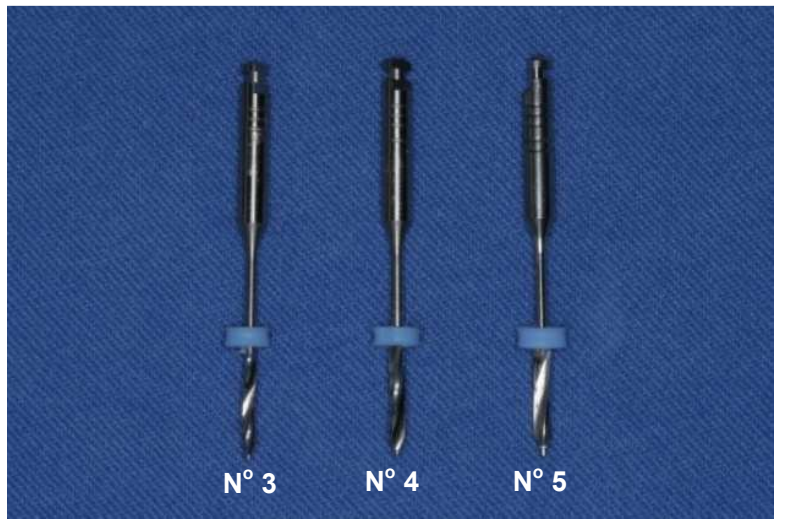

Figura 3 - Brocas Largo $n^{\circ} 3,4$ e 5, apresentando $1,00 \mathrm{~mm} ; 1,25 \mathrm{~mm}$ e $1,50 \mathrm{~mm}$ de diâmetro.

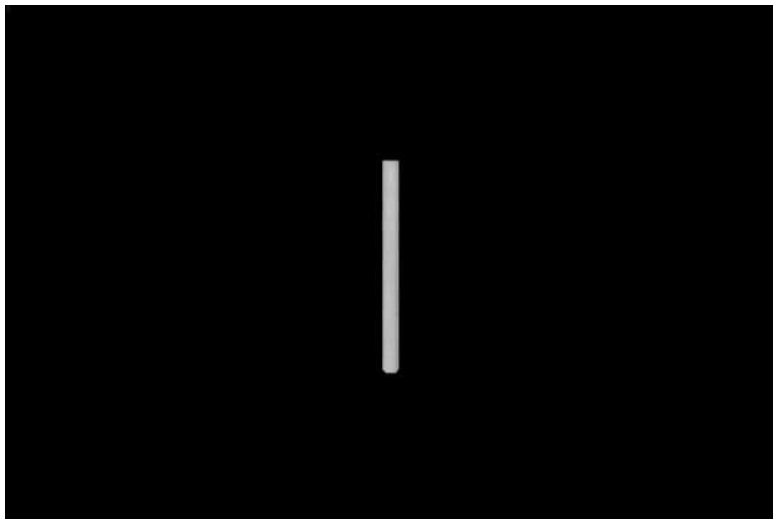

Figura 4 - Pino de resina reforçado por fibra de vidro cilíndrico $n^{\circ} 1$ de 1,00 mm de diâmetro. 


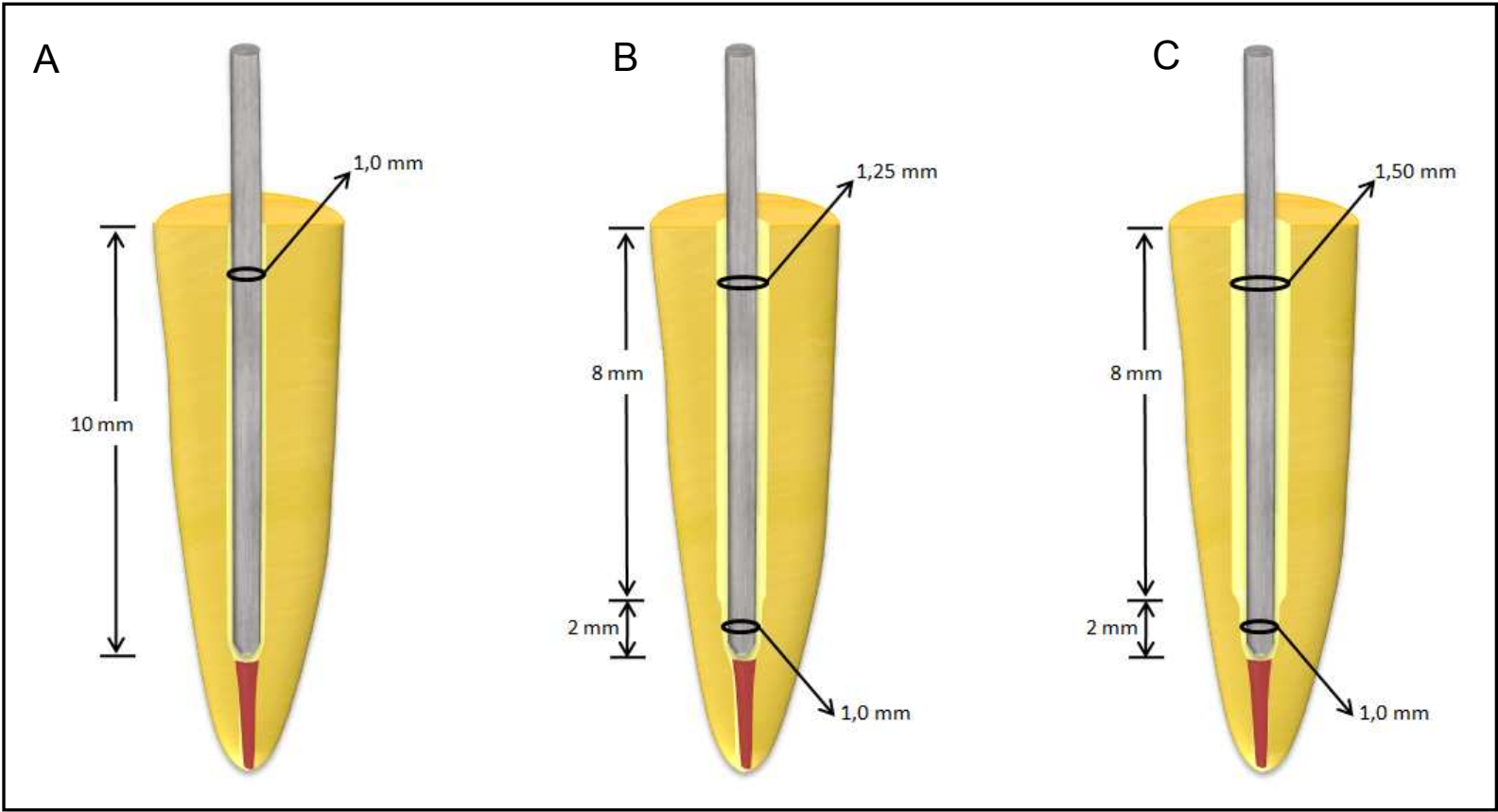

Figura 5 - Desenho esquemático mostrando as três condições experimentais testadas no estudo. A) Grupo de espessura fina (grupo L3 - Controle); B) Grupo de espessura média (grupo L4); C) Grupo de espessura grossa (grupo L5).

As raízes foram montadas em um cilindro de PVC (altura: $2 \mathrm{~cm}$, diâmetro 2 $\mathrm{cm}$ ) utilizando resina acrílica autopolimerizável (Clássico, Artigos Odontológicos Clássico, São Paulo, SP, Brasil), sendo que a resina acrílica se estendeu $4 \mathrm{~mm}$ acima do ápice. O paralelismo entre o pino, o canal e o cilindro foi obtido por meio do uso de um paralelômetro (BioArt, São Carlos, SP, Brasil). A raiz foi posicionada centralmente no cilindro de PVC, e a resina acrílica e o monômero foram misturados e vazados no interior do mesmo. Para prevenir o aquecimento das raízes, o conjunto raiz-cilindro de PVC foi imerso em água deionizada imediatamente após o início do aquecimento da resina acrílica. Após a fixação da raiz, os condutos foram preparados utilizando um motor de baixa rotação (Dabi Atlante, Ribeirão Preto, SP, Brasil) acoplado ao paralelômetro, de modo que a broca estivesse paralela ao eixoy. Esse procedimento objetivou evitar possíveis desvios e/ou deformações que poderiam ocorrer durante o preparo manual dos condutos. Cursores de borracha individuais foram usados nas brocas para assegurar o controle da profundidade do conduto preparado, e a broca foi avançada em aproximadamente $3 \mathrm{~mm}$ de cada vez, com remoções freqüentes para eliminação dos resíduos e irrigação com água destilada também com o objetivo de evitar o aquecimento das raízes. 


\subsection{Procedimentos de cimentação}

Após o preparo do conduto radicular, o mesmo foi irrigado com água destilada utilizando uma seringa endodôntica e então seco com pontas de papel absorvente. As raízes foram envoltas em compressa de gaze úmida para evitar o ressecamento e simular o ambiente úmido in vivo. Os pinos foram cimentados aos condutos radiculares utilizando um dos cimentos resinosos apresentando modos de polimerização diferentes empregados no estudo. As características dos dois cimentos resinosos disponíveis comercialmente estão apresentadas na Tabela 1. Duolink é um cimento resinoso dual comumente usado para a cimentação de pinos. Teoricamente, a camada de cimento não deveria apresentar graus variáveis de polimerização, pois as regiões onde a luz polimerizadora não alcançasse seriam polimerizadas através do componente de ativação química presente no sistema dual. C\&B Cement é um cimento resinoso autopolimerizável no qual a foto-polimerização não é necessária. Assim, a camada de cimento também não deveria apresentar graus variáveis de polimerização, uma vez que ela independe da presença da luz.

Tabela 1 - Características dos cimentos resinosos.

\begin{tabular}{llll}
\hline $\begin{array}{l}\text { Cimento resinoso/ modo } \\
\text { de ativação/ número do } \\
\text { lote }\end{array}$ & $\begin{array}{l}\text { Sistema adesivo/ } \\
\text { modo de ativação/ } \\
\text { tipo }\end{array}$ & Composição do cimento & Fabricante \\
\hline $\begin{array}{l}\text { Duolink: polimerização dual/ } \\
\text { 0600010325 }\end{array}$ & $\begin{array}{l}\text { One Step Plus/ } \\
\text { polimerização fotoativada/ } \\
\text { convencional de 2 passos }\end{array}$ & $\begin{array}{l}\text { Sílica, BIS-GMA, TEG-DMA, } \\
\text { UDMA }\end{array}$ & Bisco, Schaumburg, USA \\
C \& B Cement: polimerização & $\begin{array}{l}\text { One Step Plus/ } \\
\text { polimerização fotoativada/ } \\
\text { química/0600005072 }\end{array}$ & $\begin{array}{l}\text { TEG-DMA, vidro fundido, } \\
\text { convencional de 2 passos }\end{array}$ & fluoreto de sódio \\
& & \\
\hline
\end{tabular}


Os procedimentos de cimentação seguiram estritamente as recomendações do fabricante. Nos grupos Duolink/L3, Duolink /L4 e Duolink /L5, os condutos radiculares foram condicionados por $15 \mathrm{~s}$ usando ácido fosfórico em gel a 32\% (UNIETCH, Bisco, Schaumburg, IL, USA), lavados com água destilada de uma seringa endodôntica e, então, gentilmente secos com o ar da seringa tríplice. O excesso de água do conduto radicular foi removido utilizando-se pontas de papel absorvente. Duas finas camadas de adesivo com carga (One-Step Plus, Bisco, Schaumburg, IL, USA) foram aplicadas no interior do conduto radicular por meio de um micro-pincel fino (Extrafine KG brush Aplicadores Descartáveis, KG Sorensen Indústria e Comércio Ltda, Barueri, SP, Brasil), secas cuidadosamente com pontas de papel e ar livre de óleo por $10 \mathrm{~s}$, e fotopolimerizadas aplicando-se a luz na embocadura do conduto por $10 \mathrm{~s}$ a $600 \mathrm{mV} / \mathrm{cm} 2$. Os pinos reforçados por fibra foram limpos com álcool e cobertos com uma camada de um agente de união silano (Porcelain Primer, Bisco, Schaumburg, IL, USA) por 5 min. Antes da cimentação, cada pino foi marcado a uma distância de $10 \mathrm{~mm}$ da extremidade apical correspondendo ao comprimento do preparo do conduto. Assim, o completo assentamento dos pinos pôde ser verificado. Partes iguais das pastas base e catalisadora do cimento resinoso de polimerização dual Duolink foram misturadas e aplicadas no interior do conduto radicular usando-se uma broca lentullo (Dentsply Maillefer, Ballaiguess, Switzerland). O pino reforçado por fibra foi preso a um dispositivo adaptado fixado ao paralelômetro, e então inserido no conduto radicular, sob a orientação do guia de inserção (Figura 6). O pino foi mantido em posição por 5-10 s, o excesso de cimento removido com um micro-pincel, e o cimento remanescente foto-polimerizado por $40 \mathrm{~s}$ através do pino.

Nos grupos C\&B Cement/L3, C\&B Cement /L4 e C\&B Cement /L5, foram realizados os mesmos procedimentos de adesão anteriormente descritos. Partes iguais das pastas base e catalisadora do cimento resinoso autopolimerizável C\&B Cement foram misturadas e o cimento foi injetado no interior do conduto radicular utilizando uma ponta aplicadora de dose única (Pontas agulha para Centrix, DFL Indústria e Comércio S. A., Rio de Janeiro, RJ, Brasil) e o auxílio de uma seringa aplicadora (Centrix, DFL Indústria e Comércio S. A., Rio de Janeiro, RJ, Brasil). O pino, marcado a $10 \mathrm{~mm}$ da extremidade apical, foi então inserido no conduto radicular com o auxílio do dispositivo adaptado do paralelômetro, mantido em posição por 5-10 s, o excesso de cimento removido com um micro-pincel, e deixado 
polimerizar por 10 min. Trinta minutos após a cimentação, todos os espécimes foram armazenados em água destilada por $48 \mathrm{~h}$ a $37^{\circ} \mathrm{C}$.

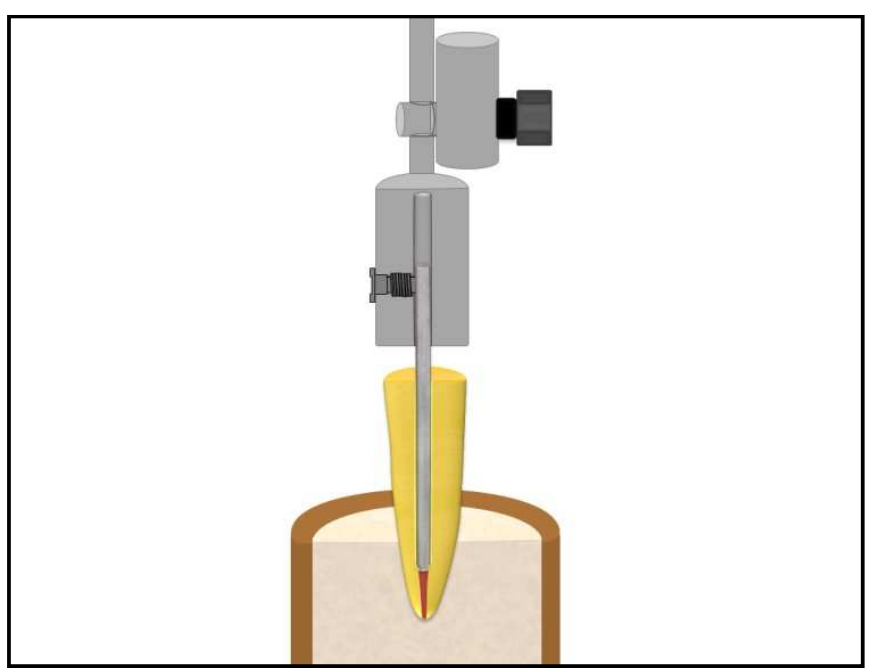

Figura 6 - Desenho esquemático mostrando o pino reforçado por fibra preso ao dispositivo-guia adaptado no paralelômetro e inserido no conduto radicular durante a cimentação.

\subsection{Preparo dos espécimes para as mensurações em MEV}

A fim de determinar a espessura do cimento formada entre o pino reforçado por fibra e a dentina radicular, assim como observar eventuais fendas que se formassem na interface cimento-dentina durante a polimerização do cimento resinoso, réplicas dos espécimes foram confeccionadas e submetidas a uma análise por meio de MEV, sendo essa realizada nas dependências do Núcleo de Apoio à Pesquisa em Microscopia Eletrônica de Varredura aplicada à Pesquisa Agropecuária (NAP/MEPA), localizado na Escola Superior de Agricultura "Luiz de Queiroz" - SP (ESALQ).

Quarenta e oito horas após a cimentação dos pinos, os espécimes foram removidos dos cilindros de PVC utilizando uma broca esférica $n^{\circ} 3$ (KG Sorensen, Barueri, SP, Brasil) acoplada ao motor de baixa rotação, e fixados a uma base na máquina de corte utilizando cera pegajosa plastificada. A porção do espécime contendo o pino reforçado por fibra foi então secionada horizontalmente em três seções radiculares com aproximadamente $2 \mathrm{~mm}$ de espessura utilizando um disco diamantado em baixa velocidade sob irrigação abundante a água (Figura 7). 0 objetivo desse procedimento foi expor a interface entre o pino e o cimento, e entre o 
cimento e a dentina, para posterior exame em MEV. As três seções obtidas para cada espécime foram denominadas cervical, média e apical como referência à sua localização no interior do conduto preparado.

Devido ao fato de a superfície observável das seções radiculares apresentar-se ligeiramente desnivelada após o corte, foi necessário realizar uma padronização da mesma, seguindo o protocolo de polimento descrito na Tabela 2. Esse procedimento objetivou regularizar a superfície da seção para facilitar a obtenção do foco no microscópio. Entretanto, devido à quantidade de estrutura dentária perdida durante o polimento, apenas uma das superfícies de cada seção (superfície cervical) foi utilizada para a análise em MEV. Para isso, cada seção foi fixada com cera pegajosa plastificada em um disco de resina acrílica, estando a superfície apical voltada para o disco, e polida em politriz metalográfica (APL 4, Arotec, Cotia, SP, Brasil) sob refrigeração abundante com água destilada (Figura 8). As seções foram limpas ultrassonicamente com água destilada (T7 Thornton, Unique Ind. e Com. de Produtos Eletrônicos Ltda., Indaiatuba, SP, Brasil), por 10 min entre cada etapa de polimento e 30 min após o polimento, com o objetivo de promover uma limpeza adequada para a análise em MEV.

Tabela 2 - Protocolo de polimento das seções radiculares para análise em MEV.

\begin{tabular}{lcccc}
\hline & Granulometria & Fabricante & Tempo & Velocidade \\
& & & & \\
& & & & \\
Lixa de carbeto de silício & 600 & 3M ESPE, São Paulo, Brasil & 2 min & baixa \\
Lixa de carbeto de silício & 1200 & 3M ESPE, São Paulo, Brasil & 3 min & baixa \\
Lixa de carbeto de silício & 2500 & Indasa, Aveiro, Portugal & 5 min & baixa \\
Pano para polimento TOP & $6 \mu m$ & Arotec, São Paulo, Brasil & 1,5 min & alta \\
+ pasta diamantada & & & & \\
\\
$\begin{array}{l}\text { Pano para polimento RAM } \\
+ \text { pasta diamantada }\end{array}$ & $3 \mu \mathrm{m}$ & Arotec, São Paulo, Brasil & 1,5 min & alta \\
\end{tabular}




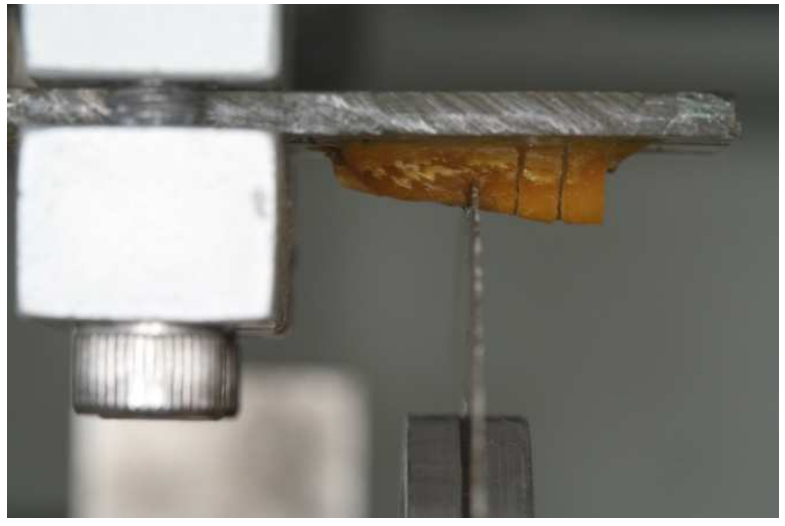

Figura 7 - Corte horizontal do espécime em três seções radiculares de dois $\mathrm{mm}$ de espessura utilizando um disco diamantado sob refrigeração abundante com água.

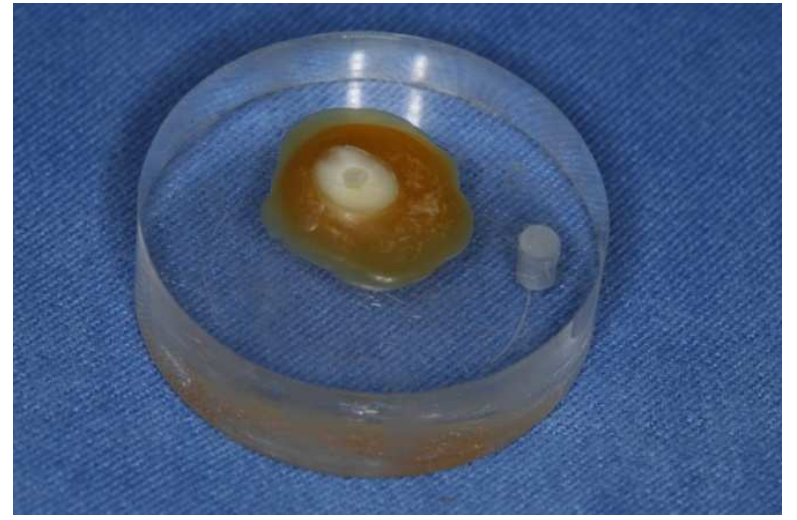

Figura 8 - Secção fixada ao disco de resina acrílica utilizando cera pegajosa, estando a superfície apical voltada para o disco.

Após o polimento, moldes das superfícies observáveis foram obtidos utilizando polivinil siloxano de baixa viscosidade (Aquasil Ultra XLV, Dentsply International Inc., Petrópolis, RJ, Brasil). A técnica de réplica foi usada para evitar artefatos produzidos durante o preparo da amostra para exame em MEV, e, simultaneamente, permitir a análise da interface cimento-dentina antes do teste push-out. Uma ponta misturadora (Pontas misturadoras, Zhermack S.p.A., Rovigo, Itália) e uma ponta intra-oral (Pontas intra-orais, Zhermack S.p.A., Rovigo, Itália) foram encaixadas no cartucho contendo o material de moldagem, e esse, por sua vez, foi acoplado a um aplicador fornecido pelo fabricante (Dentsply International Inc.). O aplicador foi acionado aplicando-se uma pressão manual moderada sobre o gatilho, para iniciar a auto-mistura do material pela ponta aplicadora, e o material de moldagem auto-misturado foi dispensado sobre a superfície polida da amostra. Os moldes foram cuidadosamente removidos das seções radiculares, armazenados por $24 \mathrm{~h}$ a $37^{\circ} \mathrm{C}$ para a liberação de gases, limpos ultrassonicamente por 10 min com água destilada, e secos com jato de ar (Figuras 9 e 10).

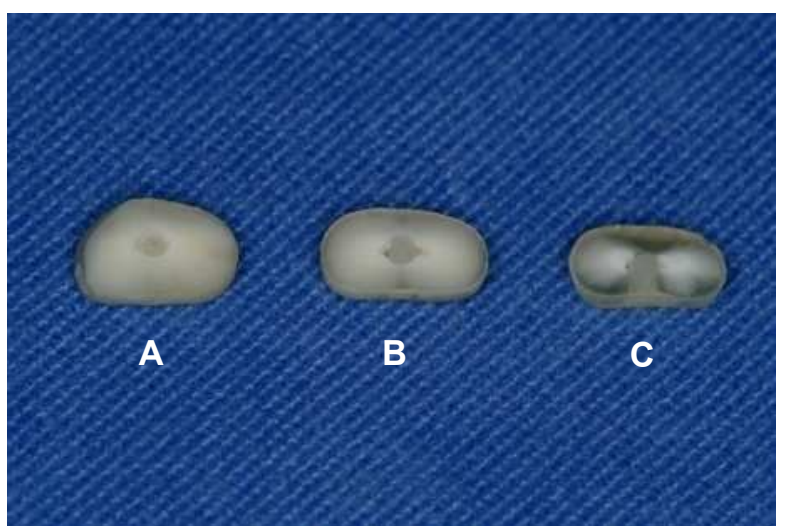

Figura 9 - Seções radiculares. A) Cervical; B) Média; C) Apical.

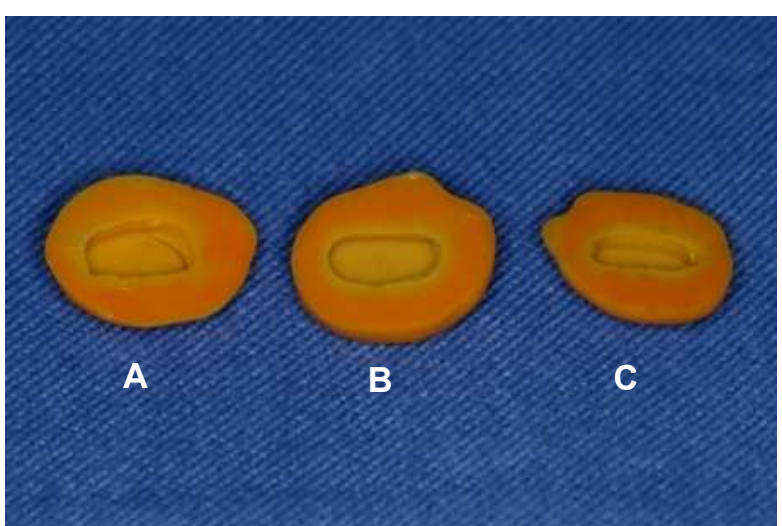

Figura 10 - Moldes das seções. A) Cervical; B) Médio; C) Apical. 
Os moldes foram então vazados com resina epóxica de baixa viscosidade para a obtenção de réplicas positivas das seções radiculares. A mistura da resina epóxica seguiu as normas do fabricante e foi realizada manualmente utilizando-se $10 \mathrm{ml}$ da resina (Epo Thin Epoxy Resin, Buehler, Lake Bluff, IL, EUA) para 3,9 ml do endurecedor (Epo Thin Epoxy Hardner, Buehler, Lake Bluff, IL, EUA). Depois de manipulada cuidadosamente, a resina epóxica foi mantida em um degaseificador acoplado ao compressor aspirador (Diapump, Fanem LTDA, São Paulo, SP, Brasil) a $500 \mathrm{~mm} / \mathrm{Hg}$ por 30 min para a eliminação de bolhas. A resina epóxica foi então inserida cuidadosamente nos moldes com uma espátula $\mathrm{n}^{0} 1$ (SS White Art. Dentários LTDA, Rio de Janeiro, RJ, Brasil), mantida a $500 \mathrm{~mm} / \mathrm{Hg}$ no degaseificador por $10 \mathrm{~min}$, e polimerizada quimicamente à temperatura e pressão ambiente por $9 \mathrm{~h}$.

Em seguida, as réplicas foram cuidadosamente removidas dos moldes e armazenadas em potes individuais devidamente identificados para prevenir 0 acúmulo de poeira (Figura 11). Posteriormente, foram fixadas em uma base de alumínio do MEV (stub) por meio de uma fita carbonada dupla-face destinada especificamente para esse fim, sempre com a superfície cervical voltada para cima. Esse procedimento objetivou a estabilização das réplicas, prevenindo o seu deslocamento pelo vácuo gerado na câmara do metalizador e do MEV. Como o uso da fita dupla-face carbonada permite o fluxo de elétrons das réplicas em direção aos stubs, foi possível evitar também a ocorrência de áreas intensamente brilhantes na superfície analisada (efeito charging). As réplicas fixadas aos stubs foram então desidratadas em estufa a $37^{\circ} \mathrm{C}$ por $5 \mathrm{~min}$, cobertas com ouro em um metalizador por 180 s (Bal-tec SCD 050 Sputter Coater, Bal-Tec Union, Liechtenstein) e observadas em microscópio eletrônico de varredura a 15 kV (ZEISS DSM 940 A, Carl Zeiss Inc., Oberkochen, Germany) (Figuras 12 e 13). 


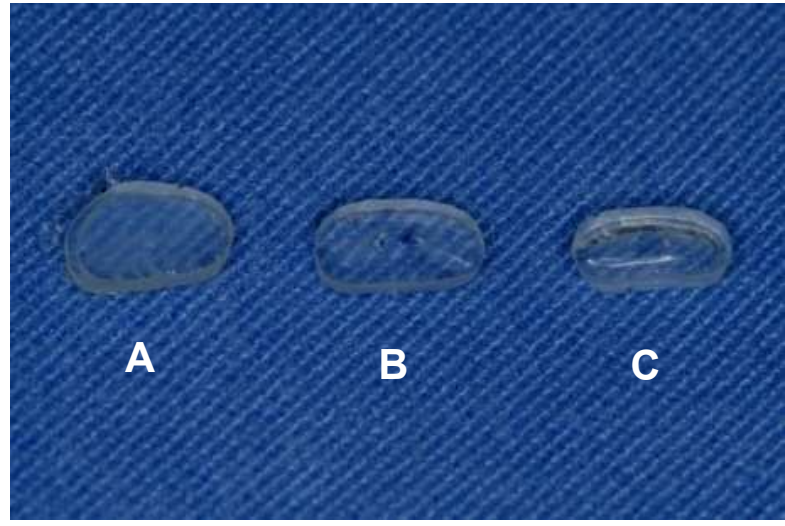

Figura 11 - Réplicas em resina epóxica. A) Cervical; B) Média; C) Apical.

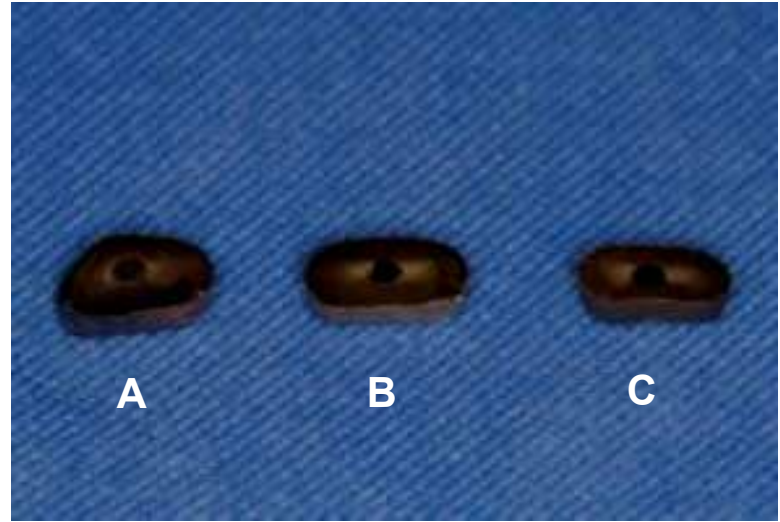

Figura 12 - Réplicas em resina epóxica cobertas com uma camada de ouro, após a metalização. A) Cervical; B) Média; C) Apical.

\subsection{Mensuração da espessura do cimento e da integridade adesiva da interface cimento-dentina por meio de MEV}

Marcações foram confeccionadas na superfície da réplica utilizando uma lâmina de bisturi, dividindo a interface cimento-dentina em oito partes aproximadamente iguais, com o objetivo de orientar a leitura no microscópio eletrônico de varredura. Fotomicrografias seriadas das réplicas foram obtidas com diferentes magnificações padronizadas (50x para o conduto radicular; 100-700x para a interface cimento-dentina). A espessura do cimento resinoso $(\mu \mathrm{m})$ foi mensurada na fotomicrografia obtida em pequena magnificação (50x) utilizando o programa Image Tool for Windows 3.00 (Dental Diagnostics Science, University of Texas, Health Science Center, San Antonio Dental School, San Antonio, TX, USA). Uma linha tangente virtual foi traçada, e a mensuração foi realizada perpendicular a essa linha. Os valores médios $(\mu \mathrm{m})$ da espessura do cimento de cada réplica foram obtidos a partir de quatro mensurações realizadas em quatro posições diametralmente opostas.

A integridade da interface cimento-dentina também foi mensurada utilizando o programa Image Tool for Windows 3.00. A percentagem da interface contínua de cada réplica foi obtida a partir da proporção entre o perímetro total da interface cimento-dentina disponível observado em pequena magnificação (50x), e a interface cimento-dentina que apresentou continuidade (livre de fendas) observada em grande magnificação (100-700x). As fotomicrografias seriadas em MEV foram alinhadas em 
um computador para formar uma faixa contínua de exame circular nas oito regiões analisadas. Independentemente do número de fotomicrografias necessárias para completar o círculo completo, cada círculo foi subdividido em oito "unidades de análise". Uma linha curva foi traçada progressivamente sobre a interface cimentodentina e os valores da interface total e contínua foram registrados $(\mu \mathrm{m})$. Os valores (\%) foram expressos como uma percentagem da interface contínua.

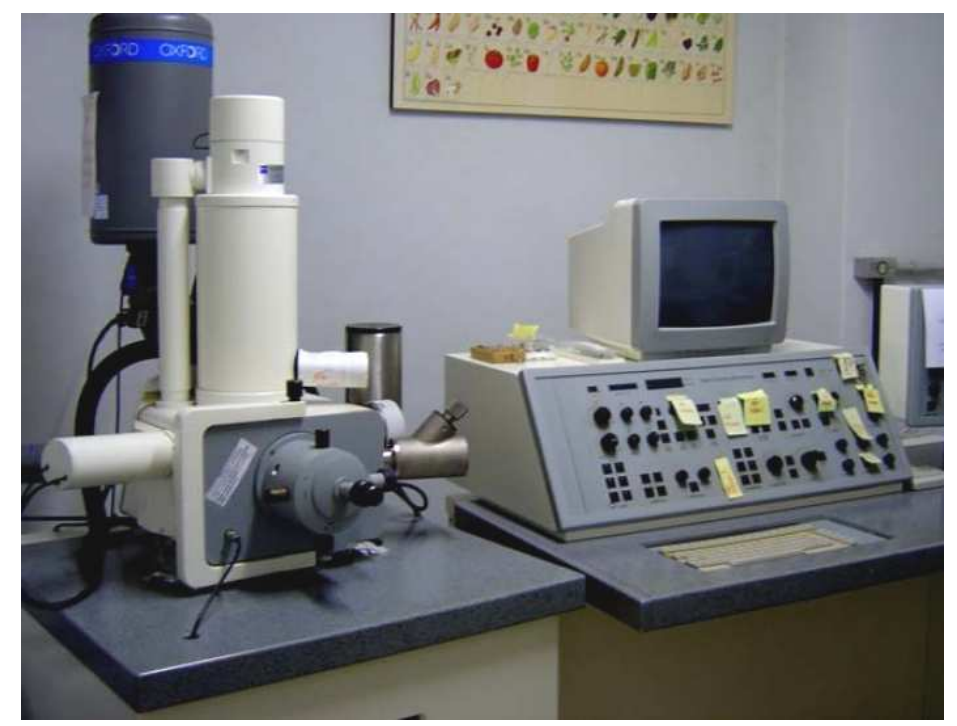

Figura 13 - Microscópio eletrônico de varredura ZEISS DSM 940 A.

\subsection{Preparo das seções radiculares para o teste push-out}

Após o corte e o polimento, as seções foram utilizadas para a avaliação da resistência adesiva ao deslocamento do pino através do teste push-out. Inicialmente, a espessura de cada seção foi mensurada utilizando um paquímetro eletrônico digital (Starret Ind. E Com. LTDA., Itu, SP, Brasil) (Figura 14). Em seguida, cada amostra foi posicionada, sempre com a porção cervical voltada para baixo, em um suporte metálico (altura: 0,5 cm; diâmetro: $0,5 \mathrm{~cm}$ ), apresentando uma abertura central maior do que o diâmetro do canal radicular. Os pinos reforçados por fibra foram carregados à velocidade $0,5 \mathrm{~mm} / \mathrm{min}^{-1}$ por uma haste cilíndrica de $0,9 \mathrm{~mm}$ de diâmetro interligada a uma máquina de ensaio universal (Emic DL - 1000, Equipamentos e Sistemas de Ensaio Ltda, São José dos Pinhais, PR, Brasil) até a falha, caracterizada pelo deslocamento do segmento do pino da seção radicular (Figura 15). 


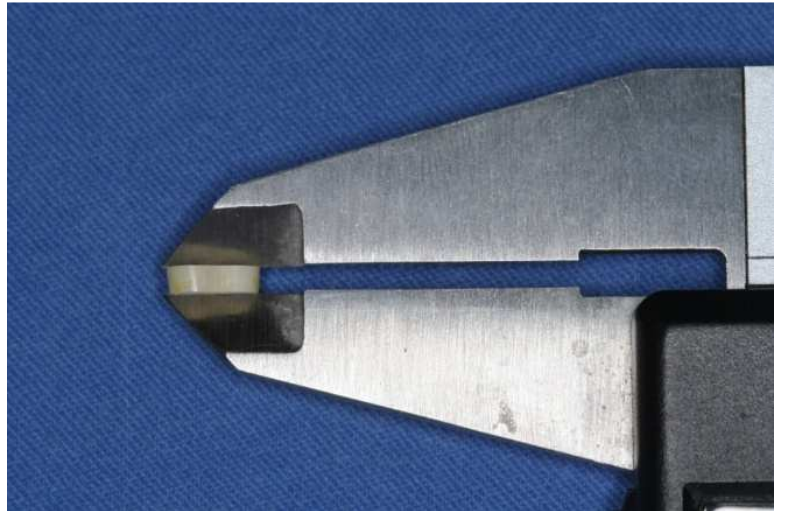

Figura 14 - Mensuração da amostra utilizando o paquímetro eletrônico digital.

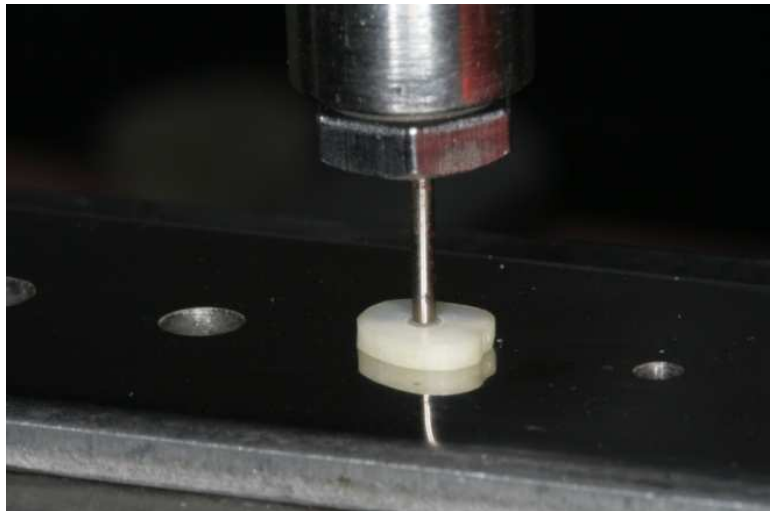

Figura 15 - Carga aplicada pela haste cilíndrica sobre o pino em uma direção apico-coronal.

A carga $(\mathrm{N})$ foi aplicada na superfície apical do espécime em direção apicocoronal, resultando em força de cisalhamento ao longo da interface cimento-dentina e empurrando o pino em direção à região mais larga da raiz. Tomou-se cuidado para assegurar que o contato entre a ponta da haste e a seção do pino se estendesse na maior área possível, com o objetivo de evitar qualquer efeito de entalhe da ponta cilíndrica sobre a superfície do pino, o que poderia interferir com a análise da resistência adesiva da interface. A resistência adesiva média de cada espécime foi calculada a partir de três amostras por dente.

A resistência adesiva ao deslocamento do pino ( $\sigma)(\mathrm{MPa})$ foi obtida pela seguinte fórmula:

$$
\sigma=\mathrm{C} / \mathrm{A}
$$

Onde:

$\mathrm{C}=$ carga no momento da falha da amostra $(\mathrm{N})$;

$\mathrm{A}=$ área da interface aderida $\left(\mathrm{mm}^{2}\right)$.

Devido ao fato de o pino usado no estudo apresentar um formato cilíndrico, a área aderida foi calculada utilizando a seguinte fórmula para cálculo da área lateral (A) do cilindro:

$$
A=2 \pi r \times h
$$

Onde:

II $=3,14$;

$r=$ raio do pino de fibra de vidro $(\mathrm{mm})$;

$\mathrm{h}=$ espessura da seção mensurada utilizando o paquímetro digital ( $\mathrm{mm}$ ). 


\subsection{Forma de análise dos resultados}

Os dados foram analisados utilizando o programa estatístico (GraphPad Prism 5; Graph Software, La Jolla, CA, USA).

Para uma análise da integridade adesiva dos cimentos resinosos em relação à espessura do cimento presente ao redor do pino, as diferenças entre a percentagem de interface cimento-dentina contínua mensurada nas três condições experimentais foram avaliadas estatisticamente, dentro de cada cimento, através da ANOVA a um critério e teste de Tukey para comparações múltiplas $(p<0,05)$. O teste " $t$ " de Student foi usado para determinar diferenças significantes na integridade adesiva entre os dois cimentos resinosos em cada uma das três condições experimentais avaliadas no estudo $(p<0,05)$.

Considerando os resultados de resistência adesiva, ANOVA a um critério com teste de Tukey para comparações post hoc foram novamente utilizados, dentro de cada cimento, para determinar diferenças significantes na retenção dos cimentos resinosos em relação às diferentes condições experimentais testadas $(p<0,05)$. 0 teste " $t$ " de Student foi também usado, dentro de cada condição experimental, para determinar diferenças significantes entre os dois cimentos resinosos avaliados no estudo $(p<0,05)$.

Por fim, as correlações existentes entre a integridade adesiva, a resistência adesiva e a espessura do cimento foram determinadas (Pearson, $p<0,05$ ). 



\section{RESULTADOS}

Os valores individuais da espessura da camada de cimento $(\mu \mathrm{m})$, do perímetro total da interface adesiva cimento-dentina disponível $(\mu \mathrm{m})$, da interface adesiva que apresentou continuidade (livre de fendas) ( $\mu \mathrm{m} \mathrm{e} \mathrm{\% ),} \mathrm{assim} \mathrm{como} \mathrm{os}$ valores da força (MPa) necessária para promover o deslocamento do pino do interior do conduto radicular encontrados para os dois cimentos resinosos nas diferentes condições experimentais e regiões da raiz foram registrados e agrupados nos Apêndices (A a F). 


\subsection{Integridade adesiva da interface cimento-dentina}

\subsubsection{Comparação entre as condições experimentais para cada cimento}

A espessura do cimento afetou significantemente a integridade adesiva obtida no cimento resinoso Duolink utilizado neste estudo $(p<0,05)$, fazendo com que a primeira hipótese fosse parcialmente rejeitada. Os valores médios da percentagem de interface cimento-dentina contínua (livre de fendas) em relação ao perímetro total da interface adesiva disponível para contato entre o cimento e a dentina (\%), encontrados para os dois cimentos resinosos nas três condições experimentais avaliadas no estudo estão apresentados nas Tabelas 3 e 4, e estão representados nos gráficos box-plot (Gráficos 1 e 2).

Quando todas as regiões radiculares foram agrupadas, a comparação entre as condições experimentais em cada cimento revelou que a maior percentagem de integridade adesiva para o cimento resinoso Duolink foi encontrada no grupo controle $(61,79 \pm 18,06 \%)$, a qual não foi significantemente diferente de L4 (57,19 \pm $4,55 \%, p=0,79)$, mas foi significantemente maior do que L5 (38,91 $\pm 5,75 \%$, $p=0,01)$. Não foram encontradas diferenças estatisticamente significantes entre L4 e L5 $(p=0,06)$. Para o cimento resinoso C\&B Cement, não foram observadas diferenças estatisticamente significantes entre a integridade adesiva encontrada no grupo controle $(44,61 \pm 13,66 \%)$ e nos grupos experimentais $L 4(47,28 \pm 13,28 \%)$ e L5 $(49,37 \pm 15,84 \%)$, os quais, por sua vez, também não foram significantemente diferentes entre si $(p=0,87)$. 
Tabela 3 - Comparação da integridade adesiva encontrada nas diferentes condições experimentais para Duolink (\%).

\begin{tabular}{c|c|c}
\hline Condição experimental & Média $(d p)$ & $N^{\circ}$ de espécimes \\
\hline L3 (controle) & $61,79(18,06)$ & 5 \\
\hline L4 & $57,19(4,55)$ & 5 \\
\hline L5 & $38,91(5,75)$ & 5 \\
\hline
\end{tabular}

Probabilidade $=0,018996 ; p<0,05$.

Diferença significante na comparação entre as condições experimentais L3 X L5.

Tabela 4 - Comparação da integridade adesiva encontrada nas diferentes condições experimentais para C\&B Cement (\%).

\begin{tabular}{c|c|c}
\hline Condição experimental & Média $(d p)$ & $N^{0}$ de espécimes \\
\hline L3 (controle) & $44,61(13,66)$ & 5 \\
\hline L4 & $47,28(13,28)$ & 5 \\
\hline L5 & $49,37(15,84)$ & 5 \\
\hline
\end{tabular}

Probabilidade $=0,870703 ; p>0,05$.

Diferença não significante na comparação entre as condições experimentais.

\section{Duolink}

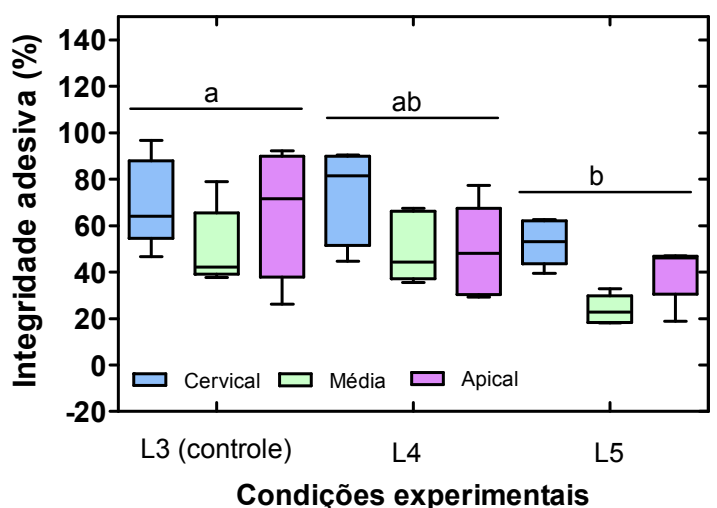

Gráfico 1 - Box plot da integridade adesiva das regiões radiculares cervical, média e apical por condição experimental para o cimento Duolink (\%). Letras minúsculas se referem às diferentes condições experimentais quando todas as regiões radiculares foram agrupadas. Letras superescritas diferentes indicam diferenças significantes.
C\&B Cement

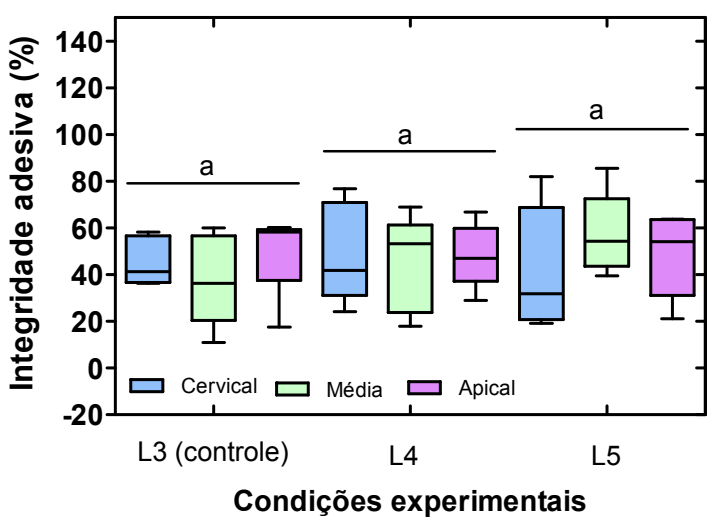

Gráfico 2 - Box plot da integridade adesiva das regiões radiculares cervical, média $e$ apical por condição experimental para o cimento C\&B Cement (\%). Letras minúsculas se referem às diferentes condições experimentais quando todas as regiões radiculares foram agrupadas. Letras superescritas diferentes indicam diferenças significantes. 


\subsubsection{Comparação entre os cimentos para cada condição experimental}

Os valores médios de integridade adesiva (\%) encontrados para os dois cimentos resinosos em cada condição experimental avaliada no estudo estão apresentados nas Tabelas 5 a 7 , e estão representados nos gráficos box-plot (Gráficos 3 a 5). Novamente considerando todas as regiões radiculares agrupadas, não foram encontradas diferenças significantes entre os cimentos resinosos para cada condição experimental $(p>0,05)$. Contudo, a maior percentagem de interface contínua foi encontrada no cimento resinoso Duolink para todas as condições experimentais, à exceção do grupo L5. Nesse último, o cimento resinoso C\&B Cement apresentou integridade adesiva superior ao cimento resinoso Duolink.

Tabela 5 - Comparação da integridade adesiva entre os cimentos no grupo controle (L3) (\%).

\begin{tabular}{c|c|c}
\hline Cimento & Média $(d p)$ & $N^{0}$ de espécimes \\
\hline Duolink & $61,79(18,06)$ & 5 \\
\hline C\&B Cement & $44,60(13,66)$ & 5 \\
\hline
\end{tabular}

Probabilidade $=0,128272$ (não significante); $p>0,05$.

Tabela 6 - Comparação da integridade adesiva entre os cimentos no grupo L4 (\%).

\begin{tabular}{c|c|c}
\hline Cimento & Média $(d p)$ & $N^{0}$ de espécimes \\
\hline Duolink & $57,19(4,55)$ & 5 \\
\hline C\&B Cement & $47,28(13,28)$ & 5 \\
\hline
\end{tabular}

Probabilidade $=0,153092$ (não significante); $p>0,05$.

Tabela 7 - Comparação da integridade adesiva entre os cimentos no grupo L5 (\%).

\begin{tabular}{c|c|c}
\hline Cimento & Média $(d p)$ & $N^{\circ}$ de espécimes \\
\hline Duolink & $38,91(5,75)$ & 5 \\
\hline C\&B Cement & $49,39(15,85)$ & 5 \\
\hline
\end{tabular}

Probabilidade $=0,20218$ (não significante); $p>0,05$. 


\section{L3 (grupo controle)}

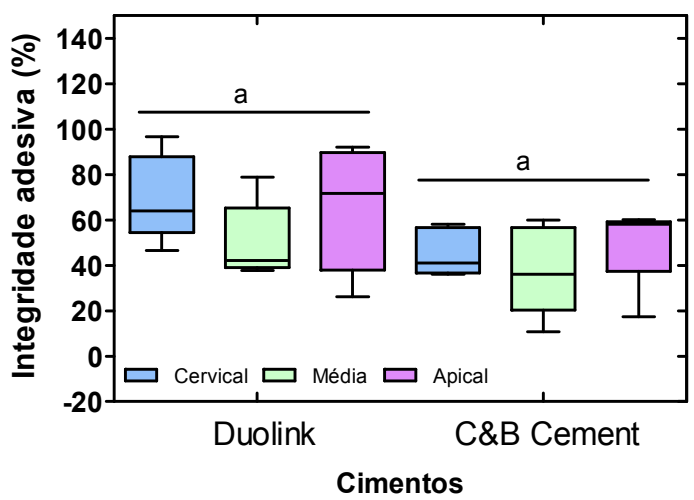

Gráfico 3 - Box plot da integridade adesiva das regiões radiculares cervical, média e apical por cimentos para o grupo controle (\%). Letras minúsculas se referem aos diferentes cimentos quando todas as regiões radiculares foram agrupadas. Letras superescritas diferentes indicam diferenças significantes.
L4

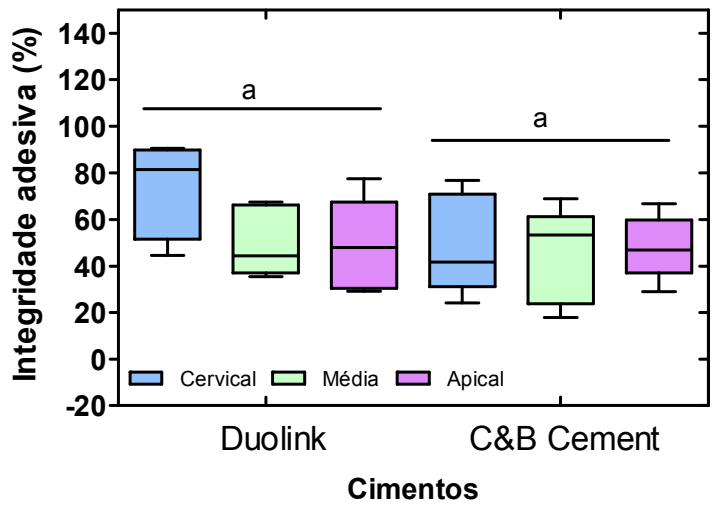

Gráfico 4 - Box plot da integridade adesiva das regiões radiculares cervical, média e apical por cimentos para o grupo L4 (\%). Letras minúsculas se referem aos diferentes cimentos quando todas as regiões radiculares foram agrupadas. Letras superescritas diferentes indicam diferenças significantes.

\section{L5}

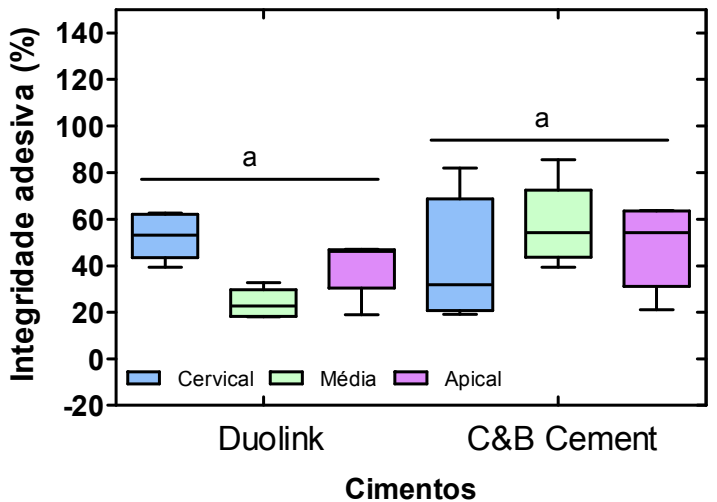

Gráfico 5 - Box plot da integridade adesiva das regiões radiculares cervical, média e apical por cimentos para o grupo L5 (\%). Letras minúsculas se referem aos diferentes cimentos quando todas as regiões radiculares foram agrupadas. Letras superescritas diferentes indicam diferenças significantes. 


\subsubsection{Fotomicrografias em MEV da interface cimento-dentina}

No geral, a análise em MEV mostrou um padrão bastante regular de distribuição das fendas na interface cimento-dentina entre os cimentos resinosos nas três condições experimentais. No cimento resinoso Duolink, a maioria das fendas estava localizada nas regiões média e apical da raiz, independentemente da espessura do cimento (Figuras 16, 18 e 20). Interfaces livres de fendas foram observadas geralmente no terço cervical desse cimento resinoso (Figuras 17, 19 e 21).

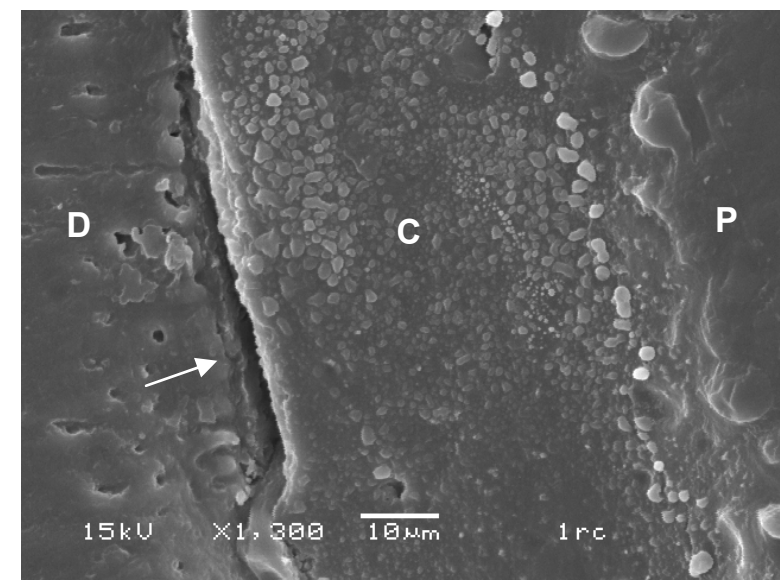

Figura 16 - Fotomicrografia em MEV de espécime do cimento Duolink (L3 - grupo controle). Presença de descontinuidade na interface cimento-dentina (fenda) da região apical da raiz, apontada pela seta branca. $P$ : pino; C: cimento; D: dentina.

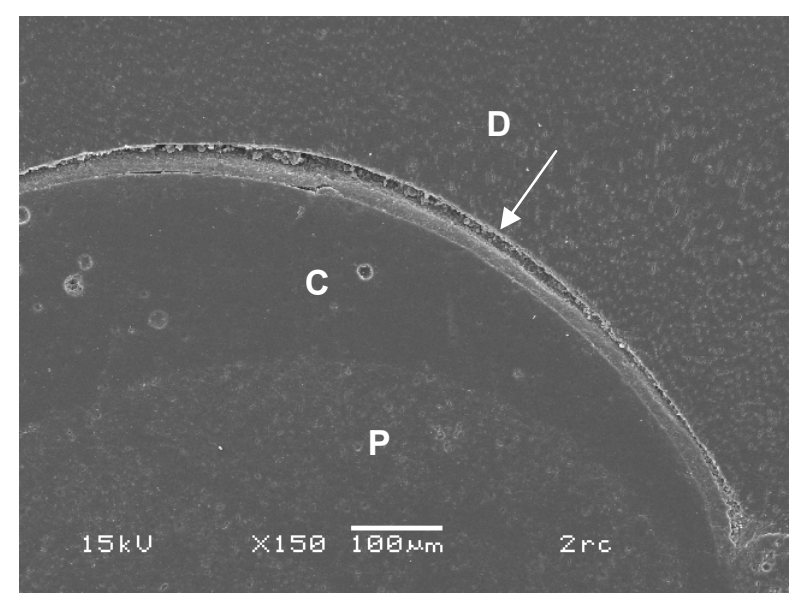

Figura 18 - Fotomicrografia em MEV de espécime do cimento Duolink (Grupo L4). Presença de descontinuidade na interface cimento-dentina (fenda) da região média da raiz, apontada pela seta branca. P: pino; C: cimento; D: dentina.

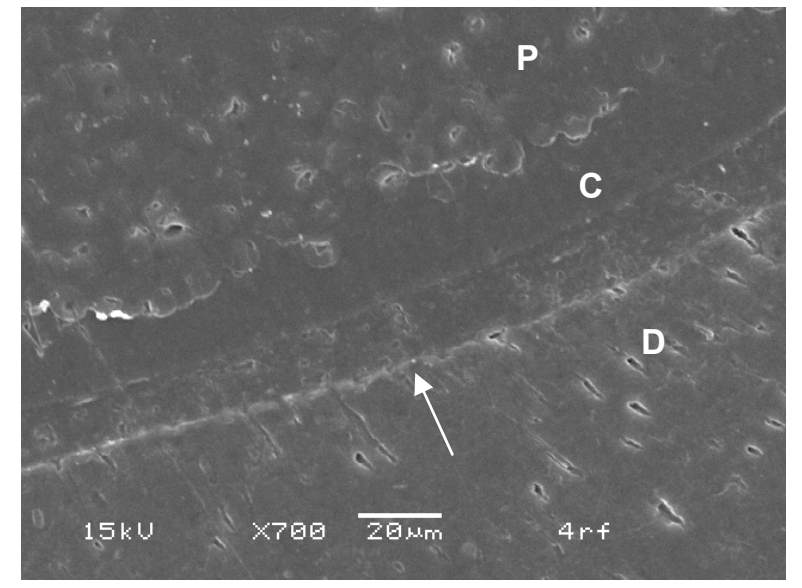

Figura 17 - Fotomicrografia em MEV de espécime do cimento Duolink (L3 - grupo controle). Presença de continuidade na interface cimento-dentina da região cervical da raiz, apontada pela seta branca. P: pino; C: cimento; D: dentina.

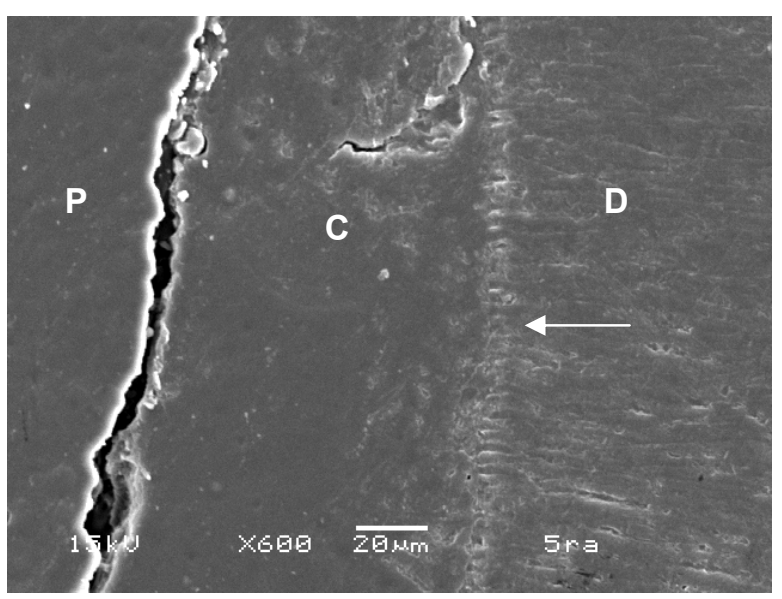

Figura 19 - Fotomicrografia em MEV de espécime do cimento Duolink (Grupo L4). Presença de continuidade na interface cimento-dentina da região cervical da raiz, apontada pela seta branca. Notar a presença de fenda na interface entre o cimento e o pino. $P$ : pino; $C$ : cimento; $D$ : dentina. 


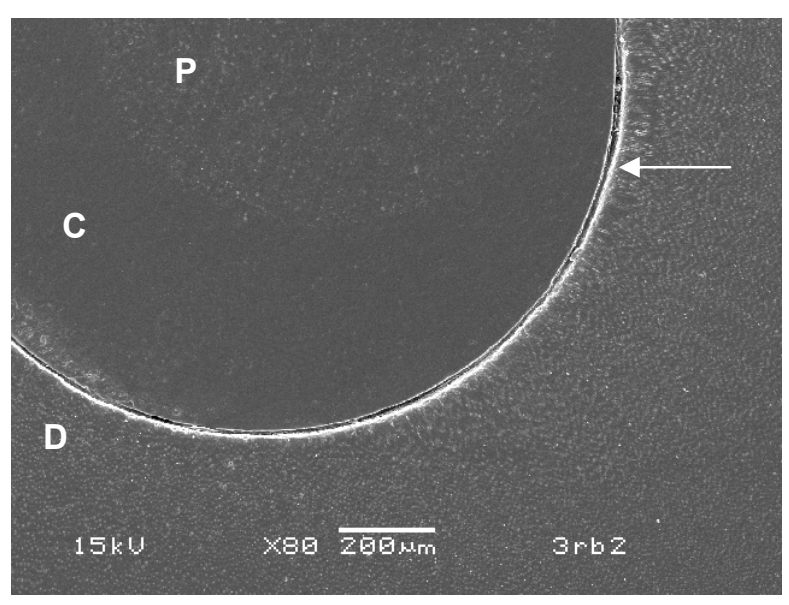

Figura 20 - Fotomicrografia em MEV de espécime do cimento Duolink (Grupo L5). Presença de descontinuidade na interface cimento-dentina (fenda) da região média da raiz, apontada pela seta branca. P: pino; C: cimento; D: dentina.

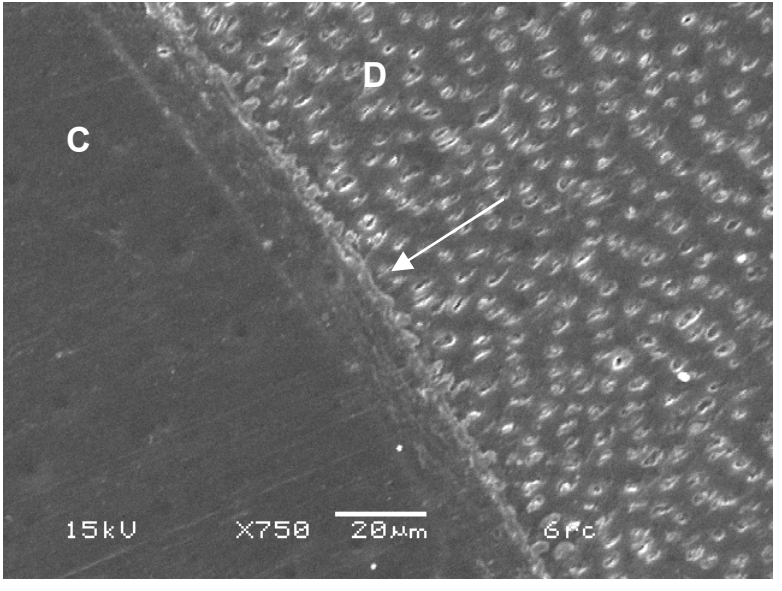

Figura 21 - Fotomicrografia em MEV de espécime do cimento Duolink (Grupo L5). Presença de continuidade na interface cimento-dentina da região cervical da raiz, apontada pela seta branca. P: pino; C: cimento; D: dentina.

O cimento resinoso C\&B Cement, por sua vez, também mostrou uma maior concentração das fendas nas regiões radiculares média e apical, independentemente da espessura do cimento (Figuras 22, 24 e 26). Interfaces livres de fendas foram observadas geralmente no terço cervical desse cimento resinoso (Figuras 23, 25 e 27).

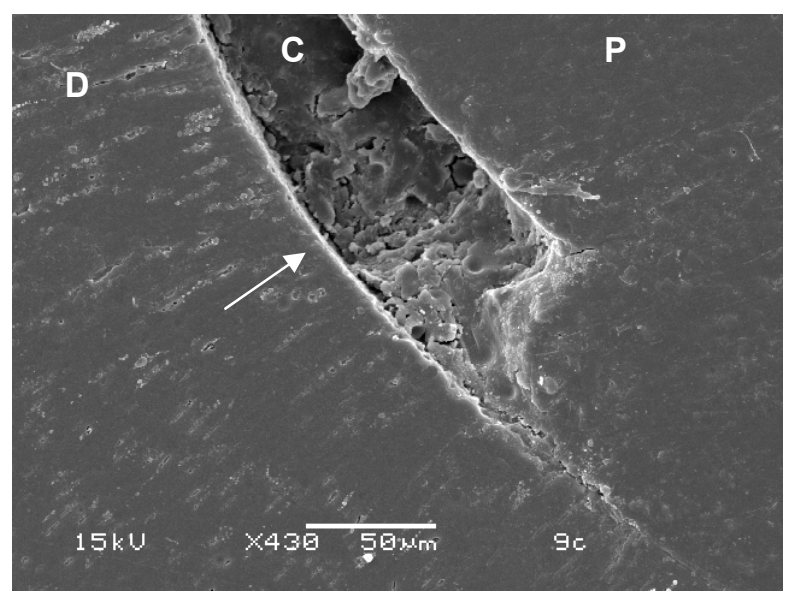

Figura 22 - Fotomicrografia em MEV de espécime do cimento C\&B Cement (L3 - grupo controle). Presença de descontinuidade na interface cimento-dentina (fenda) da região apical da raiz, apontada pela seta branca. P: pino; C: cimento; D: dentina.

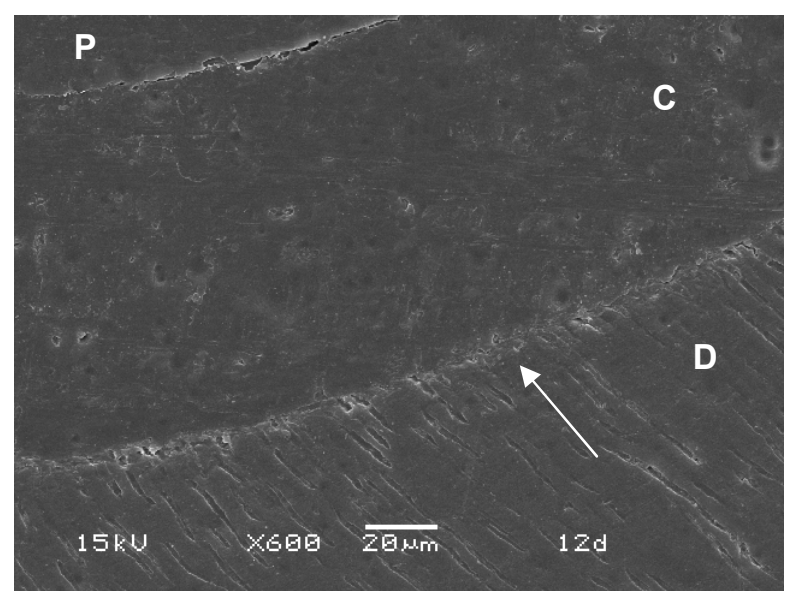

Figura 23 - Fotomicrografia em MEV de espécime do cimento C\&B Cement (L3 - grupo controle). Presença de continuidade na interface cimentodentina da região cervical da raiz, apontada pela seta branca. P: pino; C: cimento; D: dentina. 


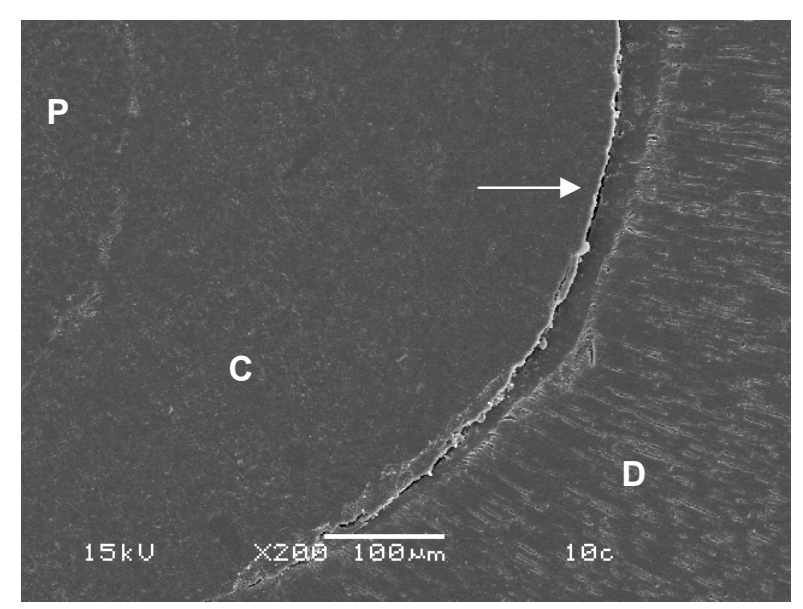

Figura 24 - Fotomicrografia em MEV de espécime do cimento C\&B Cement (Grupo L4). Presença de descontinuidade na interface cimento-dentina (fenda) da região média da raiz, apontada pela seta branca. P: pino; C: cimento; D: dentina.

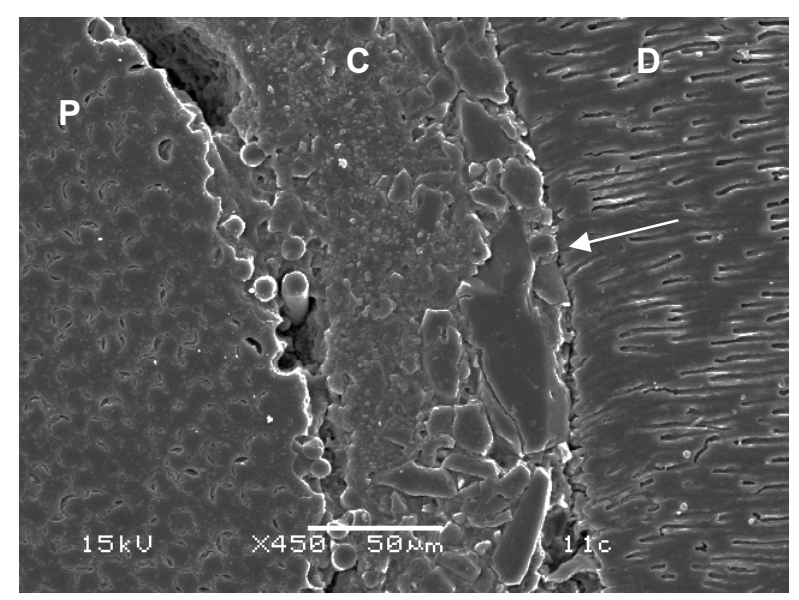

Figura 26 - Fotomicrografia em MEV de espécime do cimento C\&B Cement (Grupo L5). Presença de descontinuidade na interface cimento/dentina (fenda) da região média da raiz, apontada pela seta branca. P: pino; C: cimento; D: dentina.

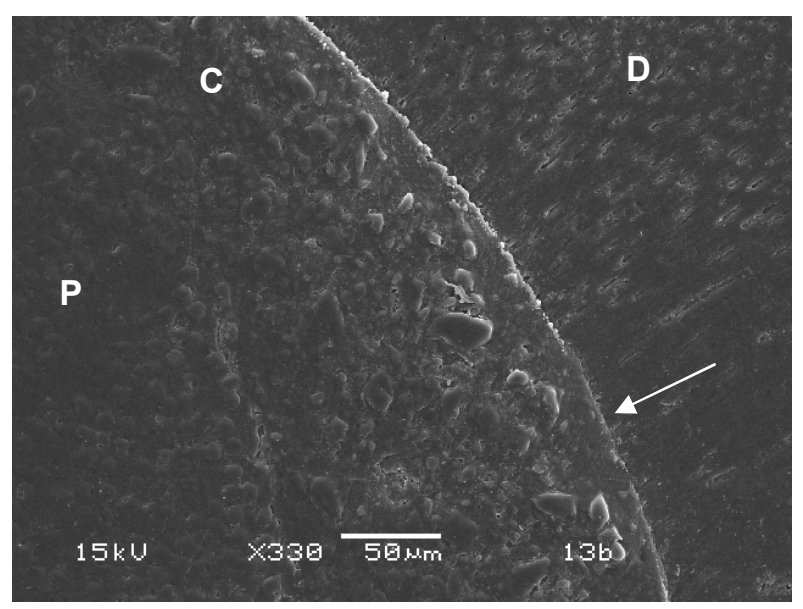

Figura 25 - Fotomicrografia em MEV de espécime do cimento C\&B Cement (Grupo L4). Presença de continuidade na interface cimento-dentina da região cervical da raiz, apontada pela seta branca. P: pino; C: cimento; D: dentina.

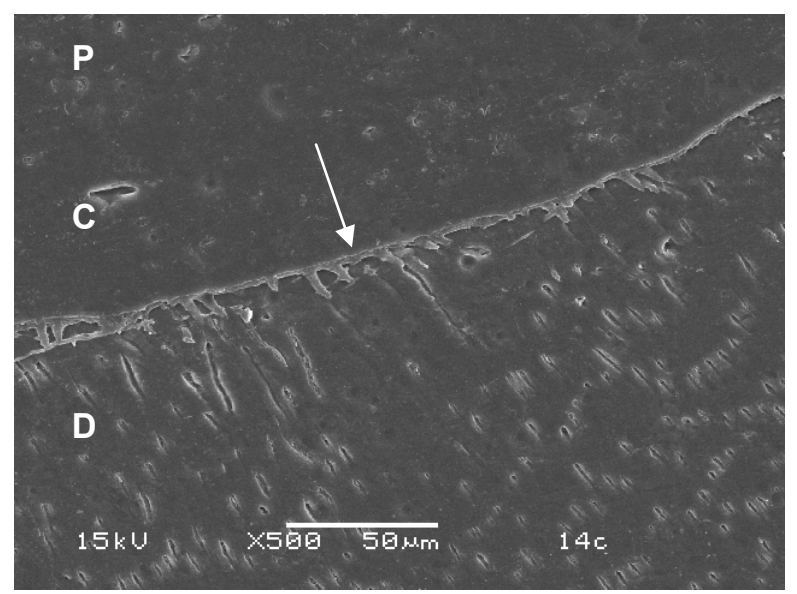

Figura 27 - Fotomicrografia em MEV de espécime do cimento C\&B Cement (Grupo L5). Presença de continuidade na interface cimento/dentina da região cervical da raiz, apontada pela seta branca. P: pino; C: cimento; D: dentina. 


\subsection{Resistência adesiva ao deslocamento do pino}

\subsubsection{Comparação entre as condições experimentais para cada cimento}

Considerando a resistência adesiva, os resultados revelaram que essa propriedade foi significantemente afetada pela espessura dos cimentos resinosos testados, o que levou à rejeição da segunda hipótese $(p<0,05)$.

Os valores médios de resistência adesiva ao deslocamento do pino ( $\mathrm{MPa}$ ), encontrados para os dois cimentos resinosos nas três condições experimentais avaliadas no estudo estão apresentados nas Tabelas 8 e 9, e estão representados nos gráficos box plot (Gráficos 6 e 7). A resistência adesiva diminuiu do grupo controle em direção ao grupo L5 (4,68 \pm 2,18 MPa) no cimento resinoso Duolink, enquanto o inverso ocorreu no cimento resinoso C\&B Cement. Considerando a resistência adesiva e as regiões radiculares novamente agrupadas em cada cimento e condição experimental, foi revelado que a retenção do pino reforçado por fibra foi significantemente afetada pela espessura do cimento em ambos os agentes cimentantes investigados. Duolink apresentou significantemente mais retenção no grupo controle $(11,33 \pm$ 4,66 MPa) do que em L5 (4,68 $\pm 2,18 \mathrm{MPa}, p=0,03)$, mas não em comparação a L4 $(6,77 \pm 3,74 \mathrm{MPa}, p=0,17)$. Inversamente, a maior resistência adesiva para C\&B Cement foi encontrada no grupo experimental L5 $(10,67 \pm 4,59 \mathrm{MPa})$, a qual não foi significantemente diferente de L4 (7,25 $\pm 2,75$ MPa, $p=0,26)$, mas foi significantemente superior ao grupo controle $(4,01 \pm 0,7$, $p=0,01)$. Não foram observadas diferenças significantes entre os grupos experimentais L4 e L5 para ambos os cimentos resinosos Duolink $(p=0,65)$ e C\&B Cement $(p=0,24)$. 
Tabela 8 - Comparação da resistência adesiva encontrada para Duolink nas diferentes condições experimentais (MPa).

\begin{tabular}{c|l|c}
\hline Condição experimental & Média $(d p)$ & $N^{0}$ de espécimes \\
\hline L3 (controle) & $11,32(4,66)$ & 5 \\
\hline L4 & $6,78(3,75)$ & 5 \\
\hline L5 & $4,68(2,19)$ & 5 \\
\hline
\end{tabular}

Probabilidade $=0,035967 ; p<0,05$.

Diferença significante na comparação entre as condições experimentais L3 X L5.

Tabela 9 - Comparação da resistência adesiva encontrada para C\&B Cement nas diferentes condições experimentais (MPa).

\begin{tabular}{c|c|c}
\hline Condição experimental & Média $(d p)$ & $N^{\circ}$ de espécimes \\
\hline L3 (controle) & $4,01(0,76)$ & 5 \\
\hline L4 & $7,25(2,75)$ & 5 \\
\hline L5 & $10,67(4,59)$ & 5 \\
\hline
\end{tabular}

Probabilidade $=0,14386 ; p>0,05$.

Diferença significante na comparação entre as condições experimentais L3 X L5.

Duolink

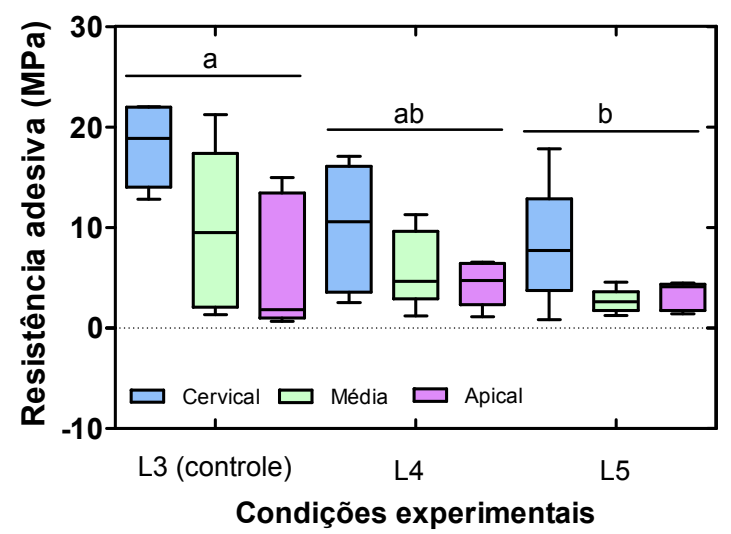

Gráfico 6 - Box plot da resistência adesiva das regiões radiculares cervical, média e apical por condição experimental para o cimento Duolink (\%). Letras minúsculas se referem às diferentes condições experimentais quando todas as regiões radiculares foram agrupadas. Letras superescritas diferentes indicam diferenças significantes.

\section{C\&B Cement}

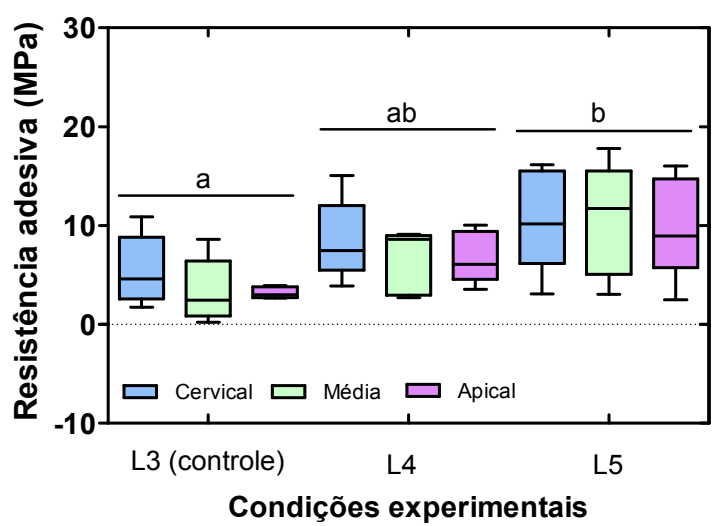

Gráfico 7 - Box plot da resistência adesiva das regiões radiculares cervical, média e apical por condição experimental para o cimento C\&B Cement (\%). Letras minúsculas se referem às diferentes condições experimentais quando todas as regiões radiculares foram agrupadas. Letras superescritas diferentes indicam diferenças significantes. 


\subsubsection{Comparação entre os cimentos para cada condição experimental}

Os valores médios da resistência adesiva $(\mathrm{MPa})$ encontrada para os dois cimentos resinosos em cada condição experimental avaliada no estudo estão apresentados nas Tabelas 10 a 12, e estão representados nos gráficos box plot (Gráficos 8 a 10). Novamente considerando todas as regiões radiculares agrupadas, Duolink e C\&B Cement diferiram significantemente entre si no grupo controle $(p=0,008)$ e em L5 $(p=0,03)$, mas não em L4 $(p=0,82)$. O cimento resinoso Duolink apresentou maior retenção no grupo controle, enquanto o cimento resinoso C\&B Cement foi significantemente mais retentivo no grupo L5.

Tabela 10 - Comparação da resistência adesiva entre os cimentos no grupo controle (MPa).

\begin{tabular}{c|c|c}
\hline Cimento & Média $(d p)$ & $N^{\circ}$ de espécimes \\
\hline Duolink & $11,32(4,66)^{\star}$ & 5 \\
\hline C\&B Cement & $4,01(0,76)^{\star}$ & 5 \\
\hline
\end{tabular}

Probabilidade $=0,00857 ; p>0,05$.

* Diferença significante na comparação entre os cimentos resinosos.

Tabela 11 - Comparação da resistência adesiva entre os cimentos no grupo L4 (MPa).

\begin{tabular}{c|c|c}
\hline Cimento & Média $(d p)$ & $N^{0}$ de espécimes \\
\hline Duolink & $6,78(3,74)$ & 5 \\
\hline C\&B Cement & $7,25(2,75)$ & 5 \\
\hline
\end{tabular}

Probabilidade $=0,825435$ (não significante); $p>0,05$.

Tabela 12 - Comparação da resistência adesiva entre os cimentos no grupo L5 (MPa).

\begin{tabular}{c|c|c}
\hline Cimento & Média $(d p)$ & $N^{\circ}$ de espécimes \\
\hline Duolink & $4,68(2,19)^{*}$ & 5 \\
\hline C\&B Cement & $10,67(4,59)^{*}$ & 5 \\
\hline
\end{tabular}

Probabilidade $=0,030168 p>0,05$.

* Diferença significante na comparação entre os cimentos resinosos. 
L3 (grupo controle)

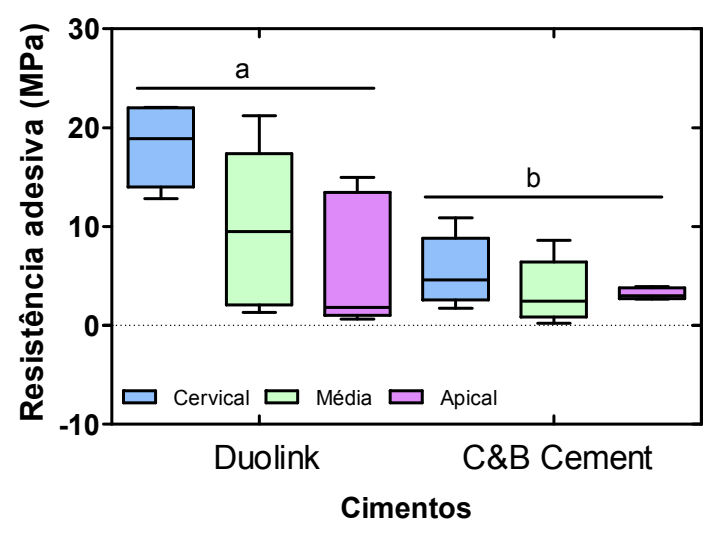

Gráfico 8 - Box plot da resistência adesiva das regiões radiculares cervical, média e apical por cimentos para o grupo controle (MPa). Letras minúsculas se referem aos diferentes cimentos quando todas as regiões radiculares foram agrupadas. Letras superescritas diferentes indicam diferenças significantes.
L4

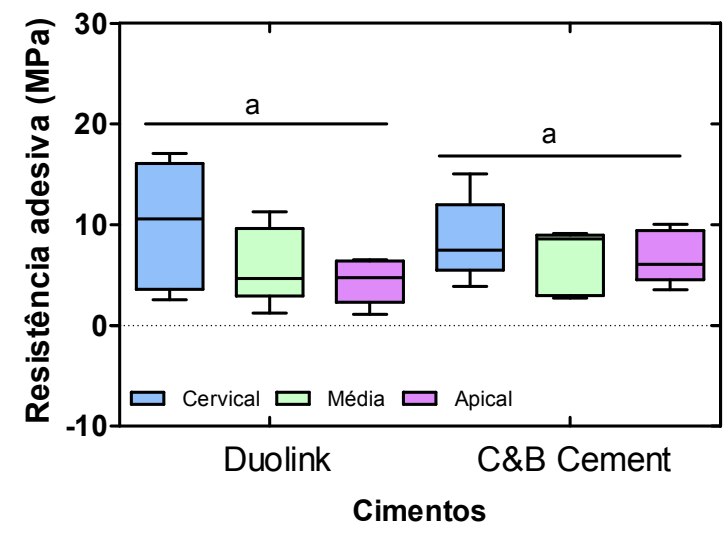

Gráfico 9 - Box plot da resistência adesiva das regiões radiculares cervical, média e apical por cimentos para o grupo L4 (MPa). Letras minúsculas se referem aos diferentes cimentos quando todas as regiões radiculares foram agrupadas. Letras superescritas diferentes indicam diferenças significantes.

L5

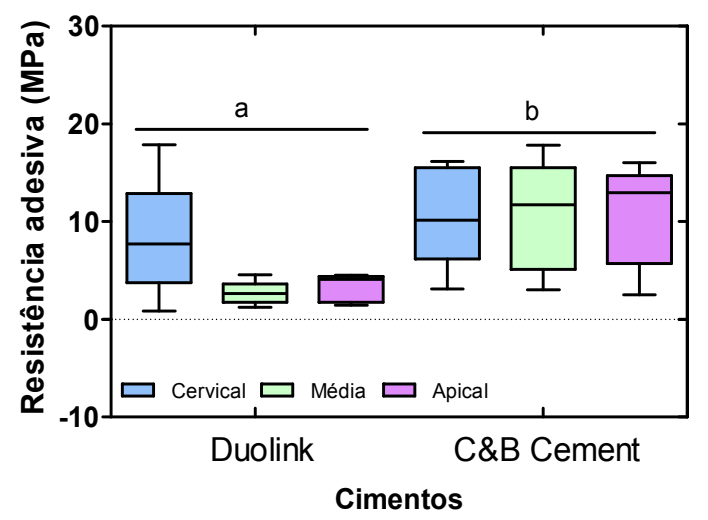

Gráfico 10 - Box plot da resistência adesiva das regiões radiculares cervical, média e apical por cimentos para o grupo L5 (MPa). Letras minúsculas se referem aos diferentes cimentos quando todas as regiões radiculares foram agrupadas. Letras superescritas diferentes indicam diferenças significantes. 


\subsection{Associação entre a espessura do cimento e a integridade adesiva}

O coeficiente de Pearson revelou uma correlação negativa significante entre os valores de espessura do cimento e de integridade adesiva obtidos para o cimento resinoso Duolink ( $r=-0,5901 ; p=0,021)$, de modo que o aumento na espessura desse cimento diminuiu significantemente a integridade da interface cimento-dentina observada em MEV (Gráfico 11). Diferentemente, não foi encontrada correlação significante entre a espessura do cimento e a integridade adesiva registrada para o cimento resinoso C\&B Cement $(r=0,153 ; p=0,586)$ (Gráfico 12). Isso sugeriu que o aumento da espessura desse cimento não diminuiu significantemente a integridade adesiva da interface cimento-dentina investigada.

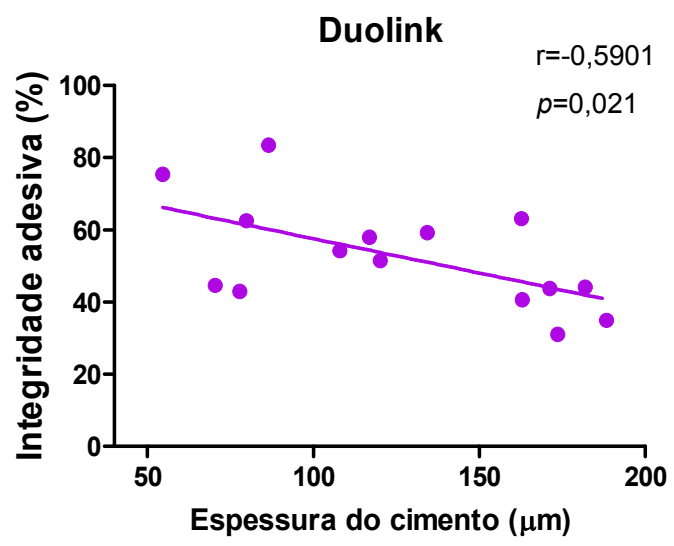

Gráfico 11 - Análise de regressão linear entre os valores de espessura do cimento $e$ de integridade adesiva obtidos para Duolink.

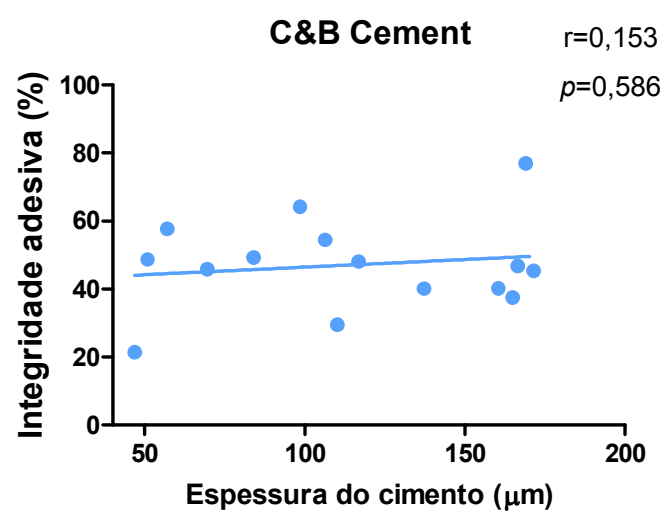

Gráfico 12 - Análise de regressão linear entre os valores de espessura do cimento $e$ de integridade adesiva obtidos para C\&B Cement. 


\subsection{Associação entre a espessura do cimento e a resistência adesiva}

Uma correlação negativa significante foi revelada pelo coeficiente de Pearson entre a espessura do cimento e a resistência adesiva obtida para o cimento resinoso Duolink ( $r=-0,5387 ; p=0,038$ ), sugerindo que o aumento na espessura desse cimento diminuiu significantemente a resistência adesiva ao deslocamento do pino avaliada (Gráfico 13). O cimento resinoso C\&B Cement, por sua vez, apresentou uma correlação positiva significante entre a espessura do cimento e a resistência adesiva registrada $(r=0,6576 ; p=0,008)$, indicando que o aumento na espessura desse cimento aumentou significantemente a resistência adesiva ao deslocamento do pino obtida nesse estudo (Gráfico 14).

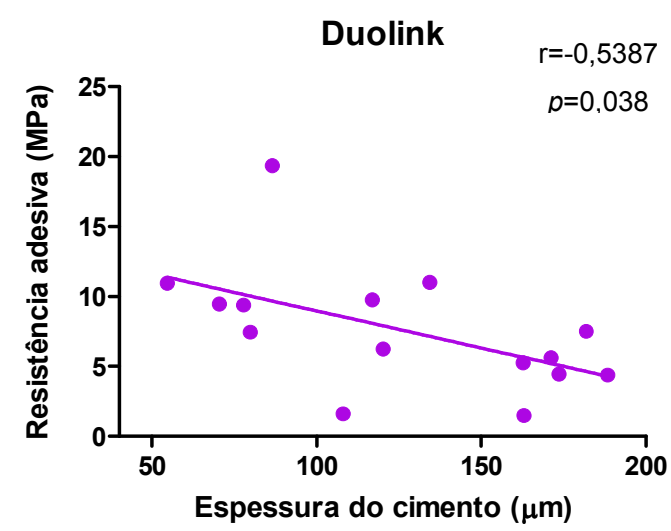

Gráfico 13 - Análise de regressão linear entre os valores de espessura do cimento e de resistência adesiva obtidos para Duolink.

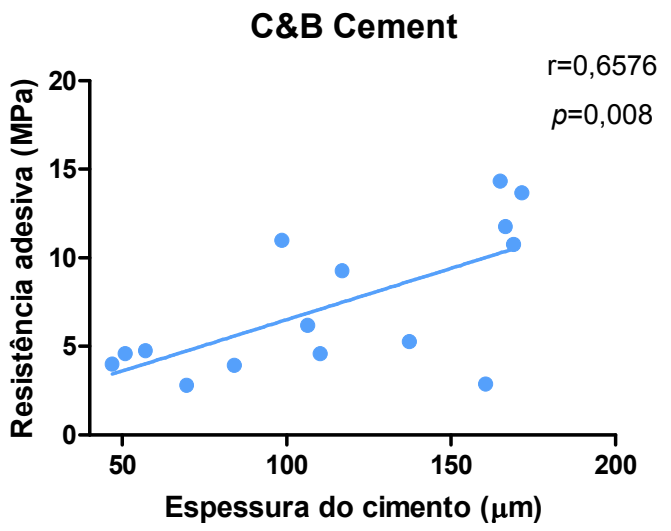

Gráfico 14 - Análise de regressão linear entre os valores de espessura do cimento e de resistência adesiva obtidos para C\&B Cement. 


\subsection{Associação entre a integridade adesiva e a resistência adesiva}

A resistência adesiva correlacionou diretamente com a integridade adesiva no cimento resinoso Duolink $(r=0,6855 ; p=0,005)$ (Gráfico 15). Isso sugeriu que o aumento na integridade adesiva desse cimento resinoso aumentou significantemente a resistência adesiva ao deslocamento do pino. No entanto, a resistência adesiva não correlacionou significantemente com a integridade adesiva no cimento resinoso C\&B Cement $(r=0,2969 ; p=0,283)$, sugerindo que a integridade adesiva não influenciou a resistência adesiva obtida (Gráfico 16).

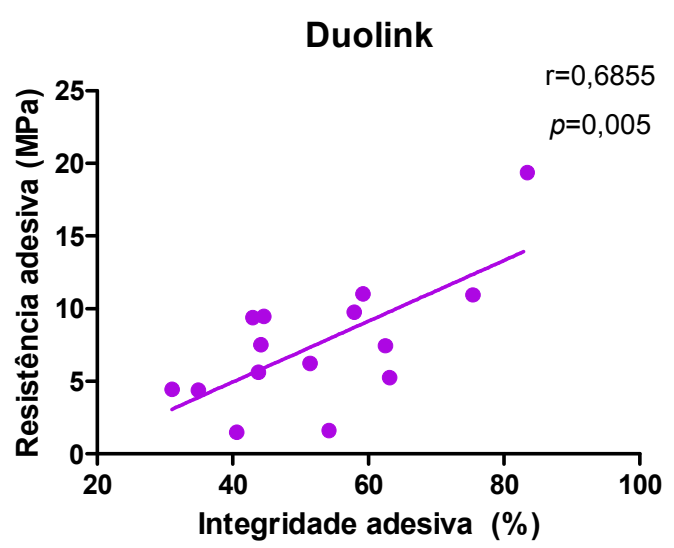

Gráfico 15 - Análise de regressão linear entre os valores de resistência adesiva e de integridade adesiva obtidos para Duolink.

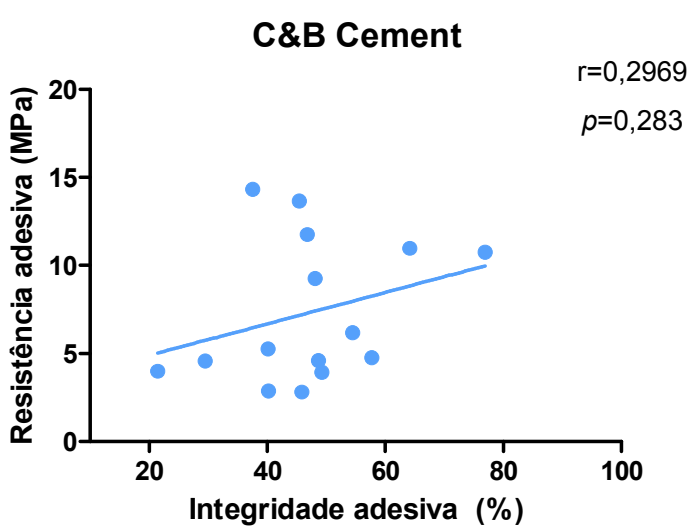

Gráfico 16 - Análise de regressão linear entre os valores de resistência adesiva e de integridade adesiva obtidos para C\&B Cement. 

6 DISCUSSÃO 



\section{DISCUSSÃO}

Neste estudo, a integridade adesiva foi avaliada em MEV, por meio de réplicas em resina epóxica, a partir do cálculo da percentagem de continuidade presente ao longo da interface entre a dentina condicionada e o cimento resinoso em relação ao comprimento total da interface adesiva cimento-dentina quando pinos reforçados por fibra foram cimentados aos condutos radiculares com camadas de cimento resinoso dual e autopolimerizável de espessuras variadas. Adicionalmente, a resistência adesiva ao deslocamento do pino foi registrada nas seções radiculares originais, permitindo que a integridade adesiva dos sistemas de cimentação adesiva pudesse ser correlacionada com a retenção do pino intra-radicular de acordo com a espessura da camada de cimento resinoso testada. Desse modo, foi possível analisar estatisticamente os dados obtidos nos dois testes realizados. Essa avaliação foi realizada devido ao fato de que a integridade adesiva da interface cimento-dentina poderia ser influenciada pela espessura da camada de cimento resinoso e contribuir para o processo de união mecânica à dentina condicionada e, conseqüentemente, aumentar a retenção dos pinos reforçados por fibra.

A avaliação da eficácia da cimentação adesiva dos pinos reforçados por fibra pode ser realizada através da análise em MEV da uniformidade da zona de interdifusão resina-dentina, prolongamentos resinosos e ramificações laterais de adesivo ou pelo registro da presença de bolhas/espaços/fendas no interior do material cimentante ou na interface entre a parede do conduto radicular, o cimento resinoso e o pino (FERRARI et al., 2001; GRANDINI et al., 2004). Recentemente, o sistema de filtração de fluidos foi considerado a técnica mais adequada para a avaliação da microinfiltração da cimentação adesiva dos pinos reforçados por fibra, devido aos dados volumétricos quantitativos coletados (ZICARI et al., 2008). Contudo, a análise em MEV provê uma observação em alta resolução das condições de adesão e permite que as características morfológicas da interface adesiva possam ser analisadas qualitativa e quantitativamente, sendo essa última preferível por ser reprodutível (GRANDINI et al., 2005a). Por essa razão, o presente estudo empregou uma análise em MEV quantitativa proposta recentemente (BONFANTE et al., 2008) para a avaliação da percentagem da continuidade presente na interface adesiva cimento-dentina. Adicionalmente, a metodologia não destrutiva apresentada 
por essa técnica permitiu que cada seção radicular fosse submetida ao teste de retenção do pino imediatamente após a confecção das réplicas para análise em MEV.

A resistência adesiva pode ser determinada através de várias técnicas, embora se acredite que o teste push-out ofereça melhor estimativa da adesão real do que o teste convencional de resistência adesiva ao cisalhamento (ZICARI et al., 2008). O teste push-out permite que a falha ocorra paralela à interface pino-cimentodentina, similarmente à condição clínica (PERDIGAO, GERALDELI e LEE, 2004). O teste de micro-tração também tem sido aplicado à dentina radicular, mas apesar disso, foi sugerido que o teste push-out é mais confiável devido à ausência de falhas prematuras e variabilidade na distribuição dos dados. A propensão às falhas adesivas prematuras pode ser causada por fendas pré-existentes e/ou pela ocorrência de estresses gerados durante o preparo dos espécimes para o teste de micro-tração (GORACCl et al., 2004). Desse modo, a análise em MEV e o teste push-out foram os métodos selecionados para avaliar, respectivamente, a integridade da interface adesiva cimento-dentina e a resistência adesiva ao deslocamento do pino reforçado por fibra neste estudo.

A causa de falha clínica mais comum dos dentes tratados endodonticamente restaurados com pinos reforçados por fibra é o descolamento do complexo pinocimento-restauração (FREDRIKSSON et al., 1998; FERRARI, VICHI e GARCIAGODOY, 2000; FERRARI et al., 2000b; HEDLUND, JOHANSSON e SJOGREN, 2003; MONTICELLI et al., 2003; GRANDINI et al., 2005b; NAUMANN, BLANKENSTEIN e DIETRICH, 2005). Isso pode ser explicado parcialmente pelo fato da área crítica do sistema restaurador localizar-se na interface entre a dentina e o cimento, para a qual os mais altos valores de tensão têm sido registrados (PEGORETTI et al., 2002). Adicionalmente, vários aspectos do tratamento, tais como o modo de polimerização dos cimentos resinosos (FERRARI et al., 2001; AKGUNGOR e AKKAYAN, 2006), a dificuldade de acesso da luz foto-polimerizadora em polimerizar os materiais adesivos foto ou duplamente-ativados localizados na porção mais profunda do conduto radicular (MALLMANN et al., 2005; MALLMANN et al., 2007), a incompatibilidade química entre os sistemas adesivos simplificados e os cimentos resinosos de polimerização química ou dual (TAY et al., 2003a; TAY et al., 2003b; VALANDRO et al., 2005), a forma geométrica desfavorável ao alívio da tensão de contração de polimerização (elevado fator-C) (BOUILLAGUET et al., 2003; 
GORACCl et al., 2005a; TAY et al., 2005) e o baixo potencial para hibridização apresentado pelo substrato dentinário radicular (MANNOCCl et al., 1999; MONTICELLI et al., 2003) podem influenciar negativamente as propriedades retentivas dos pinos reforçados por fibra. A retenção e a morfologia de falha dos pinos pré-fabricados também são influenciadas pelo material e pela forma do pino (SAHAFI et al., 2004). Diferentes tratamentos de superfície têm sido recomendados para aumentar a retenção dos pinos reforçados por fibra (AKSORNMUANG et al., 2004; MONTICELLI, GORACCI e FERRARI, 2004; GORACCl et al., 2005b; MONTICELLI et al., 2006a; MONTICELLI et al., 2006b). Vários estudos têm demonstrado que a adaptação do pino ao conduto radicular, ou mais especificamente, a espessura da camada do cimento também apresenta grande impacto na retenção dos pinos intra-radiculares (ASSIF e FERBER, 1982; CHAN, HARCOURT e BROCKHURST, 1993; HAGGE, WONG e LINDEMUTH, 2002; D'ARCANGELO et al., 2007). Conceitualmente, pinos intra-radiculares bem adaptados provêem uma camada de cimento mais fina e são mais retentivos do que pinos mal adaptados (CHEN et al., 2003). Porém, a introdução dos cimentos resinosos no mercado odontológico levou ao questionamento da necessidade de obtenção de uma adaptação íntima entre o pino e o conduto radicular, pois valores de retenção máximos foram observados para as camadas espessas de cimento resinoso em comparação às camadas finas (ASSIF e BLEICHER, 1986; HAGGE, WONG e LINDEMUTH, 2002; D'ARCANGELO et al., 2007). Portanto, existe a necessidade de se determinar a espessura da camada de cimento resinoso ideal para preservar o selamento da interface adesiva sem comprometer a retenção do pino reforçado por fibra.

Baseado nessas considerações teóricas e evidências clínicas, este estudo teve como objetivo determinar a espessura da camada de cimento ideal para melhorar a qualidade do procedimento de cimentação adesiva dos pinos reforçados por fibra. Como uma camada de cimento resinoso fina e uniformemente distribuída ao redor do pino tem sido considerada ideal para aumentar a retenção dos pinos reforçados por fibra (GRANDINI et al., 2005a), foi criada a hipótese de que quanto mais fina fosse a camada de cimento resinoso, maiores seriam a integridade da interface adesiva cimento-dentina e a retenção do pino intra-radicular. Considerando a percentagem de interface cimento-dentina contínua e as propriedades retentivas avaliadas nas diferentes espessuras para cada cimento resinoso, determinadas pela 
análise em MEV e pelo teste push-out, os resultados deste estudo revelaram que os valores de integridade adesiva e de resistência adesiva dos pinos reforçados por fibra (1 $\mathrm{mm}$ de diâmetro) cimentados com o cimento resinoso Duolink foram significantemente melhores nos condutos radiculares preparados com a broca calibrada de tamanho similar ao do pino (L3: $1 \mathrm{~mm}$ ) comparados aos condutos amplamente alargados (L5: 1,5 mm). Contudo, não foram observadas diferenças significantes para os valores de integridade adesiva e de resistência adesiva obtidos nos condutos radiculares medianamente alargados ( $L 4: 1,25 \mathrm{~mm}$ ) comparados aos demais condutos (L3-L5: 1-1,5 mm). Para o cimento resinoso C\&B Cement, não foi detectada diferença significante na integridade adesiva entre as diferentes espessuras de cimento avaliadas. No entanto, a resistência adesiva dos pinos reforçados por fibra foi significantemente maior nos condutos radiculares amplamente alargados (L5: 1,5 mm) comparativamente aos condutos preparados com a broca calibrada de tamanho similar ao tamanho do pino (L3: $1 \mathrm{~mm}$ ). Não foram observadas diferenças significantes entre os valores de resistência adesiva obtidos nos condutos radiculares medianamente alargados ( $L 4: 1,25 \mathrm{~mm}$ ) e demais condutos radiculares (L3-L5: 1-1,5 mm). As hipóteses nulas de que a integridade adesiva da interface cimento-dentina (1) e a resistência adesiva ao deslocamento do pino (2) não variam entre as diferentes espessuras, dentro de cada cimento, foram rejeitadas.

Ao se considerar, por sua vez, a integridade adesiva e a resistência adesiva avaliadas para ambos os cimentos resinosos em cada condição experimental, os resultados deste estudo indicaram que não houve diferença significante entre os valores de integridade adesiva obtidos para os dois tipos de cimentos resinosos nas três espessuras de cimento avaliadas. A hipótese nula de que o tipo de cimento resinoso não afeta a integridade adesiva da interface cimento-dentina (3), dentro de cada espessura, foi aceita. Os resultados obtidos no teste push-out, por sua vez, revelaram que os valores de resistência adesiva dos pinos reforçados por fibra cimentados com o cimento resinoso Duolink foram significantemente melhores do que aqueles obtidos com o cimento resinoso C\&B Cement nos condutos preparados com a broca calibrada de tamanho similar ao do pino ( $\mathrm{L} 3: 1 \mathrm{~mm}$ ). Inversamente, os pinos cimentados com o cimento resinoso C\&B Cement foram significantemente mais retentivos do que aqueles obtidos com o cimento resinoso Duolink nos condutos radiculares amplamente alargados (L5: 1,5 mm). Não foi encontrada 
diferença entre a retenção dos pinos reforçados por fibra cimentados com os dois tipos de cimentos avaliados nos condutos medianamente alargados (L4: 1,25 mm). A hipótese nula de que o tipo de cimento resinoso não afeta a resistência adesiva (4), dentro de cada espessura da camada de cimento, foi rejeitada.

Dentro das limitações intrínsecas aos testes laboratoriais, o achado mais notável deste estudo foi que, para o sistema de pinos e os cimentos resinosos selecionados, os valores de resistência adesiva foram dependentes da espessura e do modo de polimerização do cimento resinoso avaliado, sendo que o cimento resinoso Duolink foi mais retentivo quando a camada de cimento mais fina foi testada, ao passo que o cimento resinoso C\&B Cement apresentou maior retenção quando a camada de cimento mais espessa foi usada. Entretanto, quando a camada de cimento apresentou-se muito espessa no cimento resinoso Duolink ou muito fina no cimento resinoso C\&B Cement, a qualidade retentiva dos pinos reforçados por fibra diminuiu significantemente. O teste de correlação confirmou essa tendência, pois foram encontradas correlações significantes entre a espessura do cimento e a resistência adesiva, respectivamente, negativa para Duolink $(r=-0,5387 ; p=0,038)$ e positiva para C\&B Cement ( $r=0,6576 ; p=0,008)$.

A literatura tem recomendado que uma adaptação íntima seja obtida entre o pino e o conduto radicular para que a camada de cimento apresente a espessura ideal de $25 \mu \mathrm{m}$ ou 0,025 mm (CHAN, HARCOURT e BROCKHURST, 1993). Apesar disso, a mensuração da espessura da camada de cimento realizada nos grupos controles preparados com a broca de tamanho similar ao tamanho do pino (Duolink: 0,07 \pm 0,02 mm; C\&B Cement: 0,06 $\pm 0,02 \mathrm{~mm}$ ) permitiu aos autores concluírem que provavelmente as camadas de cimento obtidas clinicamente apresentam espessuras superiores àquela recomendada pela literatura. Desde que a presente investigação não encontrou diferença entre a resistência adesiva provida pelas camadas do cimento resinoso Duolink de 0,07 $\pm 0,02$ e 0,13 \pm 0,02 $\mathrm{mm}$ de espessura (Grupos L3-L4, respectivamente), foi sugerido que camadas excessivamente espessas $(0,2 \pm$ 0,02 mm - Grupo L5) podem afetar adversamente a retenção dos pinos reforçados por fibra para o sistema de cimentação adesiva investigado. A questão se a maior quantidade de material presente na camada mais espessa do cimento resinoso dual pode ter afetado adversamente a absorção da luz e, conseqüentemente, o processo de polimerização e a retenção do pino foi levantada no presente estudo. Embora tenha sido demonstrado que uma foto-polimerização adequada do cimento resinoso 
tenha sido obtida em um modelo experimental (ROBERTS et al., 2004), é possível que a transmissão da luz através do pino possa não ter sido suficiente para fotopolimerizar a camada mais espessa do cimento resinoso dual. A maior retenção encontrada para a camada fina desse cimento resinoso pode ter ocorrido provavelmente devido à adequada foto-polimerização obtida, a qual assegurou melhores propriedades mecânicas ao material. Outra possível explicação para esses achados consiste no fato que camadas excessivamente espessas de cimento resinoso, especialmente na região cervical, também têm sido associadas à maior probabilidade para a formação de bolhas e predisposição ao descolamento do pino reforçado por fibra (GRANDINI et al., 2005a; D'ARCANGELO et al., 2007). Infelizmente, poucos estudos avaliaram o efeito da espessura do cimento resinoso dual na retenção dos pinos reforçados por fibra. Perez et al (PEREZ et al., 2006) não observaram diferença significante na resistência adesiva ao deslocamento dos pinos reforcados por fibra cimentados com camadas fina e grossa de cimento resinoso dual $(0,09$ e 0,32 $\mathrm{mm}$, respectivamente). Assim, o problema da transmissão de luz através da camada espessa dos cimentos resinosos de polimerização dual ainda precisa ser investigado em estudos adicionais.

Os resultados relativos à baixa retenção dos pinos reforçados por fibra reportados para a camada mais espessa do cimento resinoso Duolink talvez pudessem ter sido melhores caso técnicas de cimentação que favorecessem o grau de conversão desse cimento resinoso tivessem sido empregadas. Os principais meios recomendados atualmente pela literatura para aumentar o grau de conversão dos cimentos resinosos dual, empregados na cimentação adesiva dos pinos reforçados por fibra, envolvem o uso dos pinos translúcidos (LE BELL et al., 2003; FARIA E SILVA et al., 2007) e de variantes na técnica de foto-polimerização, tais como o procedimento de retardo na exposição à luz foto-polimerizadora (MORAES et al., 2008) e o aumento no tempo de exposição, distribuição do espectro e intensidade da luz (SWARTZ, PHILLIPS e RHODES, 1983; YEARN, 1985). Quanto mais intensa for a fonte de luz e o tempo de exposição à energia luminosa, mais fótons estarão disponíveis para absorção pelos foto-iniciadores (canforoquinonas), os quais poderão ser excitados para formar mais radicais livres, iniciando e propagando o processo de polimerização (ROBERTS et al., 2004). Isso significa que esses meios auxiliares de polimerização poderiam ser usados para compensar a 
potencial gradação da polimerização ocorrida em função do aumento da profundidade e da espessura da camada do cimento resinoso dual.

Segundo o fabricante, o sistema de pinos reforçados por fibra empregado neste estudo (Fibrekor, Jeneric Pentron) apresenta a propriedade de transmissão de luz ao longo do conduto radicular devido à presença de fibras de vidro longitudinais imersas na matriz de resina composta. Roberts et al. (2004) afirmaram que o pino translúcido aumentou significantemente a dureza da resina composta fotopolimerizável à distância de $1 \mathrm{~mm}$ adjacente ao pino em níveis mais profundos. Faria e Silva et al. (2007) demonstraram que em profundidades semelhantes àquelas encontradas na cimentação dos pinos reforçados por fibra (8 a $10 \mathrm{~mm}$ ), o grau de conversão do cimento resinoso dual testado no nível médio da raiz foi otimizado pelo uso dos pinos translúcidos, embora nenhuma diferença entre os pinos translúcidos e não translúcidos tenha sido detectada nos terços cervical e apical da raiz. Apesar das evidências científicas demonstradas, os baixos valores de retenção encontrados na camada de cimento mais espessa do cimento resinoso dual no presente estudo indicaram que a quantidade de luz que passou através do pino translúcido e atingiu a profundidade do conduto radicular pode não ter sido suficiente para polimerizar adequadamente a porção foto-ativada desse cimento resinoso, particularmente nas regiões mais periféricas ao pino no terço apical da raiz. A espessura de cimento aumentada pode ter atenuado a intensidade da luz nas regiões de maior profundidade, fazendo com que a quantidade de luz que atingiu o cimento resinoso possa não ter sido capaz de ativar a iniciação induzida pela luz da reação de polimerização. Desse modo, a polimerização do cimento resinoso na camada mais espessa pode ter sido comprometida devido à dependência primária do componente auto-polimerizável do sistema de polimerização dual, reduzindo as propriedades mecânicas do cimento resinoso e, subseqüentemente, a resistência adesiva dos pinos. Sigemori et al. (2005) demonstraram que o modo auto-polimerizável isolado não é capaz de prover valores de dureza adequados para o cimento resinoso dual. Ainda considerando o cimento resinoso Duolink, não houve diferença significante na resistência adesiva entre o grupo controle e o grupo experimental $L 4$, demonstrando que a luz oriunda do aparelho foto-polimerizador pôde ativar efetivamente o componente foto-polimerizável da reação de foto-polimerização para essas espessuras da camada de cimento. 
Outra técnica sugerida recentemente pela literatura para aumentar o grau de conversão dos cimentos resinosos de polimerização dual, ainda não foi comprovada cientificamente. $\mathrm{Na}$ verdade, uma investigação recente demonstrou que o procedimento de retardo na exposição à foto-polimerização por 5 min não influenciou significantemente o grau de conversão final do cimento resinoso de polimerização dual testado (MORAES et al., 2008). Portanto, pesquisas adicionais devem ser realizadas para validar cientificamente a eficácia da técnica de polimerização utilizando pinos translúcidos, retardo na exposição à foto-ativação e o aumento na intensidade da luz, espectro e tempo de exposição em dentes endodonticamente tratados restaurados com pinos reforçados por fibra cimentados com diferentes espessuras da camada de cimentos resinosos de polimerização dual.

Embora os autores tenham especulado que a íntima adaptação obtida entre o conduto radicular e o pino reforçado por fibra possa simplesmente não ter propiciado espaço adequado para o cimento resinoso C\&B Cement desenvolver a sua resistência máxima na camada de cimento fina (L3), foi sugerido que a retenção superior alcançada na camada mais espessa (L5) pode ter sido causada por vários fatores, tais como: o aumento da área superficial para adesão do cimento à dentina proporcionado pelo conduto radicular mais largo; as forças hidrodinâmicas estabelecidas durante a inserção do pino podem ter modificado a estrutura do cimento polimerizado na camada mais fina, alterando as propriedades adesivas (CHAN, HARCOURT e BROCKHURST, 1993); e o aumento da resistência coesiva proporcionado pela concentração das tensões na periferia da interface adesiva em camadas espessas do cimento resinoso autopolimerizável (ALSTER et al., 1995). Pesquisas clínicas reportaram que o deslocamento do complexo pino-cimentonúcleo ocorreu na presença de uma camada espessa do cimento resinoso autopolimerizável (FREDRIKSSON et al., 1998; FERRARI, VICHI e GARCIAGODOY, 2000; MALFERRARI, MONACO e SCOTTI, 2003); contudo, os ensaios laboratoriais têm demonstrado consistentemente uma maior retenção para as camadas espessas desses cimentos resinosos em comparação às camadas mais finas (CHAN, HARCOURT e BROCKHURST, 1993; HAGGE, WONG e LINDEMUTH, 2002). Esses achados corroboram com os resultados encontrados no presente estudo, uma vez que a camada de cimento mais espessa do cimento resinoso C\&B Cement (Grupo L5: 0,17 \pm 0,02 mm) apresentou retenção significantemente maior do que a camada de cimento mais fina (Grupo L3: 0,07 \pm 
0,02). Apesar disso, um estudo laboratorial recente (D'ARCANGELO et al., 2007) mostrou que quando a espessura do cimento resinoso autopolimerizável aumentou muito $(0,25 \mathrm{~mm})$, a resistência ao deslocamento dos pinos reforçados por fibra diminuiu significantemente. Portanto, parece haver um limite para que a camada do cimento resinoso autopolimerizável possa ser aumentada seguramente. Desde que a presente investigação não encontrou diferença entre a resistência adesiva provida pelas camadas do cimento resinoso C\&B Cement de 0,13 $\pm 0,02$ e 0,17 $\pm 0,02 \mathrm{~mm}$ de espessura (Grupos L4-L5, respectivamente), foi sugerido que camadas excessivamente espessas podem afetar adversamente a retenção dos pinos reforçados por fibra para o sistema de cimentação adesiva investigado. Chen et al (CHEN et al., 2003) e Malferrari et al (MALFERRARI, MONACO e SCOTTI, 2003), por sua vez, afirmaram controversamente que a adaptação do pino é importante para maximizar a retenção dos pinos cimentados com cimentos resinosos autopolimerizáveis.

A retenção máxima alcançada pela camada mais fina do cimento resinoso de polimerização dual no presente estudo indicou que, para o sistema de cimentação adesiva testado, deve-ser tentar aumentar ao máximo a adaptação do pino reforçado por fibra à anatomia interna do conduto radicular. Portanto, como o alargamento do conduto radicular para permitir o posicionamento de um pino de maior diâmetro não é indicado, por enfraquecer o elemento dental em função da perda de estrutura dentária sadia, os novos desenhos desenvolvidos para os pinos reforçados por fibra, tais como os pinos duplo-cônicos e os pinos anatômicos têm sido aclamados como vantajosos em comparação aos pinos cilíndricos, duplocilíndricos e cônicos convencionais (BOUDRIAS, SAKKAL e PETROVA, 2001; GRANDINI, SAPIO e SIMONETTI, 2003). A retenção máxima provida pela camada mais espessa do cimento resinoso autopolimerizável, por sua vez, sugeriu que, para o sistema de cimentação adesiva avaliado, a instalação de um pino de diâmetro menor pode ser realizada seguramente no interior do conduto radicular, evitando o alargamento desnecessário do conduto radicular para permitir o posicionamento de um pino mais espesso. Pinos de diâmetro maior permitem uma adaptação íntima ao conduto radicular; porém enfraquecem os dentes, resultando em fraturas (GRANDINI et al., 2005a).

A baixa percentagem de continuidade (\%) encontrada na interface cimentodentina dos cimentos resinosos avaliados nas diferentes espessuras no presente 
estudo (Duolink-L3: 61,79 \pm 18,06; Duolink-L4: 57,19 \pm 4,55; Duolink-L5: 38,91 \pm 5,75; C\&B Cement-L3: 44,61 \pm 13,66; C\&B Cement-L4: 47,28 + 13,28; C\&B CementL5: $49,37 \pm 15,84$ ) levou ao questionamento se as falhas encontradas seriam resultado de artefatos criados durante o preparo dos espécimes para análise em MEV, tal como foi sugerido por Vichi et al (VICHI et al., 2002) e Ferrari et al (FERRARI et al., 2000a). Entretanto, estudos que avaliaram a microinfiltração da interface adesiva por microscopia confocal (MANNOCCl et al., 1999; MANNOCCl et al., 2003), que mantém os espécimes praticamente inalterados e elimina o risco de interpretações equivocadas, demonstraram falhas semelhantes. Além disso, como a maioria das fendas interfaciais concentra-se consistentemente no terço apical, a área menos acessível do canal, foi especulado que as fendas são verdadeiras, revelando um mecanismo de adesão de baixa qualidade (GRANDINI et al., 2004). A presença das fendas ou espaços evidenciados na interface adesiva pela análise em MEV sugeriu que a criação de um sistema em monobloco entre o pino, o cimento e a dentina é irreal (PIRANI et al., 2005; TAY et al., 2005).

A formação das fendas na interface adesiva cimento-dentina foi atribuída à tensão de contração de polimerização gerada no interior da camada de cimento resinoso, a qual pode ter apresentado magnitude suficiente para romper a união adesiva entre o cimento resinoso e a dentina radicular (ZICARI et al., 2008). O fluxo da resina é prejudicado pelo confinamento do material aderido ao dente na fase prégel e, como resultado, a contração se manifesta como tensão na interface adesiva. Existe uma relação entre a configuração da cavidade e o desenvolvimento da tensão. Se a resina pode contrair sem nenhuma restrição dentro da cavidade, nenhum problema é esperado. Quando a contração é prejudicada em três dimensões, a tensão será menos compensada pelo fluxo. Feilzer; De Gee; Davidson (1987) desenvolveram o conceito do Fator-C, a proporção entre a área de superfície do compósito livre e aderida da restauração dentária. Portanto, a tensão de contração no conduto radicular confinado pode exceder a resistência adesiva cimento-dentina, gerando o descolamento do cimento da dentina.

A contração de polimerização, que varia de 1 a $5 \%$ nos cimentos resinosos, resulta no desenvolvimento de tensões no interior do material (FERRACANE, 2005), as quais podem ser prejudiciais à integridade da interface adesiva, dependendo da sua magnitude. As tensões são transferidas para a interface cimento-dentina como forças de tração (CARVALHO et al., 1996), sendo tais forças proporcionalmente 
maiores quanto menor for o escoamento do cimento resinoso, tal como ocorre nas camadas delgadas de cimento resinoso confinadas entre o pino e as paredes dos condutos radiculares (ALSTER et al., 1997a). Outro fator adverso que pode ter predisposto a formação das fendas interfaciais refere-se ao uso do sistema adesivo convencional de dois passos (One-Step Plus, Bisco). Tal sistema adesivo, assim como os sistemas adesivos auto-condicionantes de passo único, comportam-se como membranas permeáveis após a polimerização, permitindo o fluxo de água da dentina para a camada de adesivo até mesmo nos dentes tratados endodonticamente (TAY et al., 2003a; TAY et al., 2003b; CHERSONI et al., 2005). A presença da água transudada na interface adesiva contribui para a degradação do material resinoso, levando ao questionamento da longevidade clínica das técnicas adesivas empregadas atualmente na cimentação adesiva dos pinos reforçados por fibra. Outro aspecto importante está relacionado com a incompatibilidade química entre os cimentos resinosos de polimerização química ou dual e os sistemas adesivos com pH baixo (TAY et al., 2003a; TAY et al., 2003b). A região superficial da camada adesiva, inibida pela ação do oxigênio, contém monômeros resinosos ácidos que podem ter neutralizado as aminas terciárias dos cimentos resinosos dual e autopolimerizável testados, levando ao surgimento das fendas ou espaços vazios, indicativos de inadequada polimerização dos materiais resinosos na interface adesivo-cimento. Adicionalmente, como esse material é foto-polimerizável, o difícil acesso à luz polimerizadora no interior do conduto radicular pode ter levado à polimerização inadequada do sistema adesivo testado (VALANDRO et al., 2005). Por fim, a presença de bolhas/espaços/fendas pode ter sido causada pelas variações anatômicas das raízes, que modificaram a quantidade de cimento resinoso e a sua distribuição no interior do conduto preparado (GRANDINI et al., 2004).

A percentagem de continuidade na interface adesiva cimento-dentina correlacionou-se com a espessura do cimento apenas para o cimento resinoso Duolink ( $r=-0,5901 ; p=0,021)$, sugerindo que o aumento na espessura desse cimento diminuiu significantemente a integridade adesiva. Embora modelos matemáticos (TAY et al., 2005) e estudos laboratoriais prévios (FEILZER, DE GEE e DAVIDSON, 1989; ALSTER et al., 1997a; ALSTER et al., 1997b) tenham evidenciado o aumento da tensão de polimerização de materiais resinosos a partir da redução da espessura da camada de cimento, o maior percentual de interface cimento-dentina contínua apresentado na camada fina desse cimento resinoso pode ser explicado pelo fato de 
que, como a contração de polimerização em camadas delgadas de material resinoso é pequena em senso absoluto (GRANDINI et al., 2005a; VALANDRO et al., 2005), possivelmente uma pequena deformação do substrato pode ter proporcionado alívio suficiente à tensão de polimerização e contribuído para preservar a integridade adesiva (DE JAGER, PALLAV e FEILZER, 2005). Em contraste, a integridade adesiva não correlacionou com a espessura do cimento registrada para o cimento resinoso C\&B Cement $(r=0,153 ; p=0,586)$, indicando que $o$ aumento da espessura desse cimento não afetou a integridade adesiva investigada. Isso ocorreu provavelmente devido à lenta polimerização associada ao cimento resinoso autopolimerizável, a qual pode ter conferido melhores condições ao alívio das tensões de polimerização em direção à área de superfície livre ou não aderida, contribuindo para a uniformidade dos resultados encontrados para esse cimento resinoso (FEILZER, DE GEE e DAVIDSON, 1993). Embora tenha sido hipotetizado que o maior tempo de escoamento proporcionado pela polimerização mais lenta dos cimentos resinosos autopolimerizáveis poderia reduzir a contração de polimerização, e conseqüentemente, gerar menos estresse e menor formação de fendas na interface adesiva cimento-dentina (CONDON e FERRACANE, 2000), os resultados deste estudo não mostraram nenhuma diferença significante no percentual de continuidade encontrado na interface adesiva dos cimentos resinosos dual e autopolimerizável nas diferentes espessuras da camada de cimento.

Como os resultados da integridade adesiva demonstraram a existência de fendas na interface cimento-dentina de ambos os cimentos resinosos e em todas as espessuras de cimento avaliadas, especulou-se que, neste estudo, a resistência adesiva obtida para esses dois sistemas de cimentação adesiva foi derivada predominantemente da resistência friccional ao invés da união efetiva à dentina intra-radicular (GORACCI et al., 2005a; PIRANI et al., 2005). Portanto, parece que o mecanismo de retenção micromecânica do sistema adesivo ao substrato dentário radicular, baseado na hibridização da estrutura desmineralizada e na formação de prolongamentos resinosos e ramificações laterais de adesivo (FERRARI e MANNOCCI, 2000) não contribuiu efetivamente para aumentar a retenção dos pinos reforçados por fibra no presente estudo. Tal suposição foi suportada pela discrepância entre os baixos valores revelados pelos testes de resistência adesiva à micro-tração, obtidos em condutos radiculares íntegros e os altos valores revelados pelos mesmos testes realizados em condutos radiculares seccionados (Bouillaguet, 
Troesch et al. 2003; Goracci, Tavares et al. 2004) ou, ainda, pelos testes push-out (BOUILLAGUET et al., 2003; GORACCl et al., 2004; GORACCl et al., 2005a). Os resultados do presente trabalho corroboraram com esses achados científicos, pois a menor percentagem de interface cimento-dentina contínua foi associada à redução da resistência adesiva no cimento resinoso Duolink $(r=0,6855, p=0,005)$. Um estudo prévio também associou a presença de fendas interfaciais com a redução da resistência adesiva push-out dos pinos reforçados por fibra (GORACCl et al., 2005c).

Apesar das inúmeras complicações associadas à cimentação adesiva intracanal, um elevado índice de sucesso (em torno de 95 a 99 \%) tem sido reportado por estudos clínicos prospectivos (MONTICELLI et al., 2003; GRANDINI et al., 2005b; NAUMANN, BLANKENSTEIN e DIETRICH, 2005) e retrospectivos (FREDRIKSSON et al., 1998; FERRARI, VICHI e GARCIA-GODOY, 2000; FERRARI et al., 2000b; HEDLUND, JOHANSSON e SJOGREN, 2003) para os pinos reforçados por fibra. A explicação para esses achados conflitantes parece estar relacionada com a presença de $2 \mathrm{~mm}$ de estrutura dentária coronária remanescente entre o término cervical do preparo e a união núcleo-dente ("efeito férula"), sendo esse fator destacado como o critério-chave para a obtenção do sucesso clínico na cimentação adesiva dos pinos reforçados por fibra. O entendimento científico dos conceitos relacionados à polimerização dos cimentos resinosos no interior dos condutos radiculares permitiu uma maior compreensão dos fenômenos determinantes do insucesso clínico da cimentação adesiva dos pinos reforçados por fibra.

A implicação clínica potencial para este estudo é que a retenção dos pinos reforçados por fibra através do uso de camadas de cimento resinoso dual e autopolimerizável de espessuras diferentes pode apresentar pequena relação com a capacidade real de adesão dos sistemas adesivos investigados e pode ser largamente influenciada pela fricção no interior dos condutos radiculares. Baseado nas informações coletadas para a realização deste estudo foi sugerido que, para os sistemas de cimentação adesiva e os pinos reforçados por fibra avaliados, é mais seguro e mais aconselhável usar uma camada fina de cimento resinoso dual ou uma camada espessa de cimento resinoso autopolimerizável para a cimentação dos pinos reforçados por fibra aos condutos radiculares. No entanto, as evidências científicas encontradas referentes à baixa continuidade observada na interface adesiva cimento-dentina levantam dúvidas sobre as alegadas vantagens do uso dos cimentos resinosos para a cimentação adesiva intra-canal dos pinos reforçados por 
fibra e levam ao questionamento sobre a vantajosa aplicação desses produtos em longo prazo. Estudos clínicos controlados devem ser realizados para validar o uso dos pinos reforçados por fibra associado às diferentes espessuras de cimento resinoso como uma abordagem racional para a reabilitação dos dentes tratados endodonticamente.

Novas pesquisas, utilizando uma metodologia semelhante à utilizada nesta pesquisa, devem ser realizadas com os materiais novos lançados recentemente no mercado odontológico, tais como os cimentos resinosos auto-adesivos. Os fabricantes têm divulgado esses materiais como vantajosos em relação aos cimentos resinosos convencionais, devido à técnica simplificada (devido ao fato de esses materiais não requererem a realização das etapas de condicionamento ácido e aplicação do primer/adesivo), e à superior capacidade de selamento adesivo (reduzindo drasticamente a formação de fendas ou espaços vazios na interface adesiva). Além disso, estudos clínicos futuros sobre a aplicação desses cimentos auto-adesivos em pacientes com dentes tratados endodonticamente devem ser direcionados para o desenvolvimento de protocolos terapêuticos padronizados e bem definidos. 
7 CONCLUSÕES 



\section{CONCLUSÕES}

Dentro das limitações deste estudo, concluiu-se que:

1. As hipóteses nulas 1 e 2 foram rejeitadas, pois foi demonstrado que a espessura do cimento resinoso influenciou significantemente a integridade adesiva da interface cimento-dentina e a resistência adesiva ao deslocamento do pino, dentro de cada cimento;

2. A hipótese nula 3 foi confirmada, uma vez que o modo de polimerização do cimento resinoso não influenciou significantemente a integridade adesiva da interface cimento-dentina testada, para cada espessura;

3. A hipótese nula 4 foi confirmada, pois foi demonstrado que o modo de polimerização do cimento resinoso influenciou significantemente a resistência adesiva ao deslocamento do pino, para cada espessura testada. 

REFERÊNCIAS 



\section{REFERÊNCIAS}

Akgungor G, Akkayan B. Influence of dentin bonding agents and polymerization modes on the bond strength between translucent fiber posts and three dentin regions within a post space. J Prosthet Dent. 2006 May;95(5):368-78.

Aksornmuang J, Foxton RM, Nakajima M, Tagami J. Microtensile bond strength of a dual-cure resin core material to glass and quartz fibre posts. J Dent. 2004 Aug;32(6):443-50.

Al-Tayyan MH, Watts DC, Kurer HG, Qualtrough AJ. Is a "flexible" glass fiber-bundle dowel system as retentive as a "rigid" quartz fiber dowel system? J Prosthodont. 2008 Oct;17(7):532-7.

Alster D, Feilzer AJ, De Gee AJ, Davidson CL. Tensile strength of thin resin composite layers as a function of layer thickness. J Dent Res. 1995 Nov;74(11):17458.

Alster D, Feilzer AJ, de Gee AJ, Davidson CL. Polymerization contraction stress in thin resin composite layers as a function of layer thickness. Dent Mater. 1997a May;13(3):146-50.

Alster D, Venhoven BA, Feilzer AJ, Davidson CL. Influence of compliance of the substrate materials on polymerization contraction stress in thin resin composite layers. Biomaterials. 1997b Feb;18(4):337-41.

Asmussen E, Peutzfeldt A, Heitmann T. Stiffness, elastic limit, and strength of newer types of endodontic posts. J Dent. 1999 May;27(4):275-8.

Assif D, Bleicher S. Retention of serrated endodontic posts with a composite luting agent: effect of cement thickness. J Prosthet Dent. 1986 Dec;56(6):689-91.

Assif D, Ferber A. Retention of dowels using a composite resin as a cementing medium. J Prosthet Dent. 1982 Sep;48(3):292-6.

Bachicha WS, DiFiore PM, Miller DA, Lautenschlager EP, Pashley DH. Microleakage of endodontically treated teeth restored with posts. J Endod. 1998 Nov;24(11):703-8. 
Bateman G, Ricketts DN, Saunders WP. Fibre-based post systems: a review. $\mathrm{Br}$ Dent J. 2003 Jul 12;195(1):43-8; discussion 37.

Bell AM, Lassila LV, Kangasniemi I, Vallittu PK. Bonding of fibre-reinforced composite post to root canal dentin. J Dent. 2005 Aug;33(7):533-9.

Boff LL, Grossi ML, Prates LH, Burnett LH, Jr., Shinkai RS. Effect of the activation mode of post adhesive cementation on push-out bond strength to root canal dentin. Quintessence Int. 2007 May;38(5):387-94.

Bonfante EA, Pegoraro LF, de Goes MF, Carvalho RM. SEM observation of the bond integrity of fiber-reinforced composite posts cemented into root canals. Dent Mater. 2008 Apr;24(4):483-91.

Boschian Pest L, Cavalli G, Bertani P, Gagliani M. Adhesive post-endodontic restorations with fiber posts: push-out tests and SEM observations. Dent Mater. 2002 Dec;18(8):596-602.

Boudrias P, Sakkal S, Petrova Y. Anatomical post design meets quartz fiber technology: rationale and case report. Compend Contin Educ Dent. 2001 Apr;22(4):337-40, 42, 44 passim; quiz 50.

Bouillaguet S, Troesch S, Wataha JC, Krejci I, Meyer JM, Pashley DH. Microtensile bond strength between adhesive cements and root canal dentin. Dent Mater. 2003 May;19(3):199-205.

Carvalho RM, Pereira JC, Yoshiyama M, Pashley DH. A review of polymerization contraction: the influence of stress development versus stress relief. Oper Dent. 1996 Jan-Feb;21(1):17-24.

Chan FW, Harcourt JK, Brockhurst PJ. The effect of post adaptation in the root canal on retention of posts cemented with various cements. Aust Dent J. 1993 Feb;38(1):39-45.

Chen DC, Lai YL, Chen HL, Lee SY. Effect of circumferential undercut placement in the root canal wall on the retention of a tapered post in large and small root canals. $J$ Dent. 2003 May;31(4):247-52. 
Chersoni S, Acquaviva GL, Prati C, Ferrari M, Grandini S, Pashley DH, et al. In vivo fluid movement through dentin adhesives in endodontically treated teeth. J Dent Res. 2005 Mar;84(3):223-7.

Cohen BI, Pagnillo MK, Newman I, Musikant BL, Deutsch AS. Retention of three endodontic posts cemented with five dental cements. J Prosthet Dent. 1998 May;79(5):520-5.

Condon JR, Ferracane JL. Assessing the effect of composite formulation on polymerization stress. J Am Dent Assoc. 2000 Apr;131(4):497-503.

D'Arcangelo C, Cinelli M, De Angelis F, D'Amario M. The effect of resin cement film thickness on the pullout strength of a fiber-reinforced post system. J Prosthet Dent. 2007 Sep;98(3):193-8.

Dauvillier BS, Feilzer AJ, De Gee AJ, Davidson CL. Visco-elastic parameters of dental restorative materials during setting. J Dent Res. 2000 Mar;79(3):818-23.

Davidson CL, de Gee AJ, Feilzer A. The competition between the composite-dentin bond strength and the polymerization contraction stress. J Dent Res. 1984 Dec;63(12):1396-9.

Davidson CL, Van Zeghbroeck L, Feilzer AJ. Destructive stresses in adhesive luting cements. J Dent Res. 1991 May;70(5):880-2.

De Jager N, Pallav P, Feilzer AJ. Finite element analysis model to simulate the behavior of luting cements during setting. Dent Mater. 2005 Nov;21(11):1025-32.

de Rijk WG. Removal of fiber posts from endodontically treated teeth. Am J Dent. 2000 May;13(Spec No):19B-21B.

Duret B, Reynaud M, Duret F. [A new concept of corono-radicular reconstruction, the Composipost (2)]. Chir Dent Fr. 1990 Dec 6;60(542):69-77.

Faria e Silva AL, Arias VG, Soares LE, Martin AA, Martins LR. Influence of fiber-post translucency on the degree of conversion of a dual-cured resin cement. $\mathrm{J}$ Endod. 2007 Mar;33(3):303-5. 
Feilzer AJ, De Gee AJ, Davidson CL. Setting stress in composite resin in relation to configuration of the restoration. J Dent Res. 1987 Nov;66(11):1636-9.

Feilzer AJ, De Gee AJ, Davidson CL. Increased wall-to-wall curing contraction in thin bonded resin layers. J Dent Res. 1989 Jan;68(1):48-50.

Feilzer AJ, de Gee AJ, Davidson CL. Setting stresses in composites for two different curing modes. Dent Mater. 1993 Jan;9(1):2-5.

Ferracane JL. Developing a more complete understanding of stresses produced in dental composites during polymerization. Dent Mater. 2005 Jan;21(1):36-42.

Ferrari M, Mannocci F. A 'one-bottle' adhesive system for bonding a fibre post into a root canal: an SEM evaluation of the post-resin interface. Int Endod J. 2000 Jul;33(4):397-400.

Ferrari M, Mannocci F, Vichi A, Cagidiaco MC, Mjor IA. Bonding to root canal: structural characteristics of the substrate. Am J Dent. 2000a Oct;13(5):255-60.

Ferrari M, Vichi A, Garcia-Godoy F. Clinical evaluation of fiber-reinforced epoxy resin posts and cast post and cores. Am J Dent. 2000 May;13(Spec No):15B-8B.

Ferrari M, Vichi A, Grandini S. Efficacy of different adhesive techniques on bonding to root canal walls: an SEM investigation. Dent Mater. 2001 Sep;17(5):422-9.

Ferrari M, Vichi A, Grandini S, Goracci C. Efficacy of a self-curing adhesive-resin cement system on luting glass-fiber posts into root canals: an SEM investigation. Int J Prosthodont. 2001 Nov-Dec;14(6):543-9.

Ferrari M, Vichi A, Mannocci F, Mason PN. Retrospective study of the clinical performance of fiber posts. Am J Dent. 2000b May;13(Spec No):9B-13B.

Fredriksson M, Astback J, Pamenius M, Arvidson K. A retrospective study of 236 patients with teeth restored by carbon fiber-reinforced epoxy resin posts. J Prosthet Dent. 1998 Aug;80(2):151-7.

Giachetti L, Scaminaci Russo D, Bertini F, Giuliani V. Translucent fiber post cementation using a light-curing adhesive/composite system: SEM analysis and pullout test. J Dent. 2004 Nov;32(8):629-34. 
Goracci C, Fabianelli A, Sadek FT, Papacchini F, Tay FR, Ferrari M. The contribution of friction to the dislocation resistance of bonded fiber posts. J Endod. 2005a Aug;31(8):608-12.

Goracci C, Raffaelli O, Monticelli F, Balleri B, Bertelli E, Ferrari M. The adhesion between prefabricated FRC posts and composite resin cores: microtensile bond strength with and without post-silanization. Dent Mater. 2005b May;21(5):437-44.

Goracci C, Sadek FT, Fabianelli A, Tay FR, Ferrari M. Evaluation of the adhesion of fiber posts to intraradicular dentin. Oper Dent. 2005c Sep-Oct;30(5):627-35.

Goracci C, Tavares AU, Fabianelli A, Monticelli F, Raffaelli O, Cardoso PC, et al. The adhesion between fiber posts and root canal walls: comparison between microtensile and push-out bond strength measurements. Eur J Oral Sci. 2004 Aug;112(4):353-61.

Grandini S, Goracci C, Monticelli F, Borracchini A, Ferrari M. SEM evaluation of the cement layer thickness after luting two different posts. J Adhes Dent. 2005a Autumn;7(3):235-40.

Grandini S, Goracci C, Tay FR, Grandini R, Ferrari M. Clinical evaluation of the use of fiber posts and direct resin restorations for endodontically treated teeth. Int J Prosthodont. 2005b Sep-Oct;18(5):399-404.

Grandini S, Sapio S, Goracci C, Monticelli F, Ferrari M. A one step procedure for luting glass fibre posts: an SEM evaluation. Int Endod J. 2004 Oct;37(10):679-86.

Grandini S, Sapio S, Simonetti M. Use of anatomic post and core for reconstructing an endodontically treated tooth: a case report. J Adhes Dent. 2003 Fall;5(3):243-7.

Hagge MS, Wong RD, Lindemuth JS. Effect of dowel space preparation and composite cement thickness on retention of a prefabricated dowel. J Prosthodont. 2002 Mar;11(1):19-24.

Hedlund SO, Johansson NG, Sjogren G. A retrospective study of pre-fabricated carbon fibre root canal posts. J Oral Rehabil. 2003 Oct;30(10):1036-40.

Kious AR, Roberts HW, Brackett WW. Film thicknesses of recently introduced luting cements. J Prosthet Dent. 2009 Mar;101(3):189-92. 
Le Bell AM, Tanner J, Lassila LV, Kangasniemi I, Vallittu PK. Depth of light-initiated polymerization of glass fiber-reinforced composite in a simulated root canal. Int $\mathrm{J}$ Prosthodont. 2003 Jul-Aug;16(4):403-8.

Malferrari S, Monaco C, Scotti R. Clinical evaluation of teeth restored with quartz fiber-reinforced epoxy resin posts. Int J Prosthodont. 2003 Jan-Feb;16(1):39-44.

Mallmann A, Jacques LB, Valandro LF, Mathias $P$, Muench A. Microtensile bond strength of light- and self-cured adhesive systems to intraradicular dentin using a translucent fiber post. Oper Dent. 2005 Jul-Aug;30(4):500-6.

Mallmann A, Jacques LB, Valandro LF, Muench A. Microtensile bond strength of photoactivated and autopolymerized adhesive systems to root dentin using translucent and opaque fiber-reinforced composite posts. J Prosthet Dent. 2007 Mar;97(3):165-72.

Mannocci F, Bertelli E, Watson TF, Ford TP. Resin-dentin interfaces of endodontically-treated restored teeth. Am J Dent. 2003 Feb;16(1):28-32.

Mannocci F, Innocenti M, Ferrari M, Watson TF. Confocal and scanning electron microscopic study of teeth restored with fiber posts, metal posts, and composite resins. J Endod. 1999 Dec;25(12):789-94.

Monticelli F, Goracci C, Ferrari M. Micromorphology of the fiber post-resin core unit: a scanning electron microscopy evaluation. Dent Mater. 2004 Feb;20(2):176-83.

Monticelli F, Grandini S, Goracci C, Ferrari M. Clinical behavior of translucent-fiber posts: a 2-year prospective study. Int J Prosthodont. 2003 Nov-Dec;16(6):593-6.

Monticelli F, Osorio R, Toledano M, Goracci C, Tay FR, Ferrari M. Improving the quality of the quartz fiber postcore bond using sodium ethoxide etching and combined silane/adhesive coupling. J Endod. 2006a May;32(5):447-51.

Monticelli F, Toledano M, Tay FR, Cury AH, Goracci C, Ferrari M. Post-surface conditioning improves interfacial adhesion in post/core restorations. Dent Mater. 2006b Jul;22(7):602-9. 
Moraes RR, Brandt WC, Naves LZ, Correr-Sobrinho L, Piva E. Light- and timedependent polymerization of dual-cured resin luting agent beneath ceramic. Acta Odontol Scand. 2008 Oct;66(5):257-61.

Naumann M, Blankenstein F, Dietrich T. Survival of glass fibre reinforced composite post restorations after 2 years-an observational clinical study. J Dent. 2005 Apr;33(4):305-12.

Pashley DH, Ciucchi B, Sano H, Horner JA. Permeability of dentin to adhesive agents. Quintessence Int. 1993 Sep;24(9):618-31.

Pegoretti A, Fambri L, Zappini G, Bianchetti M. Finite element analysis of a glass fibre reinforced composite endodontic post. Biomaterials. 2002 Jul;23(13):2667-82.

Perdigao J, Geraldeli S, Lee IK. Push-out bond strengths of tooth-colored posts bonded with different adhesive systems. Am J Dent. 2004 Dec;17(6):422-6.

Perez BE, Barbosa SH, Melo RM, Zamboni SC, Ozcan M, Valandro LF, et al. Does the thickness of the resin cement affect the bond strength of a fiber post to the root dentin? Int J Prosthodont. 2006 Nov-Dec;19(6):606-9.

Pilo R, Cardash HS, Levin E, Assif D. Effect of core stiffness on the in vitro fracture of crowned, endodontically treated teeth. J Prosthet Dent. 2002 Sep;88(3):302-6.

Pirani C, Chersoni S, Foschi F, Piana G, Loushine RJ, Tay FR, et al. Does hybridization of intraradicular dentin really improve fiber post retention in endodontically treated teeth? J Endod. 2005 Dec;31(12):891-4.

Radovic I, Monticelli F, Goracci C, Cury AH, Coniglio I, Vulicevic ZR, et al. The effect of sandblasting on adhesion of a dual-cured resin composite to methacrylic fiber posts: microtensile bond strength and SEM evaluation. J Dent. 2007 Jun;35(6):496502.

Reid LC, Kazemi RB, Meiers JC. Effect of fatigue testing on core integrity and post microleakage of teeth restored with different post systems. J Endod. 2003 Feb;29(2):125-31.

Roberts HW, Leonard DL, Vandewalle KS, Cohen ME, Charlton DG. The effect of a translucent post on resin composite depth of cure. Dent Mater. 2004 Sep;20(7):61722. 
Rosenstiel SF, Land MF, Crispin BJ. Dental luting agents: A review of the current literature. J Prosthet Dent. 1998 Sep;80(3):280-301.

Sahafi A, Peutzfeldt A, Asmussen E, Gotfredsen K. Retention and failure morphology of prefabricated posts. Int J Prosthodont. 2004 May-Jun;17(3):307-12.

Sigemori RM, Reis AF, Giannini M, Paulillo LA. Curing depth of a resin-modified glass ionomer and two resin-based luting agents. Oper Dent. 2005 MarApr;30(2):185-9.

Swartz ML, Phillips RW, Rhodes B. Visible light-activated resins--depth of cure. J Am Dent Assoc. 1983 May;106(5):634-7.

Tay FR, Loushine RJ, Lambrechts P, Weller RN, Pashley DH. Geometric factors affecting dentin bonding in root canals: a theoretical modeling approach. J Endod. 2005 Aug;31(8):584-9.

Tay FR, Pashley DH, Yiu CK, Sanares AM, Wei SH. Factors contributing to the incompatibility between simplified-step adhesives and chemically-cured or dual-cured composites. Part I. Single-step self-etching adhesive. J Adhes Dent. 2003a Spring;5(1):27-40.

Tay FR, Suh BI, Pashley DH, Prati C, Chuang SF, Li F. Factors contributing to the incompatibility between simplified-step adhesives and self-cured or dual-cured composites. Part II. Single-bottle, total-etch adhesive. J Adhes Dent. 2003b Summer;5(2):91-105.

Valandro LF, Filho OD, Valera MC, de Araujo MA. The effect of adhesive systems on the pullout strength of a fiberglass-reinforced composite post system in bovine teeth. J Adhes Dent. 2005 Winter;7(4):331-6.

Vichi A, Ferrari M, Davidson CL. Influence of ceramic and cement thickness on the masking of various types of opaque posts. J Prosthet Dent. 2000 Apr;83(4):412-7.

Vichi A, Grandini S, Davidson CL, Ferrari M. An SEM evaluation of several adhesive systems used for bonding fiber posts under clinical conditions. Dent Mater. 2002 Nov;18(7):495-502. 
Vichi A, Grandini S, Ferrari M. Comparison between two clinical procedures for bonding fiber posts into a root canal: a microscopic investigation. J Endod. 2002 May;28(5):355-60.

Yearn JA. Factors affecting cure of visible light activated composites. Int Dent J. 1985 Sep;35(3):218-25.

Zicari F, Couthino E, De Munck J, Poitevin A, Scotti R, Naert I, et al. Bonding effectiveness and sealing ability of fiber-post bonding. Dent Mater. 2008 Jul;24(7):967-77. 

APÊNDICES 

Apêndice A - Resultados para o grupo Duolink/L3 (controle). Valores individuais da espessura da camada de cimento $(\mu \mathrm{m})$, do perímetro total da interface adesiva cimento/dentina $(\mu \mathrm{m})$, da continuidade da interface adesiva $(\mu \mathrm{m}$ e \%) e da resistência adesiva ao deslocamento do pino (MPa).

\begin{tabular}{|c|c|c|c|c|c|c|}
\hline \multirow{2}{*}{\multicolumn{2}{|c|}{$\begin{array}{l}\text { Grupo } \\
\text { Duolink/L3 (controle) }\end{array}$}} & \multicolumn{5}{|c|}{ Ensaio } \\
\hline & & \multicolumn{4}{|c|}{ MEV } & \multirow{2}{*}{$\begin{array}{c}\text { Push-out } \\
\begin{array}{c}\text { Resistência } \\
\text { Adesiva (MPa) }\end{array}\end{array}$} \\
\hline Espécime & Terço & $\begin{array}{c}\text { Espessura } \\
(\mu \mathrm{m})\end{array}$ & $\begin{array}{l}\text { Perímetro } \\
\text { total }(\mu \mathrm{m})\end{array}$ & $\underset{(\mu \mathrm{m})}{\text { Continuidade }}$ & $\begin{array}{c}\text { Continuidade } \\
(\%)\end{array}$ & \\
\hline \multirow{3}{*}{1} & cervical & 118,71 & 2730,01 & 2164,98 & 79,30 & 21,91 \\
\hline & médio & 77,22 & 2959,53 & 2334,10 & 78,87 & 21,21 \\
\hline & apical & 63,75 & 2238,38 & 2063,32 & 92,18 & 14,97 \\
\hline \multirow{3}{*}{2} & cervical & 99,20 & 4321,39 & 2764,89 & 63,98 & 18,87 \\
\hline & médio & 65,52 & 4018,37 & 2082,46 & 51,82 & 2,84 \\
\hline & apical & 74,88 & 3542,11 & 2539,31 & 71,69 & 0,64 \\
\hline \multirow{3}{*}{3} & cervical & 126,18 & 3738,51 & 2339,72 & 62,58 & 12,81 \\
\hline & médio & 62,86 & 3715,74 & 1493,76 & 40,20 & 13,53 \\
\hline & apical & 44,53 & 3298,07 & 860,39 & 26,09 & 1,83 \\
\hline \multirow{3}{*}{4} & cervical & 61,80 & 3190,76 & 3084,75 & 96,68 & 22,02 \\
\hline & médio & 49,71 & 3431,48 & 1447,42 & 42,18 & 9,47 \\
\hline & apical & 52,24 & 2893,3 & 2527,48 & 87,36 & 1,36 \\
\hline \multirow{3}{*}{5} & cervical & 75,13 & 3194,27 & 1486,23 & 46,53 & 15,19 \\
\hline & médio & 61,10 & 3402,33 & 1282,72 & 37,70 & 1,30 \\
\hline & apical & 75,13 & 3200 & 1588,14 & 49,63 & 11,93 \\
\hline
\end{tabular}


Apêndice B - Resultados para o grupo Duolink/L4. Valores individuais da espessura da camada de cimento $(\mu \mathrm{m})$, do perímetro total da interface adesiva cimento/dentina $(\mu \mathrm{m})$, da continuidade da interface adesiva $(\mu \mathrm{m}$ e $\%)$ e da resistência adesiva ao deslocamento do pino (MPa).

\begin{tabular}{|c|c|c|c|c|c|c|}
\hline \multicolumn{2}{|l|}{ Grupo } & \multicolumn{5}{|c|}{ Ensaio } \\
\hline \multicolumn{2}{|c|}{ Duolink/L4 } & \multicolumn{4}{|c|}{ MEV } & \multirow{2}{*}{$\begin{array}{c}\text { Push-out } \\
\begin{array}{c}\text { Resistência } \\
\text { Adesiva (MPa) }\end{array}\end{array}$} \\
\hline Espécime & Terço & $\begin{array}{c}\text { Espessura } \\
(\mu \mathrm{m})\end{array}$ & $\begin{array}{l}\text { Perímetro } \\
\text { total }(\mu \mathrm{m})\end{array}$ & $\underset{(\mu \mathrm{m})}{\text { Continuidade }}$ & $\begin{array}{c}\text { Continuidade } \\
(\%)\end{array}$ & \\
\hline \multirow{3}{*}{1} & cervical & 113,61 & 2812,62 & 2543,28 & 90,42 & 15,08 \\
\hline & médio & 115,57 & 2925,3 & 1037,36 & 35,46 & 7,97 \\
\hline & apical & 121,54 & 3118,95 & 1496,44 & 47,98 & 6,25 \\
\hline \multirow{3}{*}{2} & cervical & 136,09 & 3336,88 & 1939,65 & 58,13 & 10,56 \\
\hline & médio & 113,37 & 2670,48 & 1030,00 & 38,57 & 4,65 \\
\hline & apical & 111,20 & 2587,25 & 1489,16 & 57,56 & 3,49 \\
\hline \multirow{3}{*}{3} & cervical & 166,18 & 2927,65 & 2382,39 & 81,38 & 17,05 \\
\hline & médio & 120,67 & 2285,62 & 1481,03 & 64,80 & 11,25 \\
\hline & apical & 116,31 & 2668,78 & 842,04 & 31,55 & 4,72 \\
\hline \multirow{3}{*}{4} & cervical & 113,80 & 2574,52 & 2295,09 & 89,15 & 2,54 \\
\hline & médio & 105,27 & 3052,85 & 1352,86 & 44,31 & 1,21 \\
\hline & apical & 105,08 & 2995,66 & 871,99 & 29,11 & 1,11 \\
\hline \multirow{3}{*}{5} & cervical & 179,45 & 3109,85 & 1388,26 & 44,64 & 4,62 \\
\hline & médio & 148,25 & 2871,82 & 1937,39 & 67,46 & 4,61 \\
\hline & apical & 160,45 & 2341,11 & 1810,79 & 77,35 & 6,53 \\
\hline
\end{tabular}


Apêndice C - Resultados para o grupo Duolink/L5. Valores individuais da espessura da camada de cimento $(\mu \mathrm{m})$, do perímetro total da interface adesiva cimento/dentina $(\mu \mathrm{m})$, da continuidade da interface adesiva $(\mu \mathrm{m}$ e $\%)$ e da resistência adesiva ao deslocamento do pino (MPa).

\begin{tabular}{|c|c|c|c|c|c|c|}
\hline \multicolumn{2}{|l|}{ Grupo } & \multicolumn{5}{|c|}{ Ensaio } \\
\hline \multicolumn{2}{|c|}{ Duolink/L5 } & \multicolumn{4}{|c|}{ MEV } & \multirow{2}{*}{$\begin{array}{c}\text { Push-out } \\
\begin{array}{c}\text { Resistência } \\
\text { Adesiva (MPa) }\end{array}\end{array}$} \\
\hline Espécime & Terço & $\begin{array}{c}\text { Espessura } \\
(\mu \mathrm{m})\end{array}$ & $\begin{array}{l}\text { Perímetro } \\
\text { total }(\mu \mathrm{m})\end{array}$ & $\begin{array}{c}\text { Continuidade } \\
(\mu \mathrm{m})\end{array}$ & $\begin{array}{c}\text { Continuidade } \\
(\%)\end{array}$ & \\
\hline \multirow{3}{*}{1} & cervical & 189,41 & 3312,04 & 1573,52 & 47,51 & 6,62 \\
\hline & médio & 166,38 & 3625,47 & 971,30 & 26,79 & 2,62 \\
\hline & apical & 165,19 & 2994,92 & 563,89 & 18,83 & 4,08 \\
\hline \multirow{3}{*}{2} & cervical & 178,14 & 2980,54 & 1869,36 & 62,72 & 7,83 \\
\hline & médio & 172,88 & 3037,77 & 688,11 & 22,65 & 4,54 \\
\hline & apical & 162,76 & 2856,59 & 1316,79 & 46,10 & 4,50 \\
\hline \multirow{3}{*}{3} & cervical & 183,58 & 2875,19 & 1134,49 & 39,46 & 7,69 \\
\hline & médio & 204,33 & 3466,65 & 634,69 & 18,31 & 1,23 \\
\hline & apical & 177,19 & 2991,52 & 1405,44 & 46,98 & 4,23 \\
\hline \multirow{3}{*}{4} & cervical & 201,00 & 3171,63 & 1681,20 & 53,01 & 17,83 \\
\hline & médio & 181,28 & 2504,63 & 818,14 & 32,67 & 2,65 \\
\hline & apical & 163,55 & 2685,07 & 1256,75 & 46,81 & 2,01 \\
\hline \multirow{3}{*}{5} & cervical & 198,18 & 3066,25 & 1888,83 & 61,60 & 0,82 \\
\hline & médio & 172,47 & 3000,92 & 545,14 & 18,17 & 2,21 \\
\hline & apical & 118,39 & 2648,84 & 1114,84 & 42,09 & 1,42 \\
\hline
\end{tabular}


Apêndice D - Resultados para o grupo C\&B Cement/L3 (controle). Valores individuais da espessura da camada de cimento $(\mu \mathrm{m})$, do perímetro total da interface adesiva cimento/dentina $(\mu \mathrm{m})$, da continuidade da interface adesiva ( $\mu \mathrm{m}$ e \%) e da resistência adesiva ao deslocamento do pino (MPa).

\begin{tabular}{|c|c|c|c|c|c|c|}
\hline \multirow{2}{*}{\multicolumn{2}{|c|}{$\begin{array}{l}\text { Grupo } \\
\text { C\&B Cement/L3 } \\
\text { (controle) }\end{array}$}} & \multicolumn{5}{|c|}{ Ensaio } \\
\hline & & \multicolumn{4}{|c|}{ MEV } & \multirow{2}{*}{$\begin{array}{c}\text { Push-out } \\
\text { Resistência } \\
\text { Adesiva (MPa) }\end{array}$} \\
\hline Espécime & Terço & $\begin{array}{c}\text { Espessura } \\
(\mu \mathrm{m})\end{array}$ & $\begin{array}{l}\text { Perímetro } \\
\text { total }(\mu m)\end{array}$ & $\begin{array}{c}\text { Continuidade } \\
(\mu \mathrm{m})\end{array}$ & $\begin{array}{c}\text { Continuidade } \\
(\%)\end{array}$ & \\
\hline \multirow{3}{*}{1} & cervical & 62,81 & 2046,21 & 1192,09 & 58,26 & 10,86 \\
\hline & médio & 46,24 & 2673,89 & 791,45 & 29,60 & 0,22 \\
\hline & apical & 43,62 & 2115,54 & 1230,16 & 58,15 & 2,72 \\
\hline \multirow{3}{*}{2} & cervical & 62,51 & 2710,81 & 1490,09 & 54,97 & 1,74 \\
\hline & médio & 64,50 & 2383,28 & 1428,72 & 59,95 & 8,61 \\
\hline & apical & 44,05 & 2220,01 & 1294,46 & 58,31 & 3,92 \\
\hline \multirow{3}{*}{3} & cervical & 64,24 & 2138,89 & 772,75 & 36,13 & 6,77 \\
\hline & médio & 38,01 & 2311,76 & 252,10 & 10,91 & 1,50 \\
\hline & apical & 38,51 & 2583,4 & 450,17 & 17,43 & 3,69 \\
\hline \multirow{3}{*}{4} & cervical & 113,09 & 2848,56 & 1054,95 & 37,03 & 4,60 \\
\hline & médio & 82,67 & 2522,96 & 1346,11 & 53,35 & 4,17 \\
\hline & apical & 56,38 & 2320,17 & 1333,26 & 57,46 & 2,98 \\
\hline \multirow{3}{*}{5} & cervical & 75,20 & 2550,14 & 1049,36 & 41,15 & 3,36 \\
\hline & médio & 73,38 & 3266,36 & 1183,26 & 36,23 & 2,42 \\
\hline & apical & 60,13 & 2312,77 & 1392,55 & 60,21 & 2,65 \\
\hline
\end{tabular}


Apêndice E - Resultados para o grupo C\&B Cement/L4. Valores individuais da espessura da camada de cimento $(\mu \mathrm{m})$, do perímetro total da interface adesiva cimento/dentina $(\mu \mathrm{m})$, da continuidade da interface adesiva ( $\mu \mathrm{m}$ e \%) e da resistência adesiva ao deslocamento do pino (MPa).

\begin{tabular}{|c|c|c|c|c|c|c|}
\hline \multirow{2}{*}{\multicolumn{2}{|c|}{$\begin{array}{l}\text { Grupo } \\
\text { C\&B Cement/L4 }\end{array}$}} & \multicolumn{5}{|c|}{ Ensaio } \\
\hline & & \multicolumn{4}{|c|}{ MEV } & \multirow{2}{*}{$\begin{array}{c}\text { Push-out } \\
\begin{array}{c}\text { Resistência } \\
\text { Adesiva (MPa) }\end{array}\end{array}$} \\
\hline Espécime & Terço & $\begin{array}{c}\text { Espessura } \\
(\mu \mathrm{m})\end{array}$ & $\begin{array}{l}\text { Perímetro } \\
\text { total }(\mu \mathrm{m})\end{array}$ & $\underset{(\mu \mathrm{m})}{\text { Continuidade }}$ & $\begin{array}{c}\text { Continuidade } \\
(\%)\end{array}$ & \\
\hline \multirow{3}{*}{1} & cervical & 133,73 & 3174,09 & 763,45 & 24,05 & 8,96 \\
\hline & médio & 106,09 & 2880,5 & 1543,39 & 53,58 & 8,80 \\
\hline & apical & 110,60 & 2856,99 & 1905,69 & 66,70 & 10,03 \\
\hline \multirow{3}{*}{2} & cervical & 155,51 & 2971,89 & 1131,04 & 38,06 & 7,48 \\
\hline & médio & 132,12 & 2744,92 & 809,71 & 29,50 & 2,72 \\
\hline & apical & 124,13 & 3002,38 & 1586,89 & 52,85 & 5,55 \\
\hline \multirow{3}{*}{3} & cervical & 113,3 & 2544,75 & 1953,15 & 76,75 & 15,04 \\
\hline & médio & 98,33 & 2850,53 & 1965,12 & 68,94 & 9,13 \\
\hline & apical & 83,985 & 3201,95 & 1500,95 & 46,88 & 8,76 \\
\hline \multirow{3}{*}{4} & cervical & 118,52 & 2766,82 & 1152,95 & 41,67 & 7,08 \\
\hline & médio & 111,31 & 3406,29 & 611,12 & 17,94 & 3,14 \\
\hline & apical & 100,62 & 2537,65 & 733,45 & 28,90 & 3,52 \\
\hline \multirow{3}{*}{5} & cervical & 102,20 & 2850,48 & 1851,00 & 64,94 & 3,89 \\
\hline & médio & 102,15 & 2477,45 & 1318,47 & 53,22 & 8,60 \\
\hline & apical & 114,62 & 3137,23 & 1419,41 & 45,24 & 6,07 \\
\hline
\end{tabular}


Apêndice F - Resultados para o grupo C\&B Cement/L5. Valores individuais da espessura da camada de cimento $(\mu \mathrm{m})$, do perímetro total da interface adesiva cimento/dentina $(\mu \mathrm{m})$, da continuidade da interface adesiva $(\mu \mathrm{m}$ e \%) e da resistência adesiva ao deslocamento do pino (MPa).

\begin{tabular}{|c|c|c|c|c|c|c|}
\hline \multirow{2}{*}{\multicolumn{2}{|c|}{$\begin{array}{l}\text { Grupo } \\
\text { C\&B Cement/L5 }\end{array}$}} & \multicolumn{5}{|c|}{ Ensaio } \\
\hline & & \multicolumn{4}{|c|}{ MEV } & \multirow{2}{*}{\begin{tabular}{|c} 
Push-out \\
Resistência \\
Adesiva \\
(MPa)
\end{tabular}} \\
\hline Espécime & Terço & $\begin{array}{c}\text { Espessura } \\
(\mu \mathrm{m})\end{array}$ & $\begin{array}{l}\text { Perímetro } \\
\text { total }(\mu \mathrm{m})\end{array}$ & $\underset{(\mu \mathrm{m})}{\text { Continuidade }}$ & $\begin{array}{c}\text { Continuidade } \\
(\%)\end{array}$ & \\
\hline \multirow{3}{*}{1} & cervical & 202,03 & 2935,58 & 2405,10 & 81,93 & 16,15 \\
\hline & médio & 172,15 & 2711,94 & 2317,18 & 85,44 & 7,16 \\
\hline & apical & 132,93 & 2855,82 & 1810,04 & 63,38 & 8,94 \\
\hline \multirow{3}{*}{2} & cervical & 204,13 & 3297,76 & 1832,08 & 55,56 & 14,83 \\
\hline & médio & 153,71 & 3310,59 & 1973,33 & 59,61 & 13,18 \\
\hline & apical & 156,66 & 2994,41 & 630,87 & 21,07 & 12,95 \\
\hline \multirow{3}{*}{3} & cervical & 159,61 & 3049,14 & 682,18 & 22,37 & 10,14 \\
\hline & médio & 162,33 & 2807,28 & 1524,12 & 54,29 & 11,68 \\
\hline & apical & 177,75 & 3118,17 & 1988,29 & 63,76 & 13,43 \\
\hline \multirow{3}{*}{4} & cervical & 159,61 & 3254,47 & 1035,86 & 31,83 & 3,08 \\
\hline & médio & 162,33 & 3198,68 & 1527,85 & 47,77 & 3,01 \\
\hline & apical & 159,61 & 2835,27 & 1164,94 & 41,09 & 2,51 \\
\hline \multirow{3}{*}{5} & cervical & 162,33 & 3213,66 & 614,44 & 19,12 & 9,20 \\
\hline & médio & 156,60 & 3078,8 & 1214,30 & 39,44 & 17,81 \\
\hline & apical & 175,85 & 2552,45 & 1381,22 & 54,11 & 15,98 \\
\hline
\end{tabular}

